\title{
AVALIACÃO DE MATÉRIA SECA DIGESTÍVEL E CARBOIDRATOS ESTRUTURAIS DISPONÍVEIS EM FORRAGENS POR SISTEMAS MICROBIOLÓGICO E ENZIMÁTICO
}

JOSÉ ALMURO DA PAOYÃO

Zootecnista

Orientador: PROF. DR. IILSON ROBERTO SOARES MATTOS

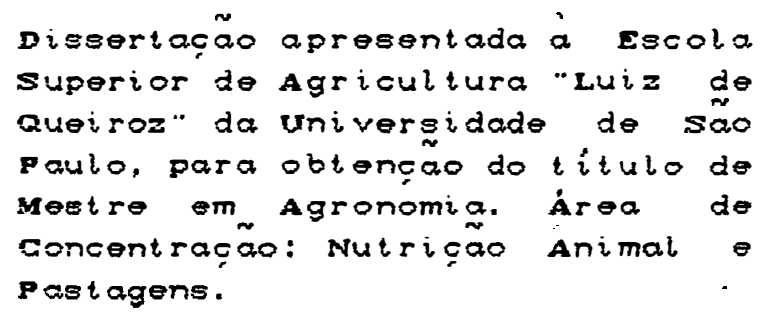

P I R A C I C A B A

Estado de São Paulo - Brasil

Março - 1990 
Ficha catalográfica preparada pela Seção de Livros da Divisão de Biblioteca e Documentação - PCAP/USP

Paixão, José Almiro da

P149a Avaliação de matéria seca digestível e carboidratos estruturais disponiveis em forragens por sistemas microbiológico e enzimático. Piracicaba, 1990.

$129 \mathrm{p}$.

Diss.(Mestre) - ESALQ

Bibliografia.

1. Carboidrato de forragem - Avaliação - Técnica "in vitro" 2. Celulase - Cinética 3. Forragem - Com posição - Avaliação 4. Forragem - Matéria seca - Dí gestibilidade 5. Matéria seca - Digestibilidade Técnica "in vitro" I. Escola Superior de Agricultura Luiz de Queiroz, Piracicaba

CDD 636.0855 


\section{AVALIAÇÃO DE MATÉRIA SECA DIGESTÍVEL E CARBOIDRATOS ESTRUTURAIS DISPONÍVEIS EM FORRAGENS POR SISTEMAS MICROBIOLÓGICO E ENZIMÁTICO}

DOSSÉ ALDMORO DA PAIXẼ̃D

Aprovada em: 28.03.90

Comissão Julgadora:

Prof. Dr. Wilson Roberto Soares Mattos ......... ESALQ/USP

Prot. Dr. Luiz Eduardo Gutierrez ............ ESALQ/USP

Prot. Dr. Max Lazaro Vieira Bose ............ ESALQ/USP

PROF. DR. WILSON ROBERTO SOARES MATTOS

Orientador 
Aos meus pais

Jose Aquilino da Paixão e Maria Josefa dos Santos Paixäo, pelo esitimulo

- confiança na minha decisão profissional.

As sobrinhas, Joyce e Marcelle, pela esperanca emplumada em seus olhares.

\section{A Tânara Lages Pereira,}

pelo carinho estimulo proporcionados.

Aos laboratoristas, pelas contribuicões para o banco de informaçöes na área de Avaliaç̃o de Alimentos. 


\section{AGRADECIMENTOS}

Ao Prof. Dr. Wilson Roberto Soares Mattos, pela paciencia, orientaçăo e estimulo no decorrer do meu preparo cientifico.

Ao Prof. Dr. João Atilio Jorge, da Faculdade de Filosofia, Ciencias e Letras, da U.S.P., Ribeirão Preto, pelo estimulo - decisivas contribuiçb̈es no desenvol vimento do projeto.

A equipe da Seção de Avaliação de Forragens, do Instituto de Zootecnia, em especial ao Dr. Edgard Leoni Caielli e ao colega pos-graduando, Gilberto Braun, por terem gentilmente cedido as instal açóes do laboratório e facilitado a execuçăo do projeto.

Ao Prof. Dr. Hilton Thadeu Zarate de Couto, do Departamento de Giencias Florestais/ESALQ, pela orientação e execuçăo das analises estatisticas e contribuiçăo na discussão dos dados.

Às pesquisadoras Maria Luiza Otero D’Almeida e Marisa Koga, do Agrupamento de Celulose e Papel, do I.P.T., pelas sugestões e discussão sobre os materiais de estudo e alguns procedi mentos.

Ao.Prof. Dr. Cássio Roberto Mello Godoi, do Departamento de Matemática e Estatistica, a a pós-graduanda Iiemi Matsuo, pela orientaçăo e execuçao de partes das análises estatisticas. 
äs pesquisadoras, Terezinha Aparecida Martins Gomes de Castro Cnivel III e Maria Aparecida Lara Porto Biancalana. Cnivel IJ, da Seção de Bioquimica do Sêmem, Instituto de Zootecnia, pelas dosagens de proteinas.

Ao Pesquisador, Alvaro Rodrigues dos Santos, do Agrupamento de Minas e Geologia Aplicada, do I.P.T., pelas análises de difraçăo de raios-X nas amostras comerciais de celulose.

so Prof. Jose Norberto Muniz, da Universidade Federal de Viçosa, pelos ensinamentos sobre Metodologia cientifica por ter me indicado para lecionar a referida disciplina na Faculdade de Agronomia de Ituverava SP.

Ao Zootecnista, Leonardo Barreto Alves Pinheiro, pela valiosa contribuiçăo e amizade durante a tomada dos dados.

$\ddot{A}$ equipe da Seçăo de Introdução e Avaliaçăo Agronomica de Forrageiras, do Instituto de Zootecnia, por terem cedido os materias forrageiros disponíveis em seu campo de introdução.

AOS 1 aboratórios, BIOBRAS, NOVO INDUSIRI DO BRASIL $\odot$ BIOCON DO BRASIL, por terem cedido seus materiais para o estudo.

Ao CNPq, Conselho Nacional de Desenvolvimento Cientifico $\theta$ Tecnologico, pela concessão de bolsa durante a fase de créditos exame de qualificaçăo. 
$\ddot{A}$ CAPES, Coordenadoria de Aperfeiçoamento de Pessoal do Ensino Superior, pela concessão de bolsa durante o desenvolvimento do projeto.

A EMBRAPA/CNPGC, pela concessão de alguns materiais e ajuda na busca de literatura, e em especial, aos amigos, que estimularam o meu preparo cientifico.

Aos amigos, Elizabeth Ann Veasey, Rosangela B. Navarro, Joå Batista de Abreu, Paulo Robson $\theta$ Elizabeth Arndt, Maria do Carmo Esteves, Sergio Duarte, Lila Carlota Lopez, Mario Sato. Mário Inomoto, Jose Roberto Scarpeliini e a todos que contribuiram decisivamente na continuidade do curso.

Aos funcionários da Biblioteca Central, em especial a Eliana - a Katia, da Seção de Referencia, pela ajuda no levantamento e apresentação do material bibliográfico.

A Eliane. Milton e Adilson. pela contribuiça na preparaça do texto. 


\section{SUMARIO}

Página

LISTA DE TABELAS ........................ vi

LISTA DE FIGURAS .................... ix.

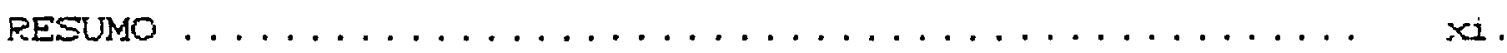

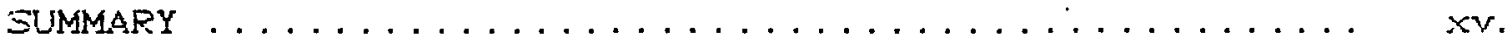

1. INTRUDUCAO ......................... 1

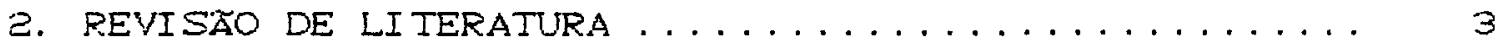

2.1. Avaliação de Carboidratos Atraves de Enzimas. 3

2. 2. Métodos de Estudo da Fração Potencialmente Digestivel em Forragens ................ 35

3. MATERIAL E METODOS ....................... 49

3.1. Fase Pre-experimental ................. 49

3. 2. Material ....................... 54

3.3. Métodos ........................ 59

4. PESULTADOS E DISCUSSÃO .................

5. GONGLUSWES ........................ 102

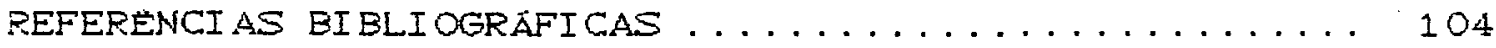

$\triangle P E N D I C E \ldots \ldots \ldots \ldots \ldots \ldots \ldots 1$ 
viii

\section{LISTA DE TABELAS}

Tabela

Página

1 Substratos preferenciais das enzimas celuloliti-

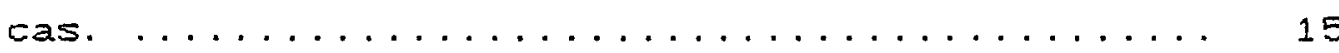

2 Celulólise por enzimas isoladas e/ou combinadas. 16

3 Metodos analiticos para atividade celulolitica.. 20

4 Recentes propostas da metodologia enzimática para estudos da fração potencialmente digestivel

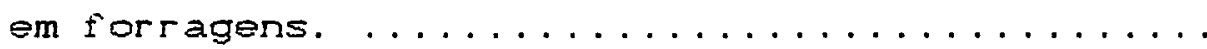

5 Indice de cristalinidade em celuloses comerciais.

51

6 Constante de Michaelis-Menten (Km) e Constante de Inibicão (Ki) para beta-glucosidase de Trichoderma reesei e de Aspergillus niger. .......

7 Enzimas celuloliticas produzidas por Trichoderma reesei e Aspergilius niger. ..............

8 Modelos e equaç̧̋es definidas para estimativa de parede celular pelos sistemas analiticos, detergente e enzimático. ..................

9 Modelos e equaçães definidas para estimativas de matéria seca digestivel entre os sistemas microbiologico e enzimático. ................ 


\section{LISTA DE FIGURAS}

Figura

Página

1 Estruturas macromoleculares da parede celular. .

2 Detalhes. .......................

3 Diagrama macromolecular proposto para hidrolise

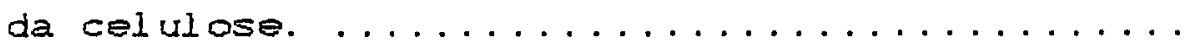

4 Modelo aceito para hidrolise da celulose. .....

5 Uso alternativo de materiais 1 ignocelulósicos em

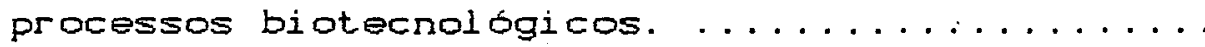

6 Diluição enzimática como indicativo do potencial hidrolitico, em três sistemas enzimáticos obtidos a partir de Trichoderma reesei (E1 e Ez)

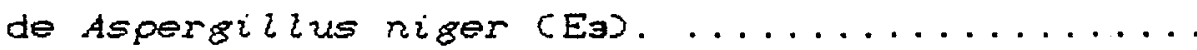

7 Reta-padrão de glucose para dosagem de açúcares

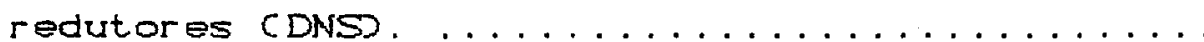

8 Potencial hidrolitico em função de concentração enzimática e de tempo de reação, em três sistemas enzimáticos obtidos a partir de Trichoderma reesei (E1 e E2) e de Aspergilius niger (Eכ). ..

9 Efeito da temperatura, tampão e pH sobre o potencial hidrolitico, em tres sistemas enzimaticos obtidos a partir de Trichoderma reesei CEl $\theta$ Ez) e de Aspergillus niger (Ë)............. 
10 Efeito da concentração molar de sódio sobre o potencial hidrolitico, em três sistemas enzimáticos obtidos a partir de Trichoderma reesei CE1 - Ez) e de Aspergillus niger (Ea). ........... 83

11 Identificaçăo bioquímica de beta-endogl ucanase e beta-glucosidase, em tres sistemas enzimáticos obtidos a partir de Trichoderma reesei (E1 e E2) e de Aspergillus niger (E). .............. 


\title{
AVALIAC̦ÃO DE MATÉRIA SECA DIGESTÍVEL E CARBOIDRATOS ESTRUTURAIS DISPONIVEIS EM FORRAGENS POR SISTEMAS MICROBIOLÓGICO E ENZIMÁTICO
}

\author{
Autor: JOSÉ ALMIRO DA PAIXÃO \\ Orientador: PROF. DR. WILSON ROBERTO SOARES MATTOS
}

RESUMO

Com o objetivo de estudar as tecnicas microbiologica (Tilley \& Terry) e enzimática para avaliação de forragens, procedeu-se inicialmente a um estudo do comportamento cinetico de celulase de Trichoderma reesei e Aspergillus niger visando fixar as condiç̋es otimas de hidrólise. Os referidos sistemas enzimáticos foram então aplicados às diferentes forragens, na tentativa de compatibilizar sistemas enzimáticos com os substratos forrageiros cforragens conservadas, gramineas, leguminosas e residuos agricolasj que melhor se correlacionassem com o procedimento microbio1 ogico.

0 estudo foi conduzido em duas fases, a primeira com substratos puro ccelulose em pó e especifico Ccarboximetilcelulose e salicinas, em condiçzes padronizadas foram analisados os açucares redutores pelo DNS Cácido dinitrosalicilicos e teor de solubilização como indicativo 
xii.

da atividade enzimática. A relaçăo enzima/substrato e o tempo de reação mostraram-se como fatores determinantes de atividade e o estudo revelou o potencial hidrolitico máximo nos distintos sistemas enzimáticos, maximizando os efeitos inibitorios e inativadores nos sitios moduladores dos respectivos componentes bioquimicos. Ainda foi determinado como outros fatores $6 \mathrm{pH}$, temperatura, tampão e concentração molar de sodios atuam sobre o referido potencial.

Na segunda fase, os substratos forrageiros, com teores de parede celular variando de 50-90\%, pelo sistema detergente neutro, foram submetidos a um estudo de correlação e regressão com o procedimento enzimático Cinsol ubilização em HCl-pepsinas. Foram aplicados três modelos de equaçóses Clinear, M1; logaritmico, Me e quadratico, M3) para selecionar efeitos de tratamentos. Os resultados mostran coeficientes de determinaçăo de 0,6821 $(M 3) ; 0,5317(M 1) ; 0,6340(M 1)$ e 0.8368 (M1) para forragens conservadas, gramineas, leguminosas e residuos agricolas, respectivamente. A parede celular tomada como covariável nas avaliaçbes de materia seca digestivel e carboidratos estruturais disponiveis revelou a heterogeneidade e especificidade dos materiais en estudo cparede celular e sistemas enzimáticoss. O método alternativo de remoção de conteúdo celular foi adotado como prétratamento nas avaliaçōes da técnica enzimática.

- procedimento enzimático apresenta algumas vantagens em relaçăo ao microbiológico, além de aferir 
materia seca digestivel pode se detectar com certa especificidade os carboidratos estruturais disponiveis nos alimentos, assumindo-se o modelo de WALDO, 1972. Os resultados mostram coeficientes de determinaçăo da ordem de 0,60 a 0,90 entre as tecnicas avaliadas para os grupos de forragens o os sistemas celuloliticos do estudo, nas avaliações gravimetricas cmatéria seca digestivel). Sendo a E1 Cde Trichoderma reeseis mais indicada para leguminosas $\theta$ forragens conservadas e a Ee Cde Aspergilius niger) recomendada para os grupos de gramineas e resíduos agricolas.

So modelos de equaç̧es aplicados mostraram-se

efotivos sem comprometer os objetivos do trabalho. Principalmente, na deteç̧ão de materia seca digestivel, o modelo quadratico ajustou-se melhor para as forragens conservadas, gramineas e residuos agricolas. Por outro lado, - grupo de legumi nosas apresentou equação com coeficiente de determinação $\simeq 0,90$ nos tres modelos estudados. Numa análise global, o modelo logaritmico apresentou melhores ajustes, corroborando com as analises do referido teste no estudo de parede celular. A analise da covariável parede celular não foi procedente para as leguminosas, onde conseguiu-se maior coeficiente de determinação para as tecnicas avaliadas.

os modelos escolhidos para explicar os dados de materia seca digostivel, em geral tambem se aplicavam para carboidratos estruturais disponiveis. A questão de especificidade enzima-substrato pode ser melhor evidenciada ao se estudar correlaç̧̋es e modelos entre os procedimentos 
gravimetricos e colorimétricos, considerando a técnica enzimatica. Neste caso, o sistema celulalitico cde Aspergizlus nigers parece ser mais especifico para os substratos em estudo $\theta$ modelo quadratico mostrou-se melhor, o que ja havia si do sugerido no grupo de legumi nosas, nas análises de correlação e regressăo com a técnica microbiológica. 


\title{
EVALUATION OF DIGESTIBLE DRY MATTER AND AVAILABLE STRUCTURAL CARBOHYDRATES IN FORAGES BY SYSTEMS MICROBIOLOGICAL AND ENZMMATIC
}

\author{
Author: JOSÉ ALMIRO DA PAIXÃO \\ Adviser: PROF. DR. WILSON ROBERTO SOARES MATTOS
}

SUMMARY

With the objectives of studying the microbiological (Tilley \& Terry) and enzymatic techniques for forage evaluation, a study of the cellulase kinetics behaviour of Trichoderma reesei and Aspergillus niger was conducted, in order to establish the best conditions for hydrolysis. These enzymatic systems were applied to the different forages trying to compatibilize the enzymatic systems with the forages substrates cpreserved forages, grasses, legumes and agriculture by-products that correlate best with the microbiological procedure.

The study was conducted in two phases. The first with pure (powder cellulose) and specific ccarboxymethylcellulose and salicin substrates, in standardized conditions, analysing the reducing sugars by DNS Cdinitrosalycilic acids and the solubilization content as indicative 
of the enzymatic activity. The relation enzyme/substrate and the time for the reaction appeared as determinant factors of activity. The study showed the maximum hidrolytic potential in the different enzymatic systems, maximizing the inhibiting and inactivating effects in the modulators sites in its respective biochemical components. The other factors that acted upon the referred potential CpH, temperature, buffer and sodium molar concentrations were also determined. On the second phase, the forages substrates with cellular wall contents varying from 50 to $90 \%$, by the neutral detergent system, were submitted to a study of correlation and regression with the enzymatic procedure Cinsolubilization in HCl-pepsin). The equation models Clinear, M1; logarithmic, Me and quadratic, M3) were used to select the effects of treatments. The results show determination coefficients of 0,6821 (M3); 0,5317.(M1); 0,6340 CM1 and 0,8368 CMI for the preserved forages, grasses, legumes and agriculture by-products, respectivelly. The celiular wall taken as covariate in the evaluations of digestible dry matter and available structural carbohydrates, showed heterogeneity and specificity of the materials studied Coeliular wall and enzymatic systems?. The alternative procedure to remove cell content was adapted as a pre-treatment in the gravimetric and colorimetric evaluations on the enzymatic technique.

The enzymatic procedure presents some advantages over the microbiological one, as besides checking 
rvii.

the digestible dry matter, it can detect with a certain specificity the available structural carbohydrates of food, according to the model proposed by WALDO, 1972. The results show determination coefficients ranging from 0,60 to 0,90 on the gravimetric evaluations (digestible dry matter) for the for age groups and the enzymatic systems studied. The enzymatic systems of Trichoderma reesei, El were the most indicated for legumes and preserved forages and the systems of Aspergillus niger, Ee were most appropriated for grasses and agriculture by-products.

The equation models used in the present studies were effective without compromising the work's objectives. The quadratic model was functional at the adjustment of the digestible dry matter, mainly for preserved forages, grasses and agriculture by-products. On the other hand, the legume's group presented an equation with determination coefficient around 0,90 in the three models studied. In general, the logarithmic model showed better adjustment, corroborating with the analyses in the same test for the cellular wall study. The analysis of the cellular wall covariate was not effective for legumes, where a better substitution among the techniques evaluated was achieved.

The models chosen to explain the digestible dry matter data, in general, were also applied to the available structural carbohydrates. The specificity of enzyme-substrate can be better shown by studying correlations and models among the gravimetric and colorimetric procedures, 
xriii

considering the enzymatic technique. In these cases the enzymatic systems of Aspergillus niger seem to be more specific for the substrate studied. Also, the quadratic model presented better results, which had already been suggested in the legume's group, by the correlation and regression analyses with the microbiological technique. 


\section{INTRODUÇÄO}

A importância dos substratos lignocelulósicos em processos biotecnológicos está associada a reciclagem de fontes de carbono no processo de obtenção de produtos de interesse alimenticio e industrial. A heterogeneidade dos referidos substratos têm dificultado o estudo do potencial de uso. As propostas mais recentes envolvem sistemas qui micos convencionais de hidrólise e as técnicas de marcadores isotópicos ou não. A enzimologia da degradaçăo destes materiais tem recebido grande atençăo ultimamente, com a vantagem do enfoque molecular com os referidos substratos.

A utilização da biomassa celulosica pelo ecossistema ruminal e complexa e o entendimento de fatores estruturais e fisico-químicos dos substratos lignocelulosicos constituem assunto de bastante especulação. Torna-se interessante conhecer de forma rapida e direta as forragens alimentos que suportam basicamente a producăo de ruminantes, que depende da disponibilidade biológica e da eficiencia de utilização dos nutrientes consumidos.

Os experimentos convencionias de digestão alimentação são bastante precisos em avaliar as forragens, entretanto, são demorados, carös e trabalhosos. Muitos pro- 
cedimentos laboratoriais (químicos, biológicos e mistos) tem sido propostos para substitui-los, avaliando-as indiretamente. Recentemente, o infravermelho e a técnica biológica Cenzimática) têm-se demonstrado procedimentos satisfatórios para tais propósitos, com a vantagem adicional de independerem completamente do animal.

o objetivo do presente estudo foi de avaliar as técnicas biológicas in vitro cmicrobiológica e enzimátical para algumas forragens. O trabalho foi conduzido em duas fases, na primeira foi direcionado para os fatores que interferem sobre a cinetica dos sistemas celuloliticos, visando otimizar as condiçöes de hidrolise. Enquanto, na segunda fase, os grupos de forragens foram submetidos às diferentes tecnicas, tentando compatibilizar fontes de substratos e enzimas que melhor se correlacionassem com a técnica microbiológica. 


\section{REYISÃO DE LITERATURA}

\subsection{Araliação de Carboidratos Através de Enzi mas}

a) Caracterização e propriedades qử micas

Os carboidratos podem ser classificados por numero de atomos de carbono por molecula, ou ainda, com base no número de moleculas de açucares simples presentes no polimero. Desta forma, tem-se os monossacarideos (1), os oligossacarideos (2-10) e os polissacarideos, com mais de dez (10) unidades simples de açucares (CHURCH \& POND, 1986$).$ Quimicamentè, os carboidratos săo classificados como polihidroxialdeidos polihidroxicetonas de acordo com a posiça do carbono anomerico (CHOHD na cadeia carbonica, respectivamente no $C_{1}$ e no Cz. A reação da carbonila em aldoses e cetoses com a hidroxila forma. respectivamente, os grupamentos hemiacetais e hemicetais, tornando o carbono da carbonila mais um centro de assimetria. As formas estaveis aldo cetopiranosidicas e furonasidicas são assim determinadas devido as formulas conformacionais que assumem após as reaçóes descritas (CHURCH \& POND, 1986 ; LEHNINGER, 1988 ).

O numero de centros assimetricos define, na maioria dos monossacarideos, o número de esterecisomeros, ou 
seja, as formas oticamente ativas, com exceção da diidroxicetona. Podem assim, desviar, no polarimetro, o plano da luz polarizada para direita (dextrorotatorios ou para a esquerda Clevorotatbrioj. As formas $D$ e L referem-se a configuraçăo do carbono quiral mais distante da carbonila, podendo-se detectar os epimeros das respectivas aldoses e cetoses. A maioria dos açucares simples assume a forma $D$, enquanto a forma L pode ser obtida sinteticamente, ao contrário do que ocorre com os amı nócidos naturais (LEHNINGER, 1988 ).

A importância dos estereoisómeros está relacionada com uma propriedade facilmente demonstravel, o poder de redução. Os polissacarideos assumem formas susceptiveis à oxidaçå, produzindo substancias com alto poder oxidativo, onde seus grupos carbonilas, em presença de agentes redutores, recebem eletrons, com certa equivalencia entre a concentraçăo de açúcares e a quantidade de reagente reduzido. Admitem-se, entretanto, interferencias dos componentes individuais do reagente $\theta$ das condiçäes de hidrólise com os substratos teste CMILLER, 1959; MARSDEN et alii, 1982b; MULLINGS \& PARISH, 19842.

Alguns metodos mais apurados como cromatografia liquida de alta pressão CMARSDEN et alii, $1982 b ;$ FOX et alii, 19842, camada delgada CGHIRICO \& BROWN JR, 1985 S ou os recentes metodos físicos de separação por peso molecular săo propostos para que se conheça melhor a natureza bioquimica dos carboidratos. As formas mais complexas, como por exemplo a cristalinidade da celulose, pode ser determinada por 
hidrolise ácida ou difratometria de raios $X$ CWEIMER \& WESTON, 19853

b) Carboidratos - fonte básica de energia renovável

Os carboidratos servem basicamente como combustivel celular para os tecidos vegetais e animais. No tecido vegetal, ocorrem na forma de monossacarídeos, de amido como polissacarideo de reserva, e de celulose, hemicelulose - derivados como polissacarideos estruturais, os quais representam, mais ou menos, $80 \%$ da biomassa renovavel. No tecido animal, ocorrem basicamente na forma de glicogenio, como polissacarídeo de reserva (LEHNINGER, 1988 ).

os vegetais sintetizam em media, o equi valente a $50 \mathrm{~kg}$ de celulose por dia, por pessoa, a partir do processo fotossintético, utilizando $0 \mathrm{CO}_{2}$ derivado da oxidaçăo aerobica e anaeróbica e do sistema respiratorio dos animais superiores (LEHNINGER, 1988). Os produtos da fotossintese servem basicamente a sobrevivencia dos animais, principalmente, ao se considerar que os carboidratos representam. mais ou menos, $50 \%$ da materia seca em forragens e $80 \%$ nas sementes, grăos e cereais CCHURCH \& POND, 1986 .

A reciclagem da biomassa celulosica através de processos fermentativos ou enzimaticos, garante a produçå de $8,5 \times 10^{7} 1$ de $\mathrm{CO}_{2}$ por ano. Se houvesse algum bloqueio no processo. a terra perderia suas reservas de dioxido de carbono em 20 anos, o que evidencia a importancia desse processo no suprimento de alimentos (VAN SOESI, 1982 . 
Nutricionalmente, os carboidratos podem ser caracterizados por sua disponibilidade. A parede celular dos vegetais \& composta basicamente por carboidratos estruturais, anidroaçúcares polimerizados e outras substancias de menor importancia nutricional. tais como lignina, cutina, pectina e ceras. Internamente, a celula vegetal contém, ainda, lipideos, proteinas, açúcares simples e amido como constituintes de alta disponibilidade (VAN SOEST, 1982 .

A parede celular e constituida por camadas que se desenvolvem em diferentes estagios de crescimento. A celula madura apresenta paredes primaria e secundária, com camadas externa (S1), intermediária (Ses e interna (S3). Uma lamela intermediária, rica em pectato de cálcio, une duas paredes primárias, e geralmente e formada na fase de crescimento, antes de se formar a parede secundaria. Apos o periodo de divisão celular, a parede secundária se espessa com a polimerizaçă de celulose e hemicelulose. Sendo que a formaĢo de lignina se inicia na fase de envelhecimento celular (ALBERTS et alii, 1983). CDetalhes nas Figuras 1, 2). 


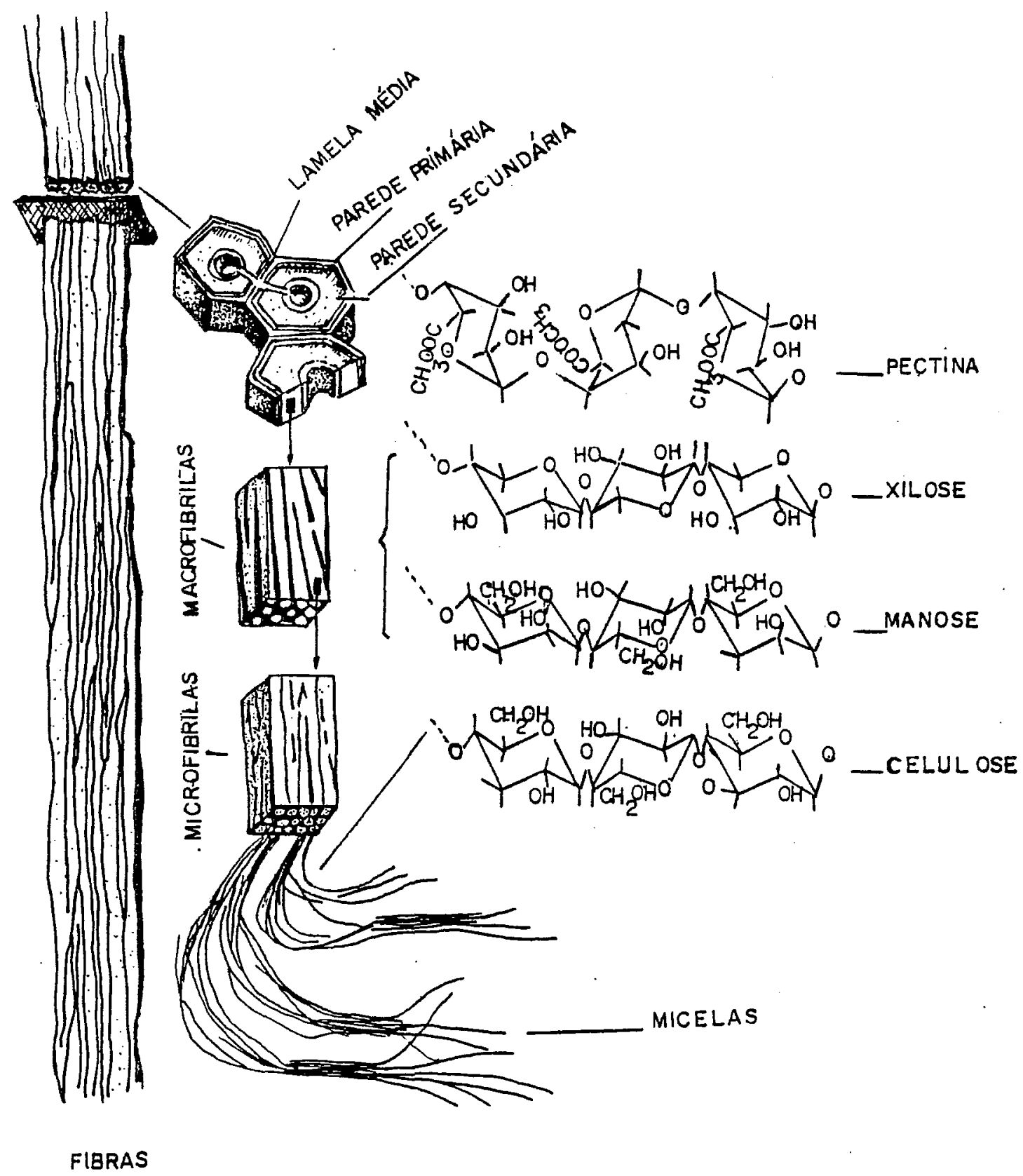

Figura 1 - Estruturas macromoleculares da parede celular. Fonte: COUGHLAN, 1985 (adaptado de ESAU, 1977 ). 


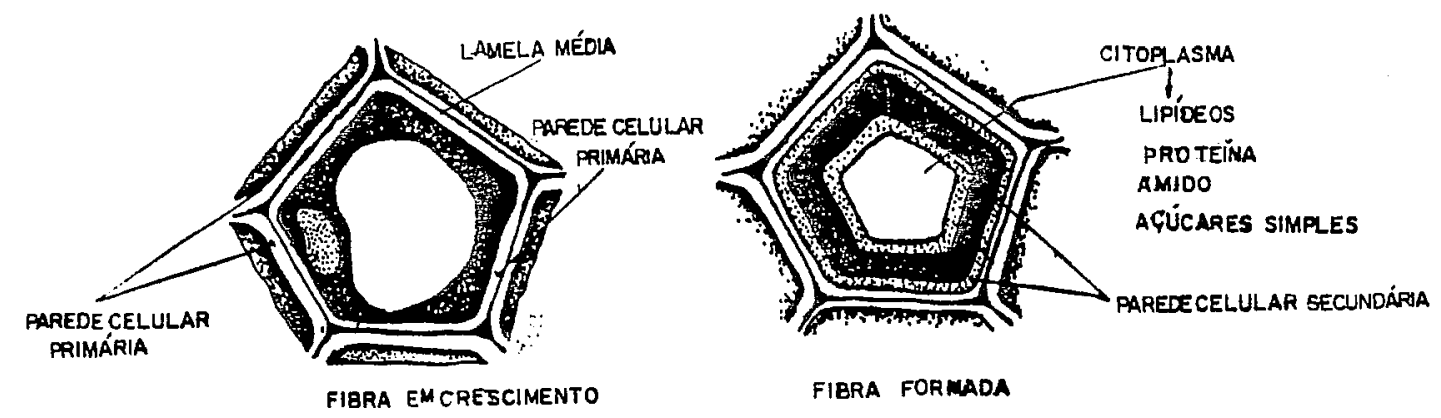

2.1. Formaçăo de parede secundaria na celula vegetal.

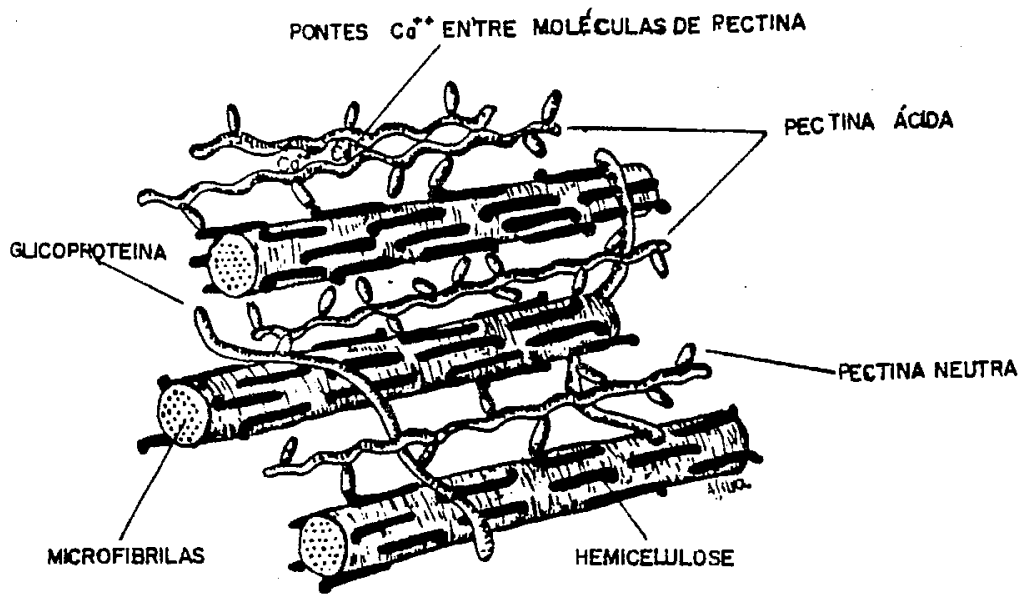

2. Z. Arranjos moleculares na parede celular.

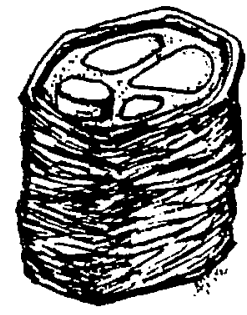

MICROF ERILAS INTERLIGADAS COM OUTROS POLISSACARÍDEOS E PROTEÍNA INTEGRANDO A PAREDE CELULAR
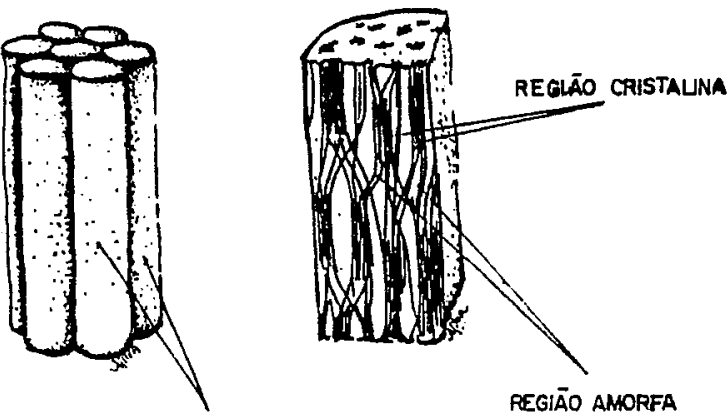

PEGIĀO AMORFA

MICROFIBRLAS (1) 


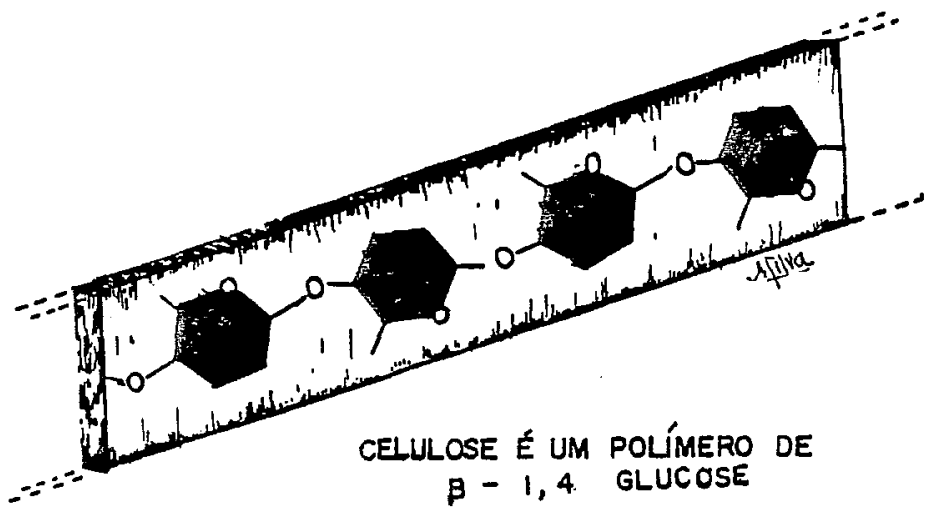

ق. 4. Estrutura linear da molecula de celulose.

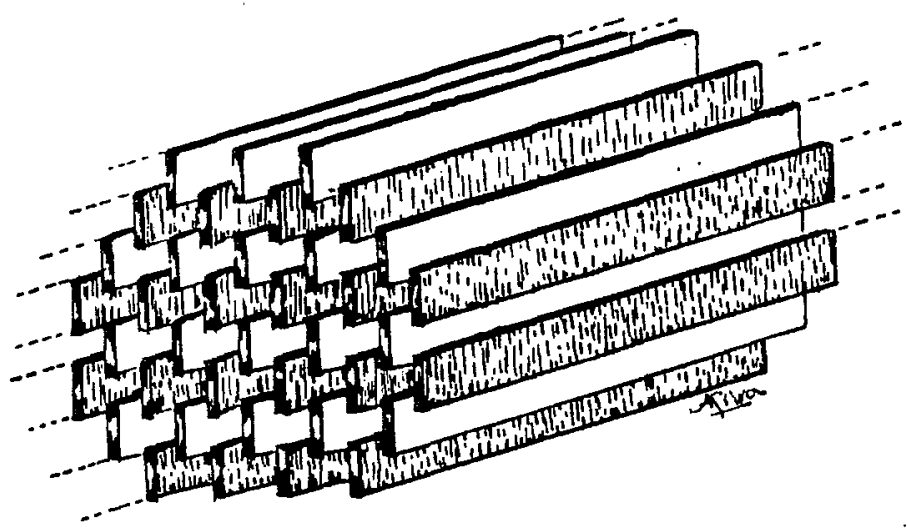

DISPOSICÃO DAS PONTES DE HIDROGẼNIO NAS
MOLÉ CULAS DE CELULOSE

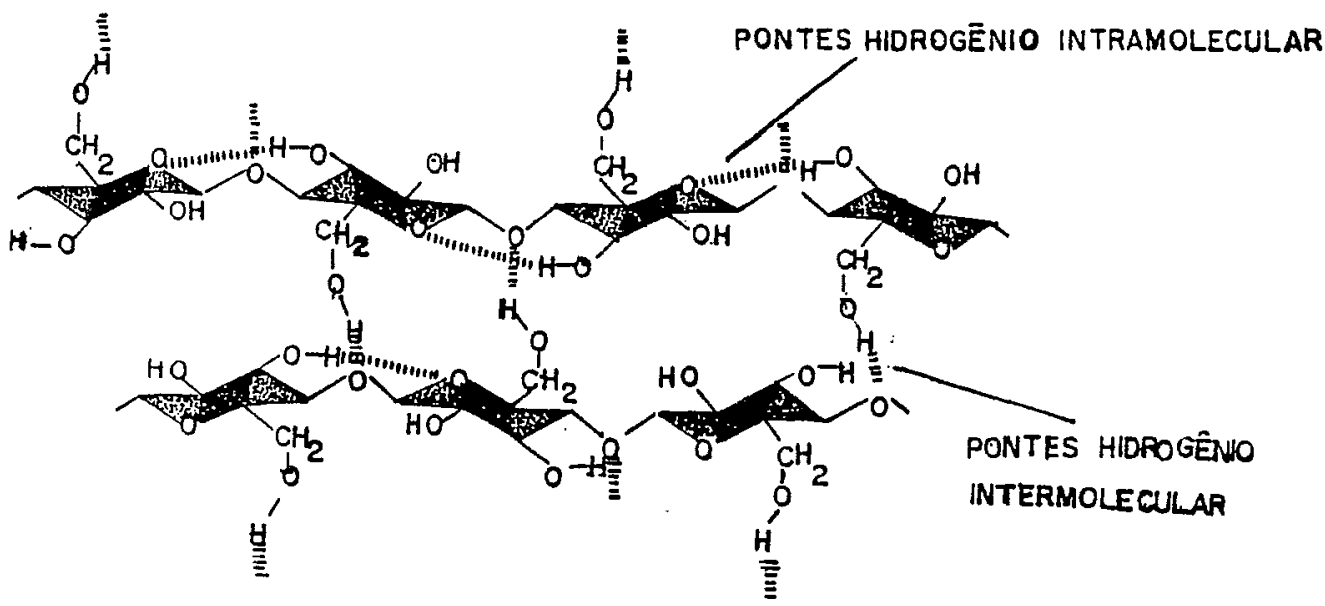

2.5. Disposiçăo de pontes de hidrogenio na molecula de celulose. 
A unidade básica da estrutura da parede celular é a microfibrila, composta por aproximadamente 20 micelas. As micelas contém em media 100 cadeias moleculares do celulose. A organizaçăo das microfibrilas segue um arranjo pouco ordenado na parede primaria, sendo frequentemente transversal ao eixo celular e longitudinal aos vertices celulares. Com o envelhecimento celular ocorre a formaça das camadas da parede secundaria, que conferem rigidez à célula, e ainda promove um arranjo definido nas microfibri1as. Na camada externa CS1J, as microfibrilas dipõem-se em duas espirais opostas com angulo aberto em relação ao eixo celular. Na camada intermediária CSes, observa-se uma espiral de ângulo agudo com o eixo celular e aneis concentricos, - na camada interna (S3), as microfibrilas ordenam-se em helicoides suaves (ESAU, 1977; CUTTER, 1978 ).

A celulose é um homopolissacarideo linear de aproximadamente 10.000 unidades monomericas de D-glucose, unidas por 1 igaçós do tipo beta 1,4 formando celooligómeros de diferentes pesos moleculares e graus de polimerização (15-14.0003. Ocorre nas formas cristalina e amorfa, organizada em microfibrilas nas diferentes camadas da parede celular, ou entrelaçada com hemicelulose e lignina na matriz da parede celular CVAN SOEST, 19823.

A hemicelulose um heteropolissacarídeo constituido por monomeros-D de glucose, xilose, arabinose, manose e galactose; xiloglucano e a molecula predominante na hemicelulose-A e a arabinoglucäno na hemicelulose-B, ambas 
com ramificaçöes principais do tipo beta e terminais do tipo alfa, com as demais unidades monomericas CVAN SOEST, 1982 ; DEKKER, 1985 .

A lignina é um polimero de alto peso molecular, que está intimamente associado aos carboidratos estruturais da parede celular. Pode limitar a disponibilidade dos carboidratos em ate 1.4 vezes o sey peso molecular e confere rigidez a estrutura tridimensional da parede celular. Quimicamente é definida como um polihidroxifenilpropano, com certa resistencia à hidrólise. Nas forragens, aparece na sua forma verdadeira, com composiçăo variável em ácido coumárico, ferulico e sinapico, como constituintes basicos CVAN SOEST, $1982 ;$ GRAWFORD \& CRAWFORD, 1984 .

O conceito de disponibilidade está relacionado a forma como a lignina se associa a estrutura dos polissacarídeos, com a formação de regibes cristalinas, e com os arranjos ordenados nas cadeias moleculares de celulose na microfibrila. A complexidade dos substratos lignocelulosicos exige criterios metodológicos na avaliaça dos carboidratos estruturais, principalmente quando se pretende conhecer seu potencial de uso industrial. Os substratos 1 ignocelulosicos compreendem $95 \%$ da biomassa terrestre. A celulose e a lignina representam, aproximadamente, $40 \%$ e $25 \%$ respectivamente destes CCRAWFORD \& CRAWFORD, 1984 , sendo a celulose a biomolecula extracelular mais abundante, enquanto que a intracelular e a proteina (LEHNINGER, 1988 ). 
12.

c) Hidrólise enzimática da celulose, hemicelulose e derivados

\section{c.1) Teoria hidrolitica}

A celulose, hemicelulose e seus derivados podem ser utilizados como fonte de carbono e energia por microrganismos aeróbicos e anaerobicos. A maioria dos estudos que visa esclarecer o mecanismo da decomposif̧ão destes polimeros e baseada, principalmente, em Trichoderma reesei e Aspergilius niger, por possuirem os sistema celuloliticos mais ativos e de mais fácil obtençăo. O mecanismo de sintese das enzimas celuloliticas dessas especies segue a teoria da indução e represså proposta por JACOB \& MONOD (1961), que é regulado geneticamente, porem com possibilidades de manipulaçöes sobre suas características básicas. As relaçbes entre induçăo, repressão e sintese, ainda não estão bem estabelecidas, principalmente pela multiplicidade dos sistemas citados na literatura (ENARI, 1983 ; COUGHLAN, 19853.

A complexidade deste mecanismo é funço do(s) substratols envolvidos e de suas diferentes formas de uso. Há proposiçbes sugerindo substratos ideais, entretanto. estes deven ser estabelecidos en funcăo dos objetivos de uso dos sistemas multienzimáticos. Existem, basicamente, três enzimas envolvidas no processo hidrolitico CENARI, 1983; GOUGHLAN, 19852

- Endoglucanase C1.4 - beta-D-glucano 4 glucanohidrolase, EC 3.2.1.4), que hidrolisa aleatoriamente ligaçðes glicosidicas, produzindo terminais redutores. 
- Celobiohidrolase (1,4 - beta - D - glucano celobiohidrolase, EC 3.2.1.91ว, que atua sobre celulose nativa produzindo celobiose com terminais não-redutores.

- Beta-gl ucosidase Cbeta - D - glicosideo glicohidrolase, EC 3.2.1.21), que hidrolisa celobiose e celooligossacarideos de pequeno peso molecular $(3-4)$.

O mecanismo de sacarificaçăo enzimática da ceIulose nativa, a nivel macromolecular, proposto atualmente, - caracterizado inicialmente pela amorfogenese (Figura 3 . Yários fatores tem sido propostos como desencadeadores do processo. ou seja, tornam o material mais susceptivel a hidrólise enzimática, porém os mesmos ainda não estao bem estabelecidos (COUGHLAN, 1985). A amorfogenese pode ser desencadeada por meio enzimático dependente de peróxido de hidrogenio e ferro (GRIFFIN et alii, 1984 ) ou por um fator de desfibrilamento ou formadores de fibra curta CHALLI WELL \& GRIFFIN, 1973). O desfibrilamento e a erosăo sobre os cristais de celulose são causados pelo rompimento de pontes de hidrogenio, o que é confirmado por tecnicas microscopicas. sem que haja alteração da estrutura original da fibra e com produção de pequenas quantidades de açúcares solúveis. CHANZY et alii, (1983) atribuiram esta atividade $\equiv$ celobiohidrolase. 


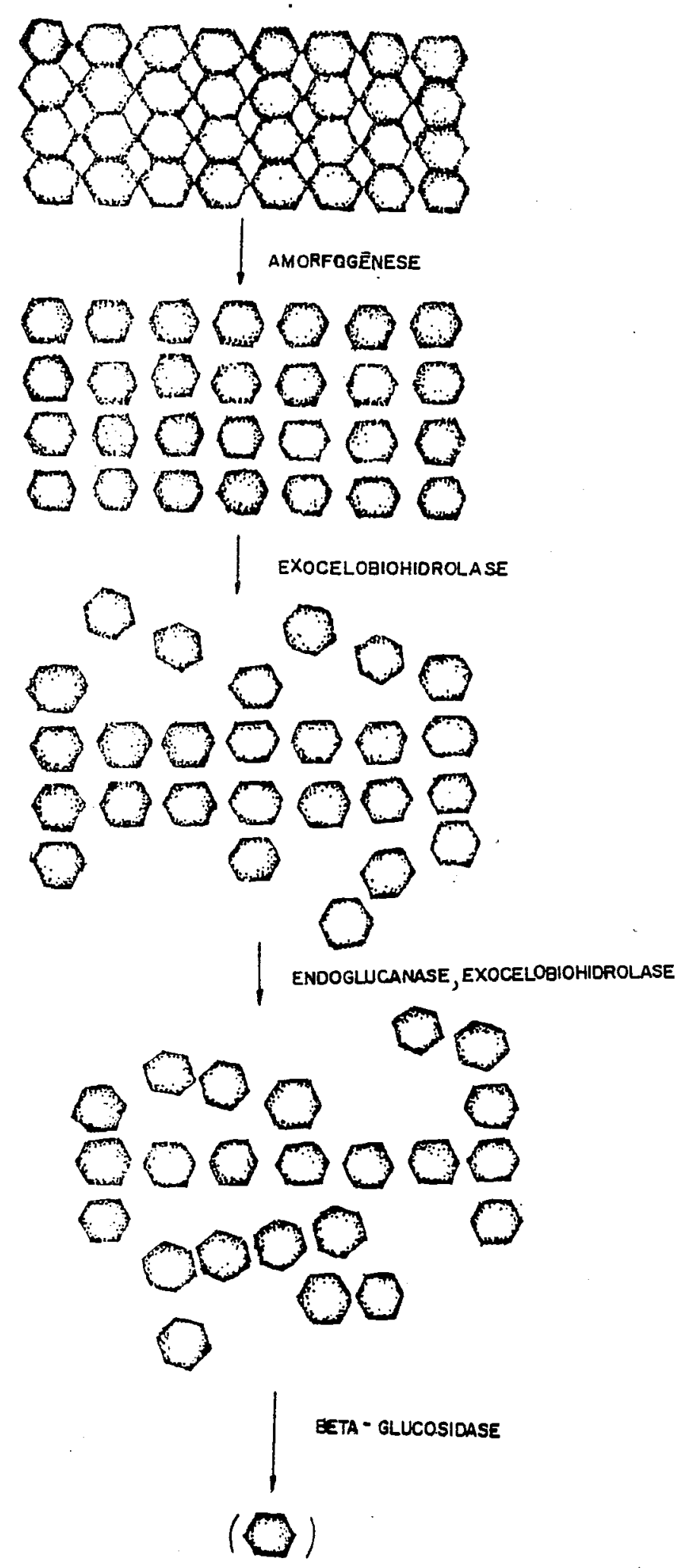

Figura 3 - Diagrama macromolecular proposto para hidrolise da celulose. Fonte: COUGHLAN, 1985. 
Tanto a amorfogenese quanto a sacarificação podem assumir formas diferentes de acordo com os substratos - os microrganismos envolvidos. Apesar de confirmada a atividade hidrolitica, o fator gerador do processo não $f$ aceito como sendo enzimático, por ter baixo peso molecular, apresentar estabilidade a altas temperaturas, liofilização e a extração com metanol. Contrapondo-se, ainda, atua sinergicamente com endo e exogl ucanase no processo de sacarificação CGRIFFIN et ai $i$ i, 1984 .

Um modelo para explicar o mecanismo foi proposto por REESE et alii (1950), porém não esclarece totalmente o processo, principalmente por aceitar-se a existencia de um fator não hidrolitico capaz de ativar a sequencia de reação hidrolitica. Assim, pode-se pelo menos distinguir os microrganismos capazes de desenvolverem-se em substratos cristalinos Cgeradores de Gil e aqueles que são capazes de crescerem em celuloses modificadas, geradores de CX ENARI (1983); COUGHLAN (1985). CDetalhes na Tabela 1 ).

Tabela 1 - Substratos preferenciais das enzimas celuloliticas.

\begin{tabular}{|c|c|c|c|c|c|}
\hline $\begin{array}{l}\text { GOMPONENTES } \\
\text { BIOQUIMICOS }\end{array}$ & $\begin{array}{l}\text { CELULOSE } \\
\text { CRISTALINA }\end{array}$ & $\begin{array}{l}\text { CARBOXIMETIL } \\
\text { CELULOSE }\end{array}$ & $\begin{array}{c}\text { CELULOSE } \\
\text { AMORFA }\end{array}$ & $\begin{array}{l}\text { CELOOLIOOS } \\
\text { SACARIDEOS }\end{array}$ & CELOBIOSE \\
\hline Endoglucanase & - & + & + & + & - \\
\hline celobiohidrolase & + & - & + & + & - \\
\hline Beta-glucosidase & - & - & - & + & + \\
\hline
\end{tabular}

Fonte: ENARI, 1083. 
O modelo aceito propठe uma forte sinergia CTabela 2 entre endogl ucanase e celobiohidrolase para substratos al tamente ordenados, entretanto, para substratos amorfos pode ocorrer forte sinergia entre endogl ucanase e cel obiase CENARI, 1983; COUGHLAN, 1985). As endoglucanases atuam al eatoriamente sobre as regibes amorfas da celulose, abrindo extremidades para o ataque de celobiohidrolase, formando celooligossacarideos de diferentes pesos moleculares. Posteriormente, a beta-glucosidase aumenta a eficiencia de hidrolise, removendo os produtos inibitorios de endogl ucanase e de celobiohidrolase CMARSDEN el alii, 1982a; ENARI, 1983; COUGHLAN, 19853

Tabela 2 - Celulólisepor enzimas isoladas e/ou combinadas.

COMPONENTES BIOQUTMICOS

\section{SOLUBILIZACÃO (ALGODÃO) \\ F. $\operatorname{solani}$ \\ T. koningi}

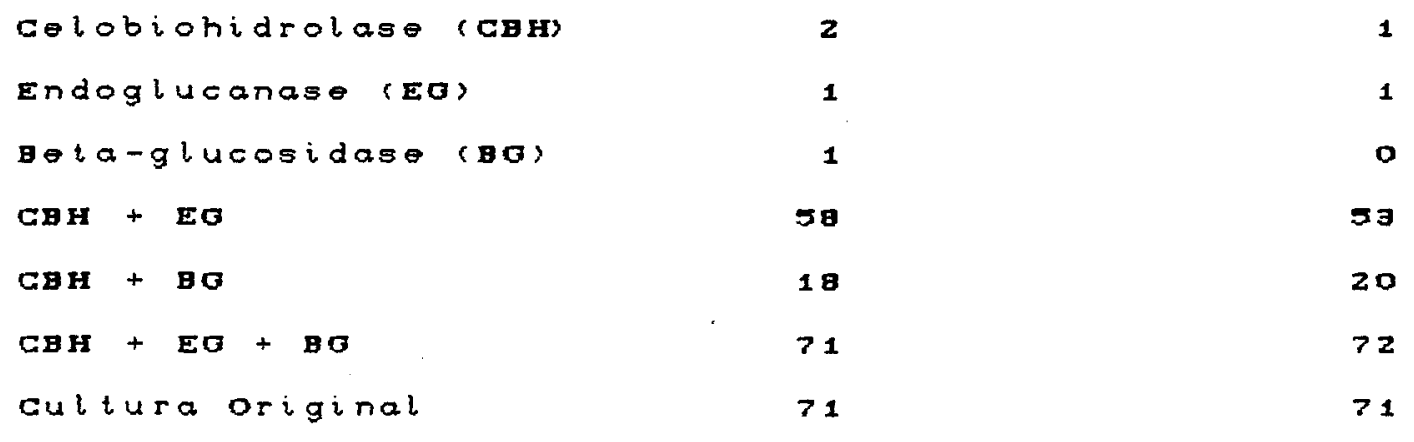

Fonte: ENARI, 1903 .

Para hemicelulose, a proposição hidrolitica segue, un mecanismo semelhante, independente da maior ou menor participaçăo de arabinose e xilose na molécula. Observa-se a participação sinergica de endo 1,4 beta-D-xilanase 
CEC 3.2.1.8) exo-1,4 beta-D-xilosidase CEC 3.2.1.375. 0 fator nåo hidrolitico năo tem sido observado para os sistemas hemiceluloliticos, entretanto, sabe-se que hemicelulase está sempre presente nos sistemas celuloliticos de microrganismos mesofilicos e termorilicos CDURAND et alii, 1984; DEKKER, 19853 .

\section{c.2) Alosteria}

As enzimas alostericas apresentam sitios cataIfticos e moduladores; os cataliticos são especificos para substratos, enquanto que os alostericos são especificos para moduladores. Neste caso, o comportamento cinético difere do proposto por MICHAELIIS-MENTEN, pelo fato de que, um modulador positivo e o proprio substrato, ativa o processo, enquanto que um negativo vem a ser o produto final CLEHNINGER, 19883.

Na visao mais recente da celulólise, CFigura 4 enquadram-se como fatores-regulatorios, a propria atividade de C1, a endoglucanase, a celobiohidrolase ou um fator năonzimático, funcionando como marcapasso do processo. Na condiça de saturaçăo, pode-se atingir a maximizaçăo dos moduladores negativos (sitios ativos), enquanto os moduladores positivos podem ser minimizados. O modulador negativo mais evidente é a glucose, que desacelera a reaçăo continuamente, em associaçăo aos outros fatores diminui a velocidade da reaçå ate o limite potencial do substrato e do sistema enzimatico CENARI, 1983 ; COUGHLAN, 19852. 
Endo-beta-(1-4)-gl ucanase

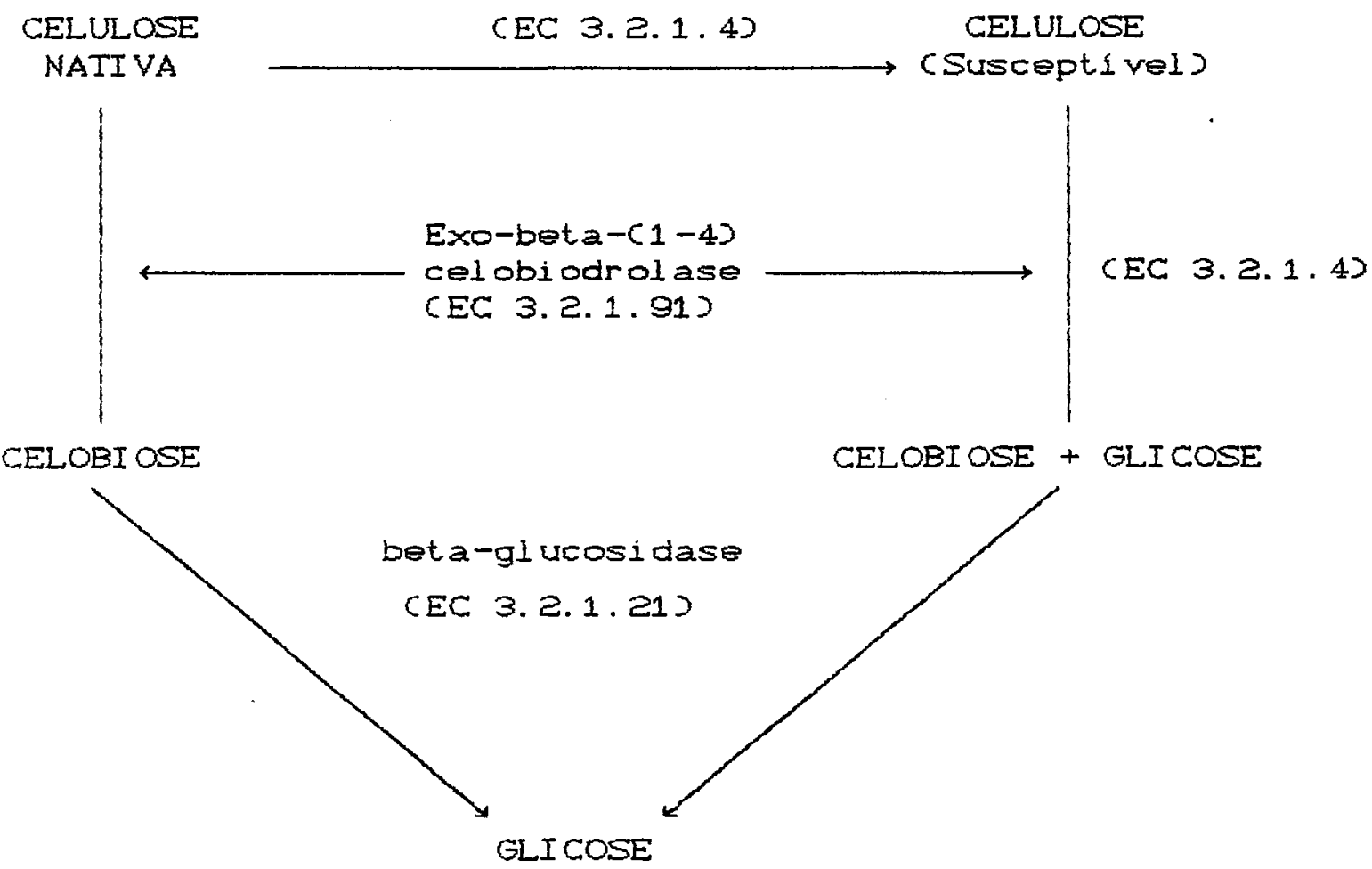

Figura 4 - Modelo aceito para hidrolise da celulose CRYU \& MANDELS, $1980 ;$ MARSDEN et ali $i, 1982 a$.

As enzimas alostéricas podem ser homotrópicas, se somente o seu substrato especifico funcionar como modulador, heterotrópicas se outros compostos além do substrato especifico puderem ocupar espaço nos respectivos sitios alostericos, associando-se a qualquer dos sitios-moduladores (LEHNINGER, 1988 .

O fato dos sistemas celulotiticos e hemiceluloliticos apresentarem inúmeros sitios alastericos, aliados à eficiencia dos processos de "separação e purificaçăo dos 
componentes destes sistemas, que não é máxima, tem dificultado a interpretação dos resultados. As medidas de atividade podem dar indicação do comportamento cinético, entretanto, necessário reconhecer se todos os sitios cataliticos estão saturados. Torna-se interessante descrever o mecanismo sem interferencias de fatores como excesso de substrato elou enzima, acessibilidade $\theta$ tamanho medio de particula do substrato e da enzima CGOEL \& RAMACHANDRAN, 1983; WEIMER \&e WESTON, 19853 .

\section{c.3) Métodos analiticos e atividade}

Basicamente nos estudos enzimáticos, a condifăo de linearidade da atividade, expressa em quantidade de produtorminuto em relação à concentraçăo de substrato, garantida pelas transformaçaes permitidas pela lei de Lineweaver-Burk (LEHNINGER, 1988). As enzimas alostéricas não se enquadram neste procedimento, e ainda, tem-se dificuldade em trabalhar com condigbes de pureza de substratos 0 de enzimas. Recomendando-se portanto uma combinaçăo de metodos para garantir a avaliaçăo.

A atividade celulolitica pode ser expressa de diferentes formas (Tabela 3). A quantificaç̃o de açúares reduzidos e, em geral, a medida mais indicada para os complexos substratos. Outros tipos de avaliaçBes, no entanto. tem fornecido altas correlaç̧⿸厂s CCOUGHLAN, 19855.0 metodo clássico de dosagens de açúcares redutores pelo (DNSO ácido dinitrosalicilico (MILLER, 1959 ) para hidrolisados lignoce- 
lulosicos tem sido mais indicado, pela sua simplicidade e reprodutibilidade. MANDELS et alii, (1976) demonstraram que pode haver interferencias de substratos, enzimas e condiços de ensaio nas avaliaçóes colorimetricas de açucares redutores, e estas avaliaçbes são comparáveis ao procedimento gravimetrico.

Tabela 3 - Métodos analíticos para atividade celulolitica.

COMPONENTES BIOQUTMTCOS
SUBSTRATOS
PROPRIEDADE E, OU PRODUTO MEDIDO

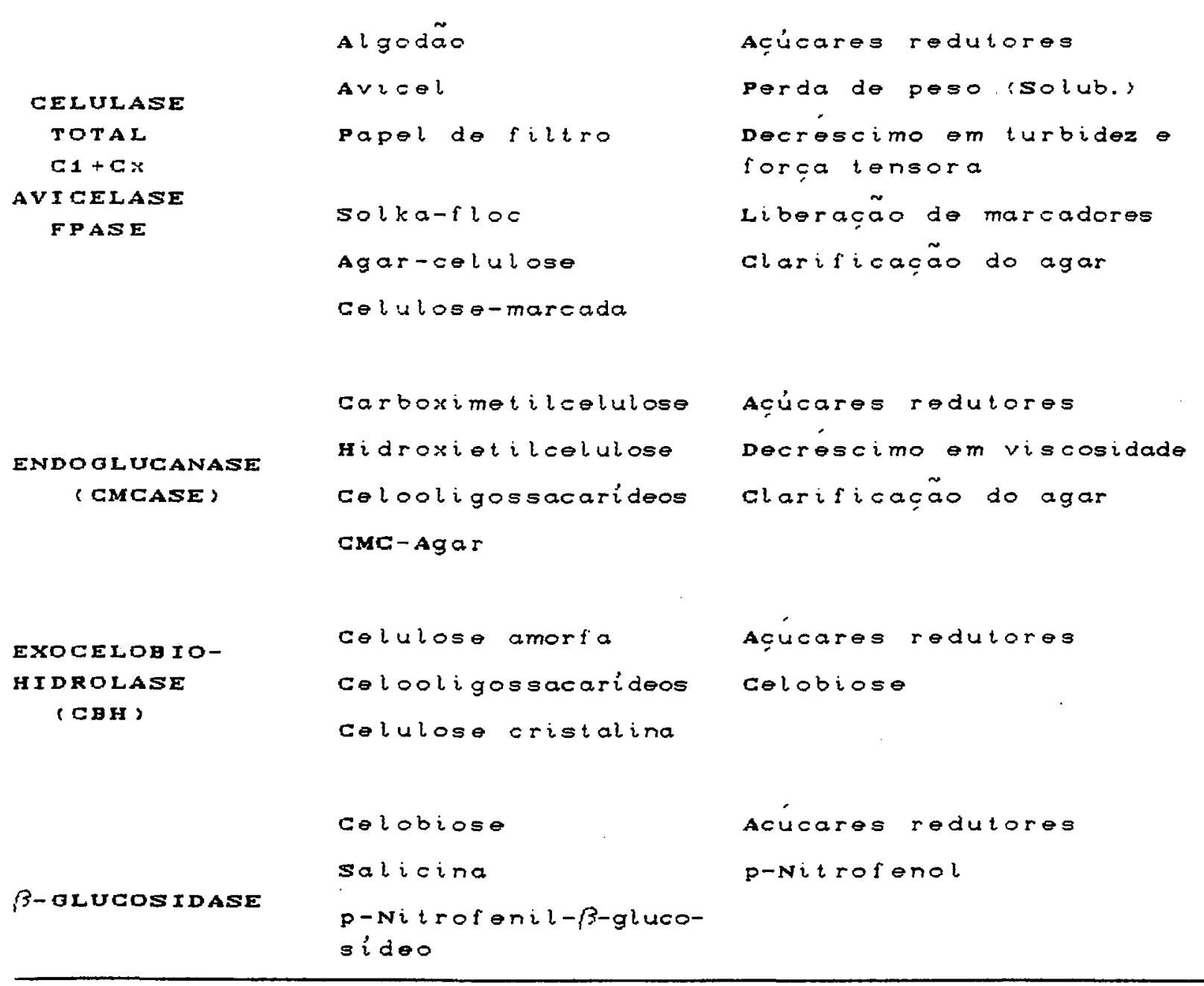


MARSDEN et alii (1982b) propuseram que os resultados com o DNS, por agrupar terminais reduzidos de diferentes oligossacarideos, podem apresentar discrepancias da ordem de $25 \%$ em comparação aos obtidos por cromatografia 1 fquida de alta pressão (H.P.L.C.). Entretanto, o DNS sofre menos interferencias de condiçßes de ensaio, tais como potencial hidrogenionico, tampoes, volume de amostra e temperatura, decorrentes basicamente das diferenças de reatividade de monomeros simples e celobiose. As diferenças observadas entre os metodos DNS e o H.P.L.C. foram atribuidas basicamente a subestimativa, dada pelo DNS, de oligossacarideos oriundos da atividade hemicelulolitica; relacionando-se numa reta padrão de glucose, substratos como o bagaço, que apresentam quantidades elevadas de xilose e arabinose e diferentes graus de polimerizaçăo (FOX et alii, 1984 ).

Comparaças dos metodos Somogyi \& Nelson a o da givcose-oxidase, tem revelado que o primeiro sofre bastante interferencias das condiços diferenciadas de ensaio. Ao se traçar curvas de sacarificaçă principalmente com periodos longos, o metodo de Somogyi \& Nelson mostra resultados discrepantes com, o DNS (BREUIL \& SADDLER, 1985 a). Por outro lado o glucose-oxidase não mostra-se muito preciso para o estudo de substratos e tratamentos que visam avaliar susceptibilidade a diferentes sistemas enzimaticos; a referida susceptibilidade deve-se principalmente ás conformaçőes estruturais Iignocelulosicas (BREUIL \& SADDLER, $1985 \mathrm{~b}$ ). 
A velocidade de reação em condiçốs padronizadas define as unidades internacionais UI (S), sendo que, a atividade molecular pode ser expressa em funça do produto ou do substrato. A atividade especifica, entretanto, define melhor a relaça entre o produto e a enzima CMANDELS et alii, 1976; ENARI, 1983; COUGHLAN, 19853.

A separaçao de celooligassacarídeos pode ser obtida por H.P.L.C. (MARSDEN et ai $i$, 1982b; DEKKER, 1985 ) cromatografia de camada delgada CCHIRICO \& BROWN JR., 1985 . dando uma melhor orientação do mecanismo de sacarificaçao. Para melhor compreender a açăo do proposto componente $C_{1}$, tem-se submetido materiais com alto indice de cristalinidade à soluçbes enzimáticas, entretanto, não se consegue distinguir metodologicamente os monomeros solúveis de regibes cristalinas. Tem-se sugerido aferir paralelamente o indice de cristalinidade no residuo (WEIMER \& WESTON, 1985 ) e/ou a técnica de ressonancia magnetica (BARTON, 1988 ).

A condiçăo de linearidade pode ser estabelecida com a beta-glucosidase, pela especificidade com substratos tais como: celobiose, p-nitrofenil-beta-D- -glicosideo e salicina, atraves de diferentes metodos como o da glucose oxidase o Somogyi \& Nelson, sem problemas na interpretaçăo (PEI JI, 1987$)$

As diferentes vias de produçăo de glucose ccelobiose, celooligossacarideos) sugerem a complexidade dos substratos e do processo hidrolitico no mecanismo de sacarificaçao parcial, demonstrando ser importante na avaliaça de 
microrganismos capazes de utilizar celulose nativa CRYU \& MANDELS, 1980; MARSDEN et ali $i, 1982 b)$.

d) Fatores determinantes da disponibilidade dos substratos lignocel ulósicos

As carbroidrases fungicas demonstram certo potencial em detectar estruturas disponiveis da celulose, hemicelulose e derivados. Como estruturas disponiveis, distingue-se aquelas que, mesmo sofrendo interferencias de diferentes fatores, conseguem produzir monómeros utilizáveis em algum processo bioquímico ou nutricional. Entre os fatores que interferem na disponibilidade, destacam-se:

\section{d. 1$)$ Lignificação}

- processo de lignificação nos materiais fibrosos, ainda de pouca compreensão. Está envolvida uma polimerização entre os acidos coumárico, ferulico e sinápico nas forrageiras. A condensaço de terpenoides e fenolicos com grupos acetatos e ligaços glicosidicas, pode explicar a ligaçăo covalente com a hemicelulose, o provavelmente, com a celulose, reduzindo a disponibilidade da parede celular em sistemas anaerb́lcos e aeróbicos (VAN SOEST, 1982; CRAWFORD \& CRAWFORD, 1984; BORGMEYER \& CRAWFORD, 1985; LIN et ali $i$, 19853.

Grande parte dos hidrolisados de lignina obtidos em sistemas anaeróbicos săo encontrados na forma de $\mathrm{CH}_{4} \odot \mathrm{CO}_{2}$, ao se utilizar tecricas isotopicas com ${ }^{14} \mathrm{C}-1$ ig- 
nina (BORGMEYER \& CRAWFORD, 1985; COLBERG \& YOUNG, 1985). Em sistemas aeróbicos por mediação da D-glucose-oxidase cbeta-D-gl ucose-oxigenio-oxiredutase, EC 1.1.3.4) e peroxidase Cperóxido de hidrogenio oxiredutase, EC 1.11 .1 .75 pode se obter compostos fenolicos solúveis e D-glucose, evidenciando uma açåo coordenada com sistemas celuloliticos de Trichoderma reesei e Phanerochaete chrysosporium CLOBARZEWSKI \& PASZCZYNSKI, $1985 ;$ KELLEY \& REDDY, $1986 \mathrm{~J}$.

A Iignolise o uma atividade mediada pelas enzimas, peroxidase e oxigenase, de peso molecular 42000 e que não mostram estereoespecificidade. A despolimerização da lignina em alfa-C e beta-C. segue o mecanismo olassico de indução e repressão CIIEN \& KIRK, 1983; FAISON \& KIRK, 1985). A dependencia extracelular de $\mathrm{H}_{2} \mathrm{O}_{2} \mathrm{O}_{2}^{-}$nas formas ativas parece ser o fator alosterico para a ligninase CIIEN \& KIRK, 1983; CRAWFORD \& GRAHFORD, 1984), pelo menos com Phanerochate chrysosporium.

o processo envol vendo transformaçß̧es bioqui micas de substratos 1 ignocelulósicos, ate entăo, tem recebido atenção apenas pelas tecnicas convencionais, tais como, recuperaçăo de fraç̋es indisponi veis, métodos isotópicos com ${ }^{14} \mathrm{C}-1$ ignocelulose analises de hidrolisados. A enzimologia deste processo tem recebido inumeros tratamentos metodologicos nos ultimos anos (CRAWFORD \& CRAWFORD, 1984 ).

Os sistemas multienzimaticos celuloliticose lignoliticos são estudados atraves de tecnicas de mutagenese - DNA-recombinante, visando obter mi crorganismos superprodu- 
tores destas enzimas. Entretanto, o fator alosterico nestes sistemas pode sofrer defeitos genéticos principalmente pela técnica mutagènica CCRAWFORD \& CRAWFORD, 1984; LEHNINGER, 19883

\section{d. 2) Cristalinidade e amorfismo}

A estabilidade dos substratos 1 ignocel ul osicos e determinada pelas pontes de hidrogenio e forfas de Van der Waals inclusive na estrutura linear cristalina, onde formam-se microfibrilas ordenadas, com maiores indices de polimerizaça (10-15000). A semel hança molecular de celulose nos diferentes materiais (algodão, madeira e forragens) garante certas suposiçB̈es para estudos comparativos, porém diferem basicamente em hemicelulose e lignina CCOUGHLAN, 1985; LIN et alii, 1985; ROLZ et alii, 1986).

o fator alosterico para o sistema celulolitico pode ser evidenciado no componente C., ultimamente identificado como celobiohidrolase I e II CCHANZY et alii, 1983; ALURRALDE \& ELLENRIEDER, 1984; VAN TILBEURGH et ali $i, 1985$; endogl ucanase (RYU \& MANDELS, 1980; MARSDEN et ali $i$, 1982a) - como agente năo enzimático, desfibrilador e despolimerizador (HALLIWELL \& GRIFFIN, 1973). Há certa tendencia de especificidade $e$ afinidade deste componente por substratos oristalinos CALURRALDE \& ELLENRIEDER, 1984; VAN IILBEURGH $\theta t$ alii, 1985 .

Diferenças estruturais em substratos cristalinos amorfos podem ser refletidas na reatividade destes 
materiais ate $24 \mathrm{~h}$; entretanto, a relaçăo enzima/substrato interage com tempo nos distintos substratos CGUSAKOV et alii, 1985; ROLZ et alii, 1986). Efetivamente, substratos cristalinos săo menos reativos que substratos amorfos, principalmente, pela variaçăo normal en grau de polimerizaçăo e de substituição destes últimos CLIN et alii, 1985; POULSEN \& PETTERSEN, 1985 .

A proposição de que o componente fi tem uma participaçăo na redução do tamanho médio de particulas, aumentando a acessibilidade aos demais componentes do sistema celulolitico, corrobora com a interação observada entre cristalinidade e tamanho de particulas. Há entretanto, um limite para ambos os fatores interferirem sobre a atividade enzimatica. Dificilmente, consegue-se amostras celulosicas puramente amorfas ou cristalinas, porem, a celulose residual tende a apresentar um indice de cristalinidade maior devido a remoção das regibes amortas e/ou deficiencias em componente ci (ALURRALDE \& ELLENRIEDER, 1984; WEIMER \& WESTON, 1985 ). O componente $\mathrm{Cl}_{1}$ ou agente despolimerizador tem efeito de solubilização sem produção de açúcares, combinando-se os efeitos de $C_{1}$ e Cx, a eficiencia do sistema celulolitico pode ser quintuplicada CHALLIWELL \& GRIFFIN, 1973). A celobiohidrolase I a II entretanto, são especificas para diferentes pesos moleculares de celooligossacarideos e susceptiveis a inibição classica por celobiose que $\theta$ principal produto final CGUSAKOV et ai $i$, 1985b; VAN TILBEURGH et alii, 19853. O êfeito limitante clássico da 
cristalinidade pode ser a inativaçăo por propriedades fisico-químicas do substrato (ALURRALDE \& ELLENRIEDER, 1984 ).

\section{d.3) Potencial enzimático e sinergia}

o potencial de um sistema celulolitico pode ser avaliado como a capacidade (taxa e extensão) de sacarificaçăo em condiçoes comparativas padronizadas. As propriedades fisico químicas dos substratos interagem com os sistemas enzimáticos (ROLZ et alii, 1986$).$

As enzimas dos sistemas celulolfticos ocorrem em diferentes formas intra (endo) ou extracelularmente (exo), seguindo o mecanismo proposto de indução e repressão CJACOB \& MONOD, 1961). A açăo coordenada das endo e exo enzima, atuando aleatoria e especificamente sobre os respectivos substratos, garante a ericiencia do processo hidrolitico (ENARI, 1983; COUGHLAN, 1985 ).

A inibicão classica por produto final ou intermediário e a sinergia entre endo e exoenzimas, endo e celobiase e diferentes formas de exoenzimas (isoenzimas) tem recebido diferentes consideraçőes matematicas. Sugere-se uma disfunção da cinetica de primeira ordem, conforme é esperado para os casos de especificidade enzimatica e de substrato. 0 referido modelo tem aplicação no estudo de diferenças estruturais e biologicas dos polissacarideos CFUJJI et alii, 1981; FUJJI \& KAWAMURA, 1985; FUJJI \& SHIMIZU, 1986.

A atividade inicial da endoglucanase promove liberaçăo de produtos que somente serão reduzidos na presen- 
ça de beta-glucosidase. Observa-se, tambem, a liberação de celooligossacarideos susceptiveis a celobiohidrolase devido 3. sua orientação e estrutura química. As exocelobiohidrolases tamben apresentam especificidade e sinergia, o produto final de CBH I é uma celobiose, enquanto da CBH II e uma celotriose. En sistemas deficientes em celobiase, provavelmente, a sinergia observada pouco significa, tendendo a acumular celooligossacarideos de pequeno peso molecular CCLESCERI et alii, 1985; POULSEN \& PETIERSEN, 1985; VAN IILBEURGH et, ai $i$, 1985; TJERNELD et ai $i, 1985 a, b) .0$ mesmo mecanismo sinergico pode ser observado com a xilanase e xilosidase, com inibiçăo por xilobiose e xilose respectivamente (DURAND et alii, 1984; DEKKER, 1986 ).

A importancia da sinergia está relacionada com a eficiencia da celulólise. O processo e visto como o balanco equilibrado da atividade especifica e coordenada de cada um dos componentes. Entretanto, a afinidade e a especificidade das celobiohidrolases, tambem podem afetar a eficioncia hidrolitica. Considerando-se os mecanismos naturais de inibiçæo, o tempo funciona como determinante da atividade, aumentando a inibiçå por acumulo dos produtos finais $\theta$ intermediários (TJERNELD et aiii, 1985a, b; GUSAKOV et ai $i$, 19872. A remoção destes dá linearidade quase perfeita após $24 \mathrm{~h}$ (TAKAGI, 1984), enquanto que $72 \mathrm{~h}$ parece ser o tempo maximo de estudo do potencial em sistema batch CGUSAKOV et alii, 1987). As tecnicas mutagenicas e do DNA-recombinante visam obter mutantes resistentes à inibiça por produto 
final e obter superprodutores, entretanto, ainda não se tem uma definição clássica do tipo de inativação promovida por estes produtos nos respectivos sitios moduladores CALURRALDE \& ELLEṆRIEDER, 1984 ; AGARWAL, 1985 ; KAWAMORI et al $i i, 1985$.

Observa-se uma forte sinergia entre $\mathrm{C}_{1} / \mathrm{Cx}_{\mathrm{x}}$, resultando também em eficiencia hidrolitica CHALLIWELL \& GRIFFIN, 1973). Os sistemas celuloliticos de Trichoderma reesei såo ricos em celobiohidrolase I e II, enquanto, os de Aspergillus niger o são em beta-glucosidade, possivelmente, orientando formas distintas de uso,considerando a especifioidade de substratos e potencia enzimatica CGROUS et ali $i$, $1985 ;$ DEKKER, 19863.

\section{d. 4) Condições estabilidade de reação}

A especificidade enzima/substrato e um reflexo da estereoespecificidade quimicamente orientada pelos celooI igossacarideos formados através das reaçöes que se sucedem, zo se expor os sistemas enzimáticos. Ou ainda, pode ser definida como a fraçăo do substrato susceptivel a hidrolise. Entăo, assume importancia a relaçăo enzima/substrato, principalmente nos estudos cineticos com enzimas alostéricas. Em termos de produção de enzimas pelos microrganismos, a compatibilidade entre substratos e microrganismos, reflete as caracteristicas estruturais dos substratos CCLESCERI et alii, 1985; GROUS et alii, 1985; TJERNELD et ai ii, $1985 a$, b).

A relaçăo enzima/substrato interage com diferenças estruturais dos substratos em condiçöes variantes da 
saturação. Entretanto, o tempo tambem determina um 1 imite da reação, em condiç̧es ótimas. Iem-se proposto que os flatores de inati vação enzimática limitam a reatividade do substrato (AGARWAL, 1985). O tempo para potencial maximo parece estar entre 24 e $72 \mathrm{~h}$, ate $24 \mathrm{~h}$ podem aparecer as diferencas estruturais mais significativas dos substratos CGOEL \& RAMACHANDRAN, 1983; CLESGERI et ai $i i, 1985$; GUSAKOV et ali $i$, 1985; MANONMANI \& SREEKANTIAH, 19872.

Sabe-se que os sistemas multienzimaticos variam em condiçбes otimas, principalmente pelo grande número de isoenzimas determinadas pelas modernas tecnicas de produf̧ăo de enzimas. Entretanto, as variaç̋es detectadas são minimas, exceto, em casos especiais. Fatores como tampão, temperatura, concentraçăo hidrogenionica e composiçăo iônica do meio, podem interferir na estabilidade da reação, refletindo na reatividade dos substratos CDURAND et alii, 1984; AGARWAL, 1985; GUSAKOV et ai $i i, 1985 ;$ TJERNELD et $a l i i, 1985 a, b)$

Admite-se em casos especificos, condiçōes padronizadas para aferir equilíbrio e estabilidade do sistema, ou de componentes individuais. Os tampares simples citratoe acetato de sódio då melhor estabilidade que os fosfato-citrato e acetato de sodio. Justifica-se assim a grande aplicaçăo destes na maioria dos ensaios de atividade celulolitica CMULLINGS \& PARISH, 1984; MANONMANI \& SREEKANTIAH, 19872.

A concentraçăo hidrogenionica está relacionada ao ponto isoeletrico CPIJ, entretanto, mostra-se bastante 
especifico em algumas condiçöes. 0 pH medio 4,8 indicado para os sistemas celuloliticos de Trichoderma reesei Aspergillus niger. Certamente, a nivel industrial pode parecer interessante trabalhar com altas temperaturas e diferentes faixas de $\mathrm{pH}$, assim há sugestbes de que a albumina serica bovina CBSA funciona como termo estabilizante das enzimas CDEKKER, 1985). Acrescimos de $10^{\circ} \mathrm{C}$ $\left(40-50^{\circ} \mathrm{C}\right.$ podem duplicar a energia de ativaçá de enzimas, dobrando a velocidade de reaçăo CLEHNINGER, 1988). Para a maioria dos sistemas celuloliticos, tem-se proposto $50^{\circ} \mathrm{C}$ como temperatura otima com maior estabilidade no início da reaçăo CDURAND et alii, 1984; GROUS et ai $t i, 1985$; TJERNELD et alii, 1985 a,b; MANONMANI \& SREEKANTIAH, 19872.

A composiça ionica do meio reduz a sacarificaç̃o em substratos puros e naturais, a diferentes tempos, 24 a $72 \mathrm{~h}$, usando celulases de Trichoderma reesei e Aspergilius ustus. Alem disso, a taxa e a extensão de sacarificaçăo respondem a diferenças em concentração enzi mática cGRoUS et alii, 1985; MANONMANI \& SREEKANTIAH, 1987 .

A taxa de sacarificaça e um bom indicativo de eficiencia hidrolitica, sendo que a extensão de sacarifica૬ăo năo se correlaciona bem com eficiencia, principalmente por diferenças estruturais dos substratos naturais. A máxima eficiencia de uso destas enzimas pode ser obtida com remoçăo de inibidores, combinando os processos biotecnológicos de sacarificaçăo e fermentação (TAKAGI, 1984). Em condiçôs subótimas, a atividade pode se estender ate 24 dias. A 
eficiencia hidrolitica pode ser melhorada simplesmente por adiça de beta-glucosidase, a de Aspergillus niger, apesar de abundante, é bastante sensivel ao produto. A adição de beta-glucosidase de Aspergilius niger em sistemas de Trichoderma reesei remove a celobiose năo-reduzida, aumentando em até 1,3 a eficiencia hidrolitica CCLESCERI et alii, 1985; GROUS et aiti, 1985; TJERNELD et alii, 1985 a,b; DEKKER, $1985)$.

A eficioncia máxima de hidrólise pode ser acompanhada de recuperaçăo máxima de enzimas, entretanto, os componentes individuais diferem em dessorçăo, principalmente por especificidade attached com substratos relacionados CALURRALDE \& ELLENRIEDER, 1984). Alem dos fatores já descritos, tratamentos especificos sobre os substratos e sistemas de reatores continuo, semicontinuo e batchl interferem na recuperaçăo das enzimas. A produçăo das enzimas responde por mais ou menos 60\% do custo do processo CDESPHANDE \& ERIKSSON, 1984; CLESCERI et alii, 1985; TJERNELD et alii, 1985; GUSAKOV et alii, 1987), o que justifica pesquisas na área de recuperaçăo das referidas enzimas.

d.5) Tratamento fisico, quimico e biológico e acessibilidade

Alguns tratamentos promovem delignificação, rompen ligaçäes de hidrogenio, reduzem grau de polimerização e de cristalinidade, tornando os substratos mais reativos. Os referidos efeitos sobrepoem-se ao de intumescimento, com 
importancia na hidrolise efetiva da matriz solida da parede celular por microrganismos. Paralelamente, podem ocorrer perdas relativas de hemicelulose e celulose CDAVID et ali $i$, 1985; ROLZ et alii, 19865.

Tratamentos fisicos em moinho bola reduzem a cristalinidade, aumentam a área superficial, aumentando portanto a acessibilidade das enzimas. 0 tempo de moagem tem se mostrado efetivo ate 96 h. A descompressăo à vapor desprende a lignina dos polissacarideos, produzindo monomeros de baixo peso molecular. A eficácia dos tratamentos pode ser avaliadas pela relação custo/aumento de reatividade, ao se conseguir aumentar a distribuiça dos poros, com consequente aumento em area superficial e acessibilidade CGRETHLEIN, 1984; DAVID et ali et alii, 19865. As dificuldades em se determinar tamanho de particulas e acessibilidade 1 imitam o uso das referidas tecnicas para avaliaçöes de tratamento. Na verdade, há baixa correlaçăo entre tamanho de particulas e acessibilidade, e há forte correlação entre area superficial e acessibilidade. A acessibilidade pode ser detectada por exclusão de soluto na matriz da parede celular, determinando a distribuição tamanho de poros (STONE et alii, 1965; GREIHLEIN, 1984 ).

Os tratamentos em meios alcalinos $\mathrm{CH}_{2} \mathrm{O}_{2}, \mathrm{Na}_{2} \mathrm{O}$, $\mathrm{SO}_{2}^{-}, \mathrm{NH}_{3}, \mathrm{NaOH}, \mathrm{Na}_{2} \mathrm{CO}_{3}, \mathrm{CaCOH}{ }_{2} \mathrm{~d}$ despolimerizam a lignina, tornando a celulose e a hemicelulose mais reativa CGREIHLEIN, 1984; ROLZ et alii, 1986; TAKAGI, 1987). Os tratamentos em meios ácidos, alteram a cristalinidade, rom- 
pem pontes de hidrogenio e dependendo da concentração e forma de aplicação, podem hidrolisar parcialmente a celulose e a hemicelulose (DAVID et ai $i$, 1985; WEIMER \& WESTON, 1985 ). Os tratamentos biologicos resumem-se em aplicaços de enzimas e/ou microrganismos sobre a biomassa Cver Figura 5). Os mecanismos naturais envolvidos na obtencão ou extração de energia, por estes tratamentos indicam maior susceptibilidade dos substratos a tratamentos enzimáticos, isto devido o processo microbiologico, não demonstrar rapidez e eficiencia na deteçăo de diferenças estruturais dos substratos. O balanço energético positivo, somente é conseguido com celulas adultas, sendo que as diferenças e incompatibilidade de substratos com microrganismos provocam retardamento no processo CDAVID et alii, 1985; COLBERG \& YOUNG, 1985; ROLZ et alii, 1986; MURRAY, 19875.

Das diferenças entre sistemas aerobicos e anaerobicos, uma das mais marcantes, é a independéncia de beta-glucosidase nos anaeróbicos. A inibicão clásica por glucose baixa, mantendo conversbes de biomassa em elevadas concentraçós molares de glucose. Assim, os sistemas anaerobicos respondem a adição de beta-glucosidase devido o acúmulo normal de celobiose. A dependencia do at tachment $e$ maior em anaerbbicos, e a digeståo ocorre nos celulasomos ou vesiculas celulares. Em geral, a digestão extracelular dos aeróbicos assume maior importancia que a intracelular CROLZ et alii, 1986; MURRAY, 19873. 
HEMI CELULOSE

CELULOSE

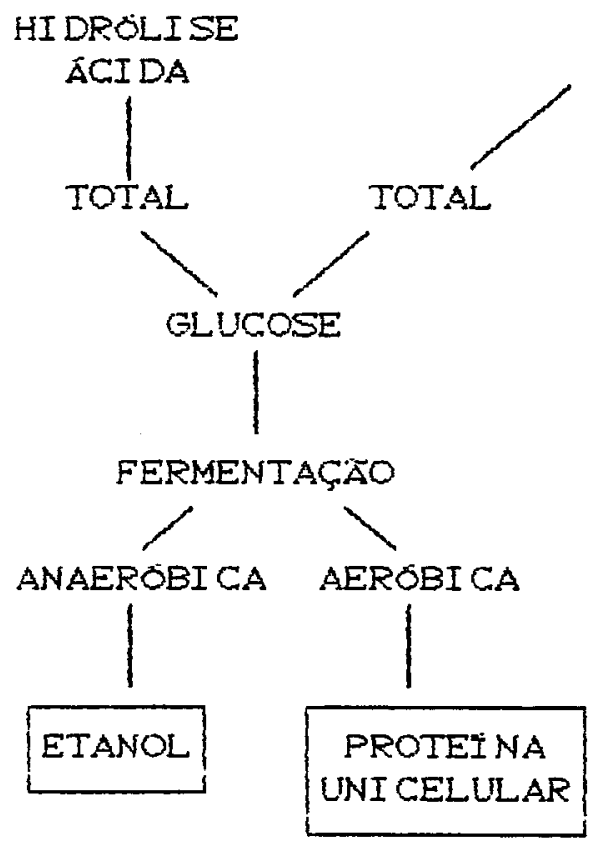

HI DROLISE

ENZI MATICA

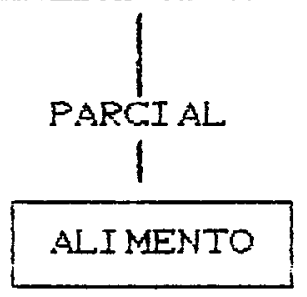

ANAEROBI COS

FERMENTADORES MI GROBI ANOS

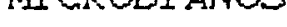

MICROBI ANOS

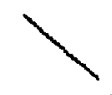

AEROBI COS

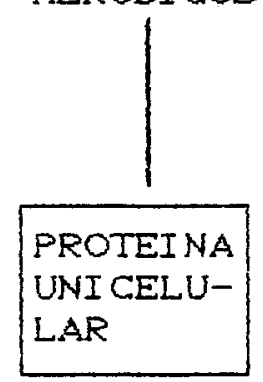

Figura 5 - Uso alternativo de materiais lignocelulosicos em processos biotecnológicos. Fonte: ENARI, 1983.

2.2. Métodos de Estudo da Fração Potencialmente Digestirel em Forragens

a) Modelo de digestäo nos ruminantes

Os modelos matemáticos têm contribuído bastante para o conhecimento do processo digestivo nos ruminantes. Principalmente por permitirem avaliaç̧es de fatores associados diretamente ao alimento, ao animal ou ambas COSBOURN, 1978; MERTENS \& ELY, 1979; MURPHY et atii, 1986 . 
Conhecida a relaça simbionte no processo digestivo dos ruminantes e o singular sistema multicompartimental referente a digestão de carboidratos estruturais. têm-se considerado uma fração potencialmente digestivel e outra indigestivel (WALDO, 1972). A primeira submetida a dois mecanismos, os quais, denominam-se digestão e passagem, enquanto que a segunda fração e submetida apenas ao mecanismo de passagem. Sabe-se hoje, que este modelo aplica-se a outras fraçoses da dieta, entretanto, muitas vezes tem-se interesse em manipular os referidos mecanismos no sentido de aumentar a digestão do referido grupo de nutrientes, a nivel de rúmen-reticulo, e por conseguinte, reduzir a passagem dos mesmos (WALDO, 1972 ; YAN SOEST, 1982 ).

Uma melhor caracterizaça da digestão da fibra pelos ruminantes inclui a relaçăo entre a fração indigestivel e consumo voluntário, tempo e taxa de turnover e taxa de passagem CMERTENS \& ELY, 1979 ; VAN SOEST. 1982). Obviamente, estes parâmetros estão associados a fatores inerentes a0 alimento e a animal, sem nenhuma relaçăo mutuamente exclusiva CVARGA \& HOOVER, 1983; MURPHY et ali i, 19863.

Modernamente, tem-se proposto um modelo no qual inclui-se 12 constituintes quimicos, crescimento microbiano e raspectivas interaç̧es com o hospedeiro CMURPHY et alii, 1986). Experimentos comparativos para testar este modelo comprovam interaç̧es de nivel e frequencia de al imentaçăo sobre os parâmetros considerados. 
Reconhecidamente, a extensão de degradaçăo no rumen é funça inversa de turnover e direta de tempo de permanencia (VAN SOEST, 1982; CZERKAWSKI, 1986). A taxa de digestão é uma função inversa da taxa de passagem, devido à competif̧ao de ambas, obviamente, considerando a fraçăo potencialmente digestivel (WALDO, 1972). Nesse sentido, tem-se proposto como forma de avaliar as forragens, o estudo paralelo de taxa e extensão de digestão. Esse enfoque caracteriza a forragem quanto a variabilidade na taxa de digestão e lag-time (VARGA \& HOOVER, 19833.

A fração indigestivel tem relaçăo direta com o estado de enchimento no rumen-reticulo, ficando claro o seu efeito sobre o valor nutritivo, caso se observe a esperada redução em consumo voluntário e taxa de digestão CMERTENS \& ELY, 1979; VAN SOEST, 1982). A fraçæo potencialmente digestivel constitui-se de conteúdo celular e parede celular verdadei ramente digesti vel CWALDO, 1972; OSBOURN, 1978; VAN SOEST, 19825

b) Métodos de estudo de digestão

A composiçă química mostra relaç̋es significativas com o valor nutritivo dos alimentos, principalmente para os constituintes do conteúdo celular, indicando sua alta disponibilidade. Entretanto, para parede celular, devido as propriedades intrinsecas e a variabilidade de seus componentes, tem-se questionado a disponibilidade, devido ao grande número de fatores determinantes CVAN SOEST, 1973; VAN 
SOEST, 1981). A fraçăo potencialmente digestivel de cel ulose - hemicelulose, entretanto fornece bons indicativos do potencial digestivel nos alimentos, e quanto menor sua participaçăo maior a variabilidade na materia seca digestivel, indicando uma maior heterogeneidade CVAN SOEST, 1982; MINSON, 19823 .

Há tentativas de se obter equaços capazes de estimar a materia seca digestivel ou energia digestivel nos alimentos, onde se leva em consideraçăo os componentes individuais da parede celular coelulose, fibra detergente ácido. Ligninas e suas relaçôes intrinsecas com valor energético. Entretanto, o problema analitico torna estas equaçäes de dificil aplicação prática CMINSON, 1982). Pode se estimar o valor nutritivo, por regressăo múltipla a partir de componentes químicos $e$ do potencial digestivel CMINSON, 1982; COITYN et alii, 1984; DEBOEVER et alii, 1988) obtidos pelos diferentes procedimentos analiticos. A energia liquida - energia metabolizável podem ser estimada no alimento a partir de lignina e lignocelulose fibra detergente ácido CMINSON, 1982). Ao se considerar o efeito do ambiente sobre os alimentos, a aplicação das referidas equaçóes torna-se mais especifica CKIRCHGESSNER \& KELLNER, 1978; OSBOURN, $1978 ;$ COTTYN et alii, 1984 .

A variabilidade, o custo e o tempo necessário, tem inviabilizado a maioria dos estudos diretos de digestão. Qualquer dos metodos diretos cooleta de fezes, marcadores isotópicos ou năo, in situ com saco de nylons pode ser 
aplicado no estudo de taxa de digestăo. Entretanto, para o estudo de extensão de digestao, os metodos in situ com saco de nylon ou in vitro microbiológico tem sido proposto CHOPSON et alii, 1963; MARTEN, 1981; MINSON, 1981; VARGA \& HOOVER, 1983; DEBOER et ali $i, 1987$. Quanto à técnica pepsina-celulase, trabalhos preliminares evidenciam ambas as possibilidades, desde que sejam controlados alguns fatores que determinam a atividade enzimática CMCOUEEN \& VAN SOEST, 1975; MCLEOD \& MINSON, 1978; MCLEOD \& MINSON, 1982). A importância dos referidos estudos está em se conhecer melhor a natureza da fração potencialmente digestivel, principalmente a contribuicão da parede celular, e assim melhor utilizar a informaça sobre digestibilidade em estrategias de al imentaçæo.

As avaliaç̋es sobre digestão tem variabilidade menor que as de consumo voluntario, tornando o primeiro mecanismo mais fácil de ser avaliado CULYATI, 1973). Algumas vezes a reprodutibilidade entre analises e laboratorios tem dificultado a aplicaçăo dos métodos convencionais, diretos e indiretos CMCLEOD \& MINSON, 1969; CLARK \& BEARD, 1977; GOLDMAN et alii, 1987; CLARY et alii, 1988). A tecnica enzimatica tem custo operacional e financeiro bastante reduzido mesmo ao se considerar a necessidade de importaçăo de enzimas e ainda é compensada pela sua alta reprodutibilidade cJONES \& HAYWARD, 1975; DOWMAN \& COLLINS, 1977; ROUGHAN \& HOLLAND, 1977 ; MCLEOD \& MINSON, 1982. 
En geral, tem-se indicado a técnica microbiologica (TILLEY \& TERRY, 1963; VAN SOEST et alii, 1966 ) para os estudos de valor nutritivo, nos programas de melhoramento - manejo agronomico de forrageiras CMINSON \& HAYDOCK, 1971; REES \& MINSON, 1979). Espera-se que a resposta da forrageira, ao ser selecionada pela sua digestibilidade, possa ser refletida também em consumo voluntario e valor nutritivo CMERTENS \& ELY, 1979). Outros grupos de alimentos, tais como: forragens conservadas CDOWMAN \& COLLINS, 1977; DOWMAN \& COLLIMS, 1982; DEBOEVER, 1988); residuos agricolas tratados ou não CREXEN, 1977; ISRAELSEN et ai $i$, 1978; WALKER et alii, 1983) e misturas de alimentos (CLARK \& BEARD, 1977; COTIYN et alii, 1984; DEBOEVER et ai ii, 1986 poderão ser avaliados indistintamente pelos métodos enzimático e microbiologico, desde que sejam observadas as respectivas modificaçöes no procedimento analitico, visando compatibilizar fonte e especificidade enzimática e composição dos substratos.

c) Procedimento analitico da técnica enzimática

CRecentes propostas descritas na Tabela 4$)$

\section{c. 1$)$ Tratamento da amostra}

Considerando-se o mecanismo de digestão da fibra pelos microrganismos ruminais, sabe-se que o efeito do intumescimento ocorre paralelamente ao processo de remoçăo do conteúdo celular CVAN SOEST, 1982 ; MCLEOD \& MINSON, 1982; MURPHY et alii, 1986). A reidrataçăo do material garante 
maior peso especifico mantendo-o em compartimentos ruminais com maior atividade celulolitica CCZERKAHSKI, 1986; HOMMA, 19863

Os métodos propostos incluem uma solubilização com HCl-pepsina, com concentração ácida de 0,1 a $2,0 \mathrm{~N}$ CJONES \& HAYWARD, 1975; MCLEOD \& MINSON, 1982; DEBOEVER et alii, 1985), apenas HCl 2N (PACE et alii, 1986) ou ainda análise de parede celular pelo sistema detergente neutro CROUGHAN \& HOLLAND, 1977; ISRAELSEN et aiii, 1978; DOWMAN \& COLLINS, 1982; MCLEOD \& MINSON, 1982). A melhor correlaça com digestibilidade in vivo do primeiro modelo tem sugerido que HCI-pepsina não só tem a função de remover o conteúdo celular, como tambem alterar a forma física da parede celular, tornando-a mais susceptivel a hidrolise com cel Ul ase CJONES \& HAYWARD, 1975; GOTO \& MINSON, 1977; MCLEOD \& MINSON, 1982J. Para estudos com residuos ou alimentos com grande quantidade de parede celular, a determinaçăo prévia desta fraçăo tem dado resultados satisfatórios para estimar a digestibilidade in vivo CMCQUEEN \& VAN SOEST, 1975; ROUGHAN \& HOLLAND, 19772. Para alimentos com al to conteúdo de amido, têm-se sugerido tratamentos adicionais no sentido de hidrolisa-lo com $\mathrm{HCl} 1 \mathrm{~N}$ ou 2 ND exou gelatiniza-lo com tratamento adicional $80^{\circ} \mathrm{C} / 45^{\prime}$, CKIRCHGESSNER \& KELLNER, 1978 ; DEBOEVER et alii, 1986; HADJIPANAYIOTOU et ai i, 1987 ; AUFRERE \& MICHALET-DOREAU, 1988). Ou ainda, outro tratamento enzimático com amiloglucosidase (AGIDEX), adicional ao HCl-pepsina, e proposto para melhorar a correlação com os 
resultados de estudos in vivo (DOWMAN \& COLLINS, 1982 ).

A solubilizaçăo com pepsina $0,2 \%$ peso/volume, Heil $0,1 \mathrm{~N}$ por 24 horas a $40^{\circ} \mathrm{C}$ tom sido utilizada como padrăo para tratamento das forragens em sistemas de deteção da fraçăo potencialmente digestivel cJONES \& HAYHARD, 1973 ; JONES \& HAYWARD, 1975; MCLEOD \& MINSON, 1982). Embora esse metodo subestime o valor real, este procedimento tem sido mais preciso do que as demais alternativas. Esta fraça da forragem esta al tamente correlacionada com consumo voluntario, for assim determinar uma maior taxa de digestăo iniaial, reduzindo o lag-time CDONEFER et alii, 1963; MINSON \& HAYDOCK, 1971 ; NARASIMHALU, 1984; MURPHY et alii, 19863.

Alguns autores propbem a solubilizaça com pepsira apos o tratamento com celulase, entretanto, nem sempre os resultados são satisfatorios CJONES \& HAYWARD, 1973; JONES \& HAYWARD, 1975; KIRCHGESSNER \& KELLNER, 1978; PACE, 1986s. Outros propbem a solubilizaçăo da forragem apenas com a celulase, os resultados obtidos têm sido satisfatorios, principalmente para substratos ou formas cristalinas com celulases mais especificas, especialmente em residuos agricolas CHARTLEY et alii, 1974; MCQUEEN \& VAN SOEST, 1975; REXEN, 1977 .

Poucos pesquisadores sugerem 0 acerto de potencial hidrogenionico do meio apos o tratamento com HCl-pepsina na forragem, o qual está com pH 1,5-2,0, antes de se expor a parede celular às enzimas celuloliticas. ALLISON \& BORZUCKI, (1978); MALOSSINI et äii, (1984) sugeriram carbo- 
nato de sodio $\left(\mathrm{Na}_{2} \mathrm{CO}_{3}\right)$ enquanto (VANDERHAEGHE \& BISTON, 19872 sugeriram acetato de sódio $20 \%$ num sistema FIBERTEC. Alimentos tratados com $\mathrm{NaOH}$ ate $8 \%$, certamente o tampão $0,1 \mathrm{M}$ ja garante condiç̃es de $\mathrm{pH}$ próximas ao ideal CREXEN, 19775 .

A forragem fresca pode ser submetida a extra૬ă de conteúdo celular atraves do sistema detergente neutro CBAILEY \& JONES, 1971; HARTLEY et ali $i$, 1974; MCCLUSKEY et alii, 1984), principalmente zo se ter interesse em determinar a digestibilidade de tecidos especializados presentes na parede celular. Os hidrolisados podem ser submetido a análises cromatograficas e colorimetricas de carboidratos estruturais, usando-se as ténicas in vitro. A técnica indireta de dosagem de ésteres de carboidratos em hidrolisados de parede celular com celulase de oxyporus sp mostrou bom indicativo do potencialmente digestivel e boa comparação à equação múltipla, incluindo os componentes de parede celular CHARTLEY et ali i, 1974$)$.

As referidas metodologias coromatografia e colorimetria) sao aplicadas a situaços en que se pretende recuperar a parede celular, ou ainda, distinguir a atividade hemicelulolitica em sistemas enzimaticos, fracionando a hemicelulose A e B. A extração incompleta de conteúdo celular pode trazer interferencias. nas referidas determinaças. Portanto, devem ser feitas modificaç̋es analiticas concernentes a composição do alimento e forma de exposição de parede celular CBAILEY \& JONES, 19̈71; HARTLEY et ali $i, 1974$. 


\section{c. 2) Especificidade enzima-substrato}

(Recentes propostas descritas na Tabela 4).

As enzimas de Trichoderma reesei tem sido indicadas para a digestão de celulose cristalina e celulose amorfa encontradas em forragens tropicais e temperadas, em diferentes proporçöes CJONES \& HAYWARD, 1975; ROUGHAN \& HOLLAND, 1977 ; MCLEOD \& MINSON, $1982 ;$ VALDES \& JONES, 19873. Por outro lado, as enzimas de Aspergillus niger tem-se mostrado mais especificas para alimentos ricos em carboidratos não estruturais CCLARK \& BEARD, 1977; DOWMAN \& COLLINS, 1977; COTTYN et alii, 1984). Também tem-se observado que celulases de basiodiomicetos coxyporus spl poderão ser usadas para formas altamente ordenadas de celulose CJARRIGE \& THIVEND, 1969; HARTLEY et alii, 1974; ISRAELSEN et ali 19783 .

A presença de atividade hemicelulolitica em celulases comerciais tem sugerido adaptaçbes na metodologia, possibilitando adequação as diferentes formas de ligaçes quimicas entre os componentes da parede celular. A distinçăo completa dos componentes individuais do sistema celulolitico - hemicelulolitico, pode indicar a eficiencia com que o material e hidrolisado CBAILEY \& JONES, 1971; HARTLEY et alii, 1974; JONES \& HAYWARD, 1975; MCQUEEN \& VAN SOEST, 1975; ROUGHAN \& HOLLAND, 19773.

A adiç̃o de enzimas no rúmen e nas dietas tem revelado interaçós com o potencial digestivel dos alimentos CDANIELS \& HASHIM, 1977; ROLZ et alii, 1986). Em dietas 
volumosas de baixa digestibilidade, observa-se efeitos mais significantes sobre o potencial do alimento em relaçăo às dietas de melhor digestibilidade CDANIELS \& HASHIM, 1977; REXEN, 1981; ROLZ et aiii, 1986). Os residuos agricolas pela sua heterogeneidade podem revelar melhor tais interaç̧es GROLZ et aiii, 1986), orientando possiveis combinaçases de tratamentos cenzimático $x$ microbiológicol visando efetivamente melhorar o aproveitamento.

\section{c.3) Condições de reação}

A variação na atividade das enzi mas produzidas por diferentes 1 aboratórios e em difierentes condiçes possivelmente justifica os diferentes niveis de concentraçăo ou relaçăo enzima/substrato ou enzima/tampão. As concentraçbes enzimáticas recomendadas na solução tampão variavam de 0,1 a 3,25\% pEso/vOl ume CJONES \& HAYWARD, 1975; MCQUEEN \& VAN SOEST, 1975; MASAOKA \& TARUMOTO, 1979, DEBOEVER et ali $i$, 1986). Ainda observaram-se que pequenas concentraç̧̋es tendem a apresentar menor desvio padrão residual CJONES \& HAYWARD, 1975; DOWMAN \& COLLINS, 1977; MCLEOD \& MINSON, 1978; VALDES 8. JONES, 1987). CDetalhes na Tabela 4 .

Alguns estudos tem avaliado o tamanho da amostra como fonte de variaçăo, há indicios de que amostras pequenas $60,2 \mathrm{~g}$ tendem a apresentar maior desvio padrao residual CMCLEOD \& MINSON, 1978; DOWMAN \& COLLINS, 19823. Com relaço ao diametro medio de particulas para análise, observa-se que as de $1,0 \mathrm{~mm}$ de diametro apresentam menor 
desvio padrão residual em relação a $0,4 \mathrm{~mm}$ CGOTO \& MINSON, 1977; MCLEOD \& MINSON, 1978).

A temperatura ideal para a atividade da celulase é de $50^{\circ} \mathrm{C}$ e tem se demonstrado que a solubilizaça pela pepsina-celulase aproxima-se bastante da digestão in vivo em gramineas tropicais CMCLEOD \& MINSON, 1978; MCLEOD \& MINSON, 1982). Entretanto, a maioria dos estudos tem proposto temperaturas entre $39-40^{\circ} \mathrm{C}$ CJARRIGE \& THIVEND, 1969; JONES \& HAYWARD, 1975; CLARK \& BEARD, 1977; DOWMAN \& COLLINS, 19773. Tentativas foram feitas no sentido de reduzir - tempo de reaçă por se observar com $24 \mathrm{~h}$ a maior parte de sol ubilização CJONES \& HAYWARD, 1973; MCLEOD \& MINSON, 1978; MASAOKA \& TARUMOTO, 1979; BUGGE, 1980; DOWMAN \& COLLINS, 1982; DEBOEVER et alii; 1986). Entretanto, essa medida e comprometida pelo alto desvio padrão residual. Outros estudos tem propostos 48 h CJONES \& HAYWARD, 1975; MCLEOD \& MINSON, 1982; VALDES \& JONES, 19872. Poucos sugerem $72 \mathrm{~h}$ CMCQUEEN \& VAN SOEST, 1975; BUGGE, 1980; NARASHIMAHLU, 1984). Em geral, supunha-se que com a redução em tempo havia necessidade de se aumentar a concentração enzimática CDOWMAN \& COLLINS, 1977; REXEN, 1977; MCLEOD \& MINSON, 1978; MASAOKA \& TARUMOTO, 1979; DEBOEVER, 19863. Entretanto, deve-se levar em consideraçăo a especificidade sobre os substratos em questão (CLARK \& BEARD, 1977; MCLEOD \& MINSON, 1982$)$ ao se estabelecer qualquer relaçăo entre concentração enzimática e tempo de reação com atividade celulalitica. CDetalhes na Tabela 4). 
Tabela 4 - Recentes propostas da metodologia enzimatica para estudos da fraçăo potencialmente digestivel.

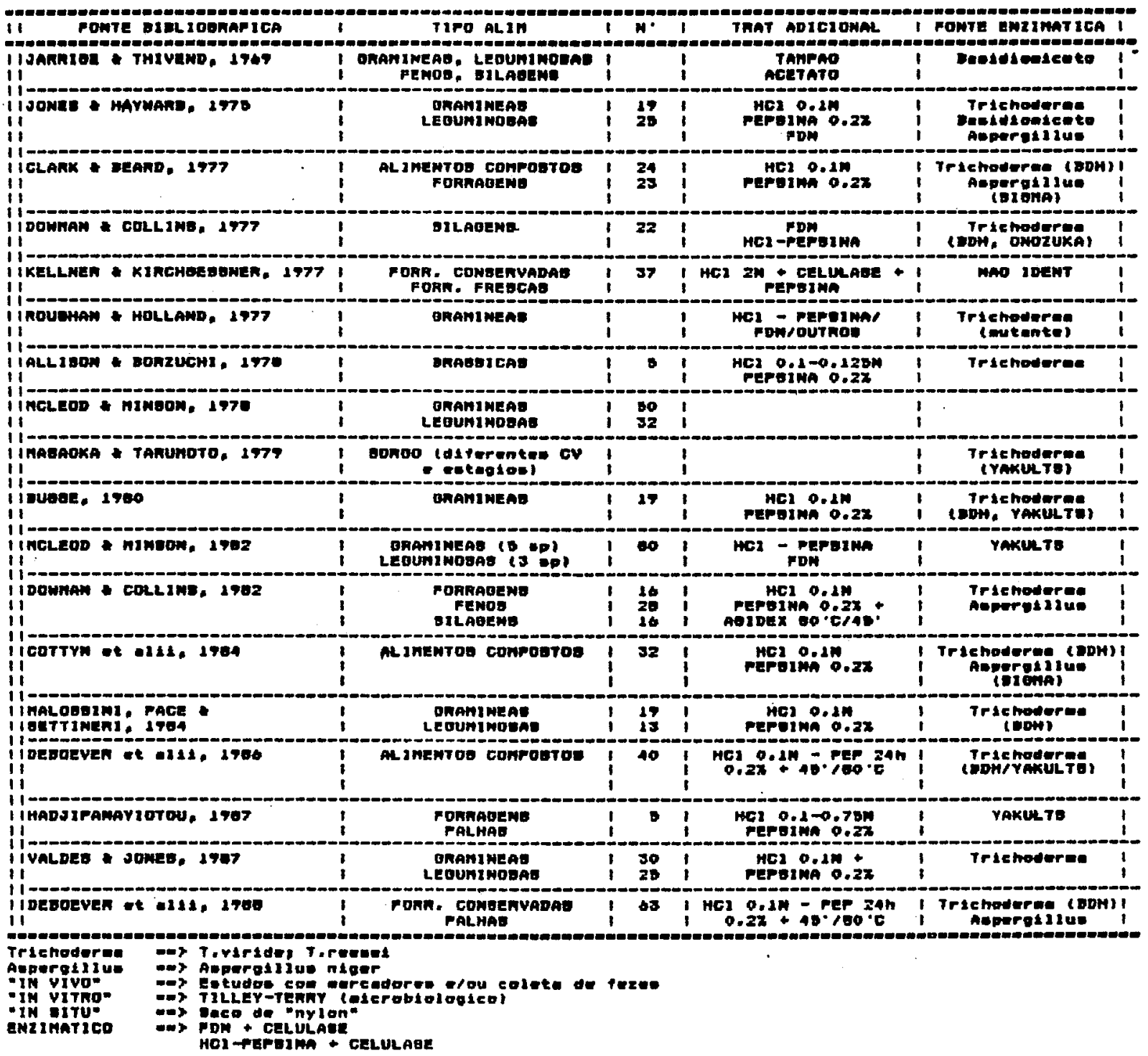


Tabela 4 - Continuaçăo.

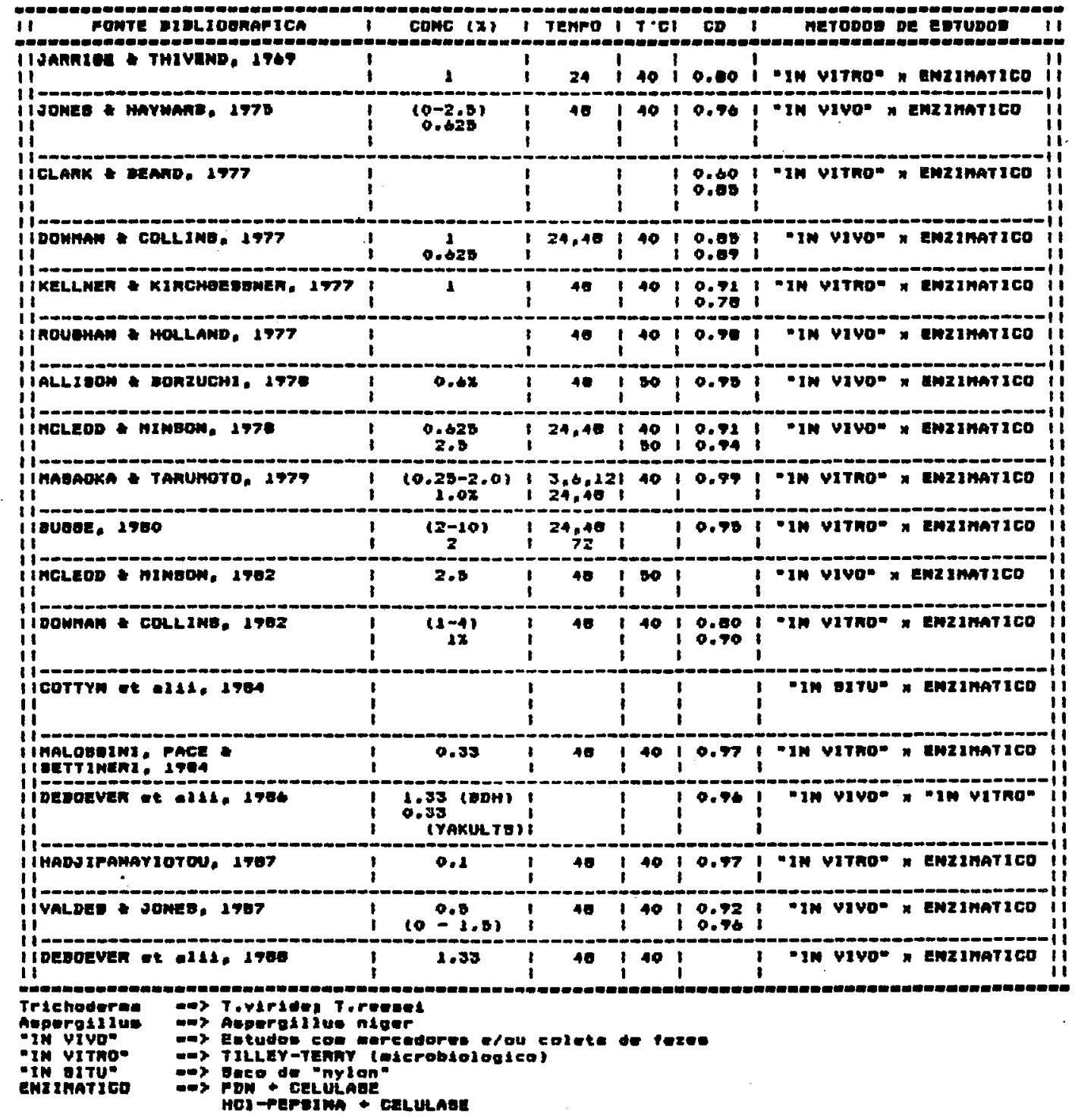




\section{MATERIAL E MÉtodos}

\subsection{Fase Pré-experimental}

3.1.1. Definições de substratos e fatores de estudo

Os estudos cineticos dos sistemas celuloliticos serão aplicados às forragens, portanto, não se proporá modificaçoses no tamanho de particulas para as analises laboratoriais. Visando os referidos estudos, inicialmente, tentou-se transformar placas de celulose comercial, em partículas de tamanho definido, em moinhos tipo faca, moinho-bola $\theta$ moinho-martelo, sem nenhum resultado significativo, principalmente devido as caracteristicas quimicas assumidas após os referidos tratamentos cmaior variabilidade en dosagens de açucares e solubilizaçãos.

Procedeu-se então a teste com substratos puros comerciais de tamanho de particulas diferenciadas, fazendo variar os possiveis fatores. de estudo, tempo de reaça e concentraçæo enzimatica. Alguns desses substratos, devido provavelmente a modificaças em acessibilidade e cristalinidade, demonstravam maior variabilidade nas leituras colorimétricas. Enquanto que os demais diferiam pouco em reativi- 
50.

dade avaliados a 24,48 e $72 \mathrm{~h}$ em relaça ao papel de filtro Whatman n: 1 tomado como padråo. Optoutse pela celulose microfina $c \simeq 70 \mu \mathrm{m}$ da BLANVER FARMOQUIMICA LTDA., pela baixa variabilidade nos diferentes ensaios. Praticamente, não se observaram diferenças nas variaveis de estudo Caçúares redutores e solubilizaçăol, entre 72,96 e $120 \mathrm{~h}$. Enquanto as relaçóes enzima/substrato foran determinadas a partir do ensaio auxiliar CD1,1\%; De, 0,1\% peso/volume) CD1, 1:1; De, 1:10) com tempo fixo, 72 h (Figura B). Foi testado o efeito da agitação sobre a atividade em alguns ensaios, sem nenhum resultado significativo.

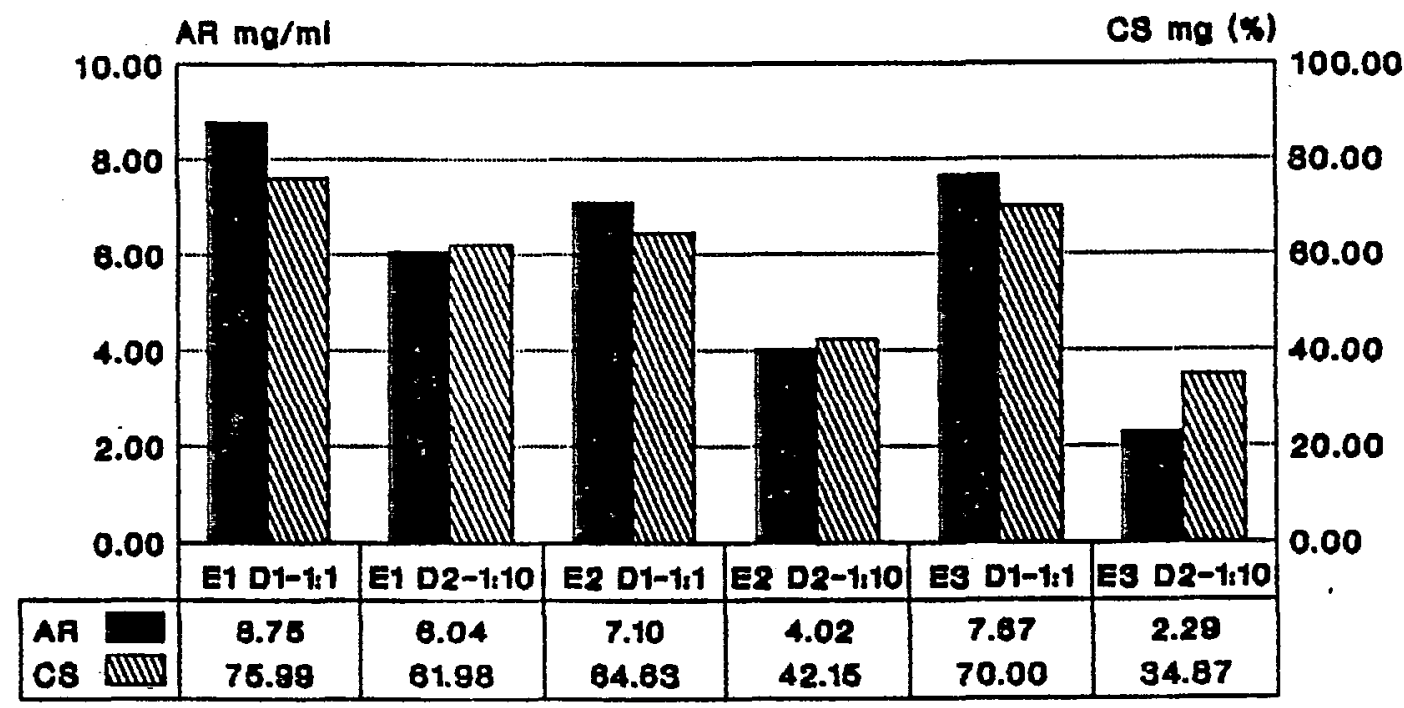

\section{AB - Apucan napuron}

os - oflulagn solutilizada

Ocen.t meste do a mettepese

Figura 6 - Efeito da diluiçăo enzimática sobre o potencial hidrolitico de trés sistemas enzimáticos, obtidos a partir de Trichoderma reesei (E1, Ez) $\theta$ de Aspergilius niger (E). 
Os materiais referidos na Tabela 5 variam em Indice de cristalinidade, entretanto, năo se observou diferenças significativas em atividade celulolitica quando comparados aos menos oristalinos. Possivelmente, os tamanhos de partioulas comparaveis nos dois substratos COURO BRANCO, BLANVER, tenham mascarado o efeito de cristalinidade. E ainda, materiais com maior Indice de cristalinidade apresentaram maior variabilidade.

Tabela 5 - Indice de cristalinidade CI. C. J em celuloses comerciais.

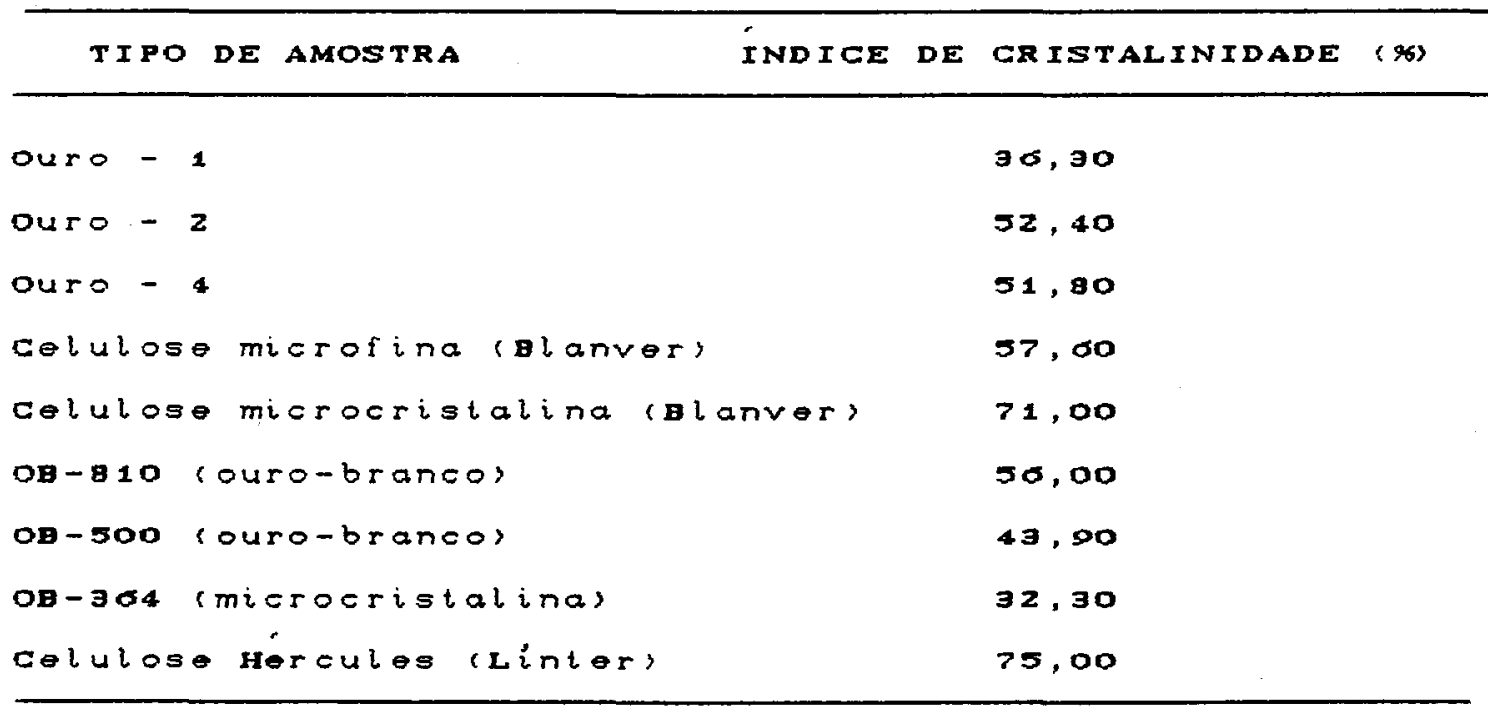

I. C. (6) tomado pelo método da triangulação proposto por STEWART \& FOSTER (1070).

Além dos substratos puros coeluloses comerciais em pó para os estudos cineticos, testou-se a forragem-padrăo (napier, 15 dias), procedente do Laboratório de Bromatologia/ESALQ. As interferencias de constituintes do conteúdo celular tornaram mais "dificeis as dosagens colori- 
52.

metricas. A solubilização com tampão citrato c26\% da materia seca indica valor subestimado do conteúdo celular na forragem-tosto c3e\%: A ofpa do frottatamento da forragem 6HCl $0,1 \mathrm{~N}$ pepsina - 0,2\% pesorvolumes poderia ser aplicado por $24 \mathrm{~h}$ ou $48 \mathrm{~h}$. Apos estudos em tempos crescentes (1-48 h), não foram observadas diferenças entre 24 e $48 \mathrm{~h}$, enquanto em intervalos inferiores a $24 \mathrm{~h}$, observou-se solubilizaço decrescente, com alteraçßes em desvio padrå residual destes $e a 48 \mathrm{~h}$. No inflio da reaça $(1-3 \mathrm{~h})$ ocorreu mais ou menos $80 \%$ da solubilização observada a $24 \mathrm{~h}$. Ainda, testaram-se as concentraçöes de pepsina, $0,2 \% e 0,1 \%$ peso/volume e näo observaram diferença a $24 \mathrm{~h} e 48 \mathrm{~h}$ em materia solubilizada.

\subsubsection{Adaptação da metodologia para o ensaio de identificação bioquỉmica}

A caracterizaçăo da beta-endoglucanase e beta-glucosidase nas soluçбes indicadas na literatura para avaIiaça de forragens e nas condif̧os padronizadas não apresentavam leituras csoluçăo de carboximetilcelulose e salicina respecti vamente a $1 \%$ peso rol ume em tampãol. As condiçós padronizadas de observação foram $0,5 \mathrm{ml}$ de soluçăo de substrato e $0,5 \mathrm{ml}$ de sol uçăo enzimática $11 \%$ peso vol ume em tampãos, em 1 h de reaçă. Apos os estudos cineticos referentes a primeira fase do trabalho, foram feitas modificaços na metodologia $65 \mathrm{ml}$ de soluçăo dë substrato $+5 \mathrm{ml}$ de soluça 
enzimátical para estudos de atividade em alguns dos tempos indicados no ensaio $1(1 \mathrm{~h}, 12 \mathrm{~h}, 24 \mathrm{~h}, 72 \mathrm{~h}$.

Definições das Yariáveis:

Variável 1: Açúcar redutor $(\mathrm{mg} / \mathrm{ml}$ ou $\mathrm{ug} / \mathrm{ml})$

Variável 2: Solubilizaçao mg CELULOSE/100 mg MS. (\%

Variável 3: Atividade espectfica (ug AR/mg PROT/mi)

Yariável 4: Velocidade de Reaçăo (ug AR/min/ml)

CVariáveis avaliadas por experimento)

\section{Estratégia Experimental}

1. FASE: Estudo das condiçaes ótimas para os sistemas enzimaticos de Trichoderma reesei $\left(E_{1}, E_{2}\right)$ e Aspergillus niger (E).

Ensaio 1: Potencial hidrolitico em funça de concentraçă enzimática e tempo de reação $\left(V_{1}, V_{2}, V_{3}, V_{4}\right)$.

(3) ENZIMAS $\times(4)$ CONCENIRACZES $\times(6)$ IEMPOS $\times(3)$ REPEII ৎðES.

Ensaio 2: Efeito de temperatura, tampão e pH sobre atividade enzimática $\left(V_{1}\right.$ e $\left.V_{2}\right)$.

(3) ENZIMAS $x$ (2) $\operatorname{TEMP}{ }^{\circ} \mathrm{C} \times(2)$ IAMPOES $x$ (2) PH $\times(4)$ REPETI GOES

Ensaio 3: Efeito da concentraçă molar de sódio sobre atividade celulolitica $\left(V_{1} \odot V_{2}\right)$.

(3) ENZIMAS $\times$ (3) MOLARIDADES $\times$ (3) REPETI GOES. 
Ensaio 4: Identificaçăo bioquimica de beta endo-gl ucanase - beta-gl ucosidase $\left(V_{1}\right.$ e $\left.V_{4}\right)$

(3) ENZIMAS $\times(2)$ COMP. BIOQUIMICOS $\times(4)$ TEMPOS $\times(3)$ REPETI GOES.

2 - Fase: Estudos da fraçăo potencialmente digestivel em forragens e alimentos por sistemas in vitro $\mathrm{cmi-}$ crobiológico e enzimáticos.

Ensaio 5: Estudos de parede celular por dois métodos Cdetergente e enzimáticol em forragens e alimentos tropicais. METODOS (2) $x$ GRUPOS $(4) \times$ REPETIÇOES $(3)$

Ensaio 6: Estudos da fração potencialmente digestivel em forragens pelos procedimentos gravimetrico e colorimétrico em sistemas in vitro.

SISTEMAS $(2) \times$ ENZIMAS $(2) \times$ PROC. $(2) \times$ GRUPOS $(4) \times$ REPETI GOES (3).

\subsection{Material}

\subsubsection{Substratos}

\section{a) Puro e especificos}

Na primeira fase do trabalho foi utilizado ceI ul ose microfina da BLANVER FARMOQUIMICA LTDA., para estudos cinéticos dos referidos sistemas celuloliticos. No ensaio de 
55.

identificaçăo bioquímica de beta-endo-glucanase e beta-glucosidase foram utilizados respectivamente carboximetilcelulose (grade coarse, 0,7 meq $/ 9$ MERCK e salicina para microbiologia CC13 His of, MERCKO.

\section{b) Forragens}

As amostras foram obtidas no campo de introduçăo e avaliaçăo de forrageiras do Instituto de Zootecnia, Coordenadoria de Pesquisa Agropecuaria, Secretaria de Agricultura do Estado de Sáo Paulo, Nova Odessa/SP, em 25 e 27 de janeiro de 1988, tentando coincidir com a fase do potencial máximo de produça de gramineas e leguminosas. As forragens conservadas e os residuos agricolas foram escolhidos conforme disponibilidade e uso dos referidos na unidade onde foi executado o trabalho, Seção de Avaliação de Forragens, Divisão de Nutriça Animal e Pastagens. Os alimentos são descritos a seguir:

I DENTIFI CAÇAO

NOME CIENTIFICO

GRAMI NEAS

$I-1$

$I-2$

$I-3$

$I-4$

$I-5$

$I-6$

$I-7$

$I-8$

$I-9$
Pennisetum purpureum

Pennisetum purpureum

Pennisetum purpureun

Paspalum virgatum

Paspalum virgatum

Setaria splendida

Setaria sphacelata

Cynodon dactyion

Brachiaria brizantha
OBSERVAÇOES

$$
\begin{aligned}
& \text { cv Guacu } \\
& \text { Roxo } \\
& \text { Mineirao } \\
& \text { (- } 60 \text { dias) } \\
& \text { (florescido } \\
& \text { sementeado) } \\
& \text { cv. kazungula }
\end{aligned}
$$


56.

$\begin{array}{ll}\text { I-10 } & \text { Brachiaria decumbens } \\ \text { I-11 } & \text { Brachiaria ruziziensis } \\ \text { I-12 } & \text { Brachiaria humidicola } \\ \text { I-13 } & \text { Hyparshenia rufa } \\ \text { I-14 } & \text { Panicum maximum } \\ \text { I-15 } & \text { Brachiaria sp chibridos } \\ \text { I-16 } & \text { Andropogon gayanus } \\ \text { I-17 } & \text { Heteropogon sayanus } \\ \text { I-18 } & \text { Panarthria altissima } \\ \text { I-19 } & \text { Panicum maximum x Macrotyloma axiliare } \\ \text { I-20 } & \text { Brachiaria sp } \\ \text { I-21 } & \text { Brachiaria humidicola + Macrotyloma axiliare } \\ \text { I-22 } & \text { Pennisetum purpureum cr Napier (Padrad } \\ \text { I-23 } & \end{array}$

\section{LEGUMI NOSAS}

II -1

II -2

II -3

II -4

II $-S$

II -6

I I -7

II -8

II -9

II -10

II -11

II -12

II -13

I I -14
Macrotyloma axil lare

Macroptiliun atropurpureum

Pueraria phaseoloides

Neonotonia wighti $i$

Neonotonia wighti (folhas danificadas?

Yisna marina

Desmodium sp

Stylosanthes hamata (initio florescimento) Stylosanthes macrocephala

Leucaena leucocephala

(folhas)

Leucaena leucocephala

(hastes)

Galactia striata

Centrosema pubescens cv. Deodoro

Centrosema virginianum

FORRAGENS CONSERVADAS
I I I -1
Silagem milho (IZ/1987)
III -2
Silagem milho (IZ/1988)
III -3
Silagem milho" (Nestle) 
57.

$\begin{array}{ll}\text { III-4 } & \text { Silagem sorgo (IZ/1986) } \\ \text { III-5 } & \text { Feno de soja perene (IZ/1986) } \\ \text { III-6 } & \text { Feno de colonião (IZ/1988) } \\ \text { III-7 } & \text { Feno de coast-cross (ESALQ/1988) } \\ \text { III-8 } & \text { Feno de soja perene (IZ/1988) } \\ \text { III-9 } & \text { Feno de alfafa (IZ/1988) } \\ \text { III-10 } & \text { Feno de rhodes (IZ/1988) }\end{array}$

RESIDUOS AGRICOLAS

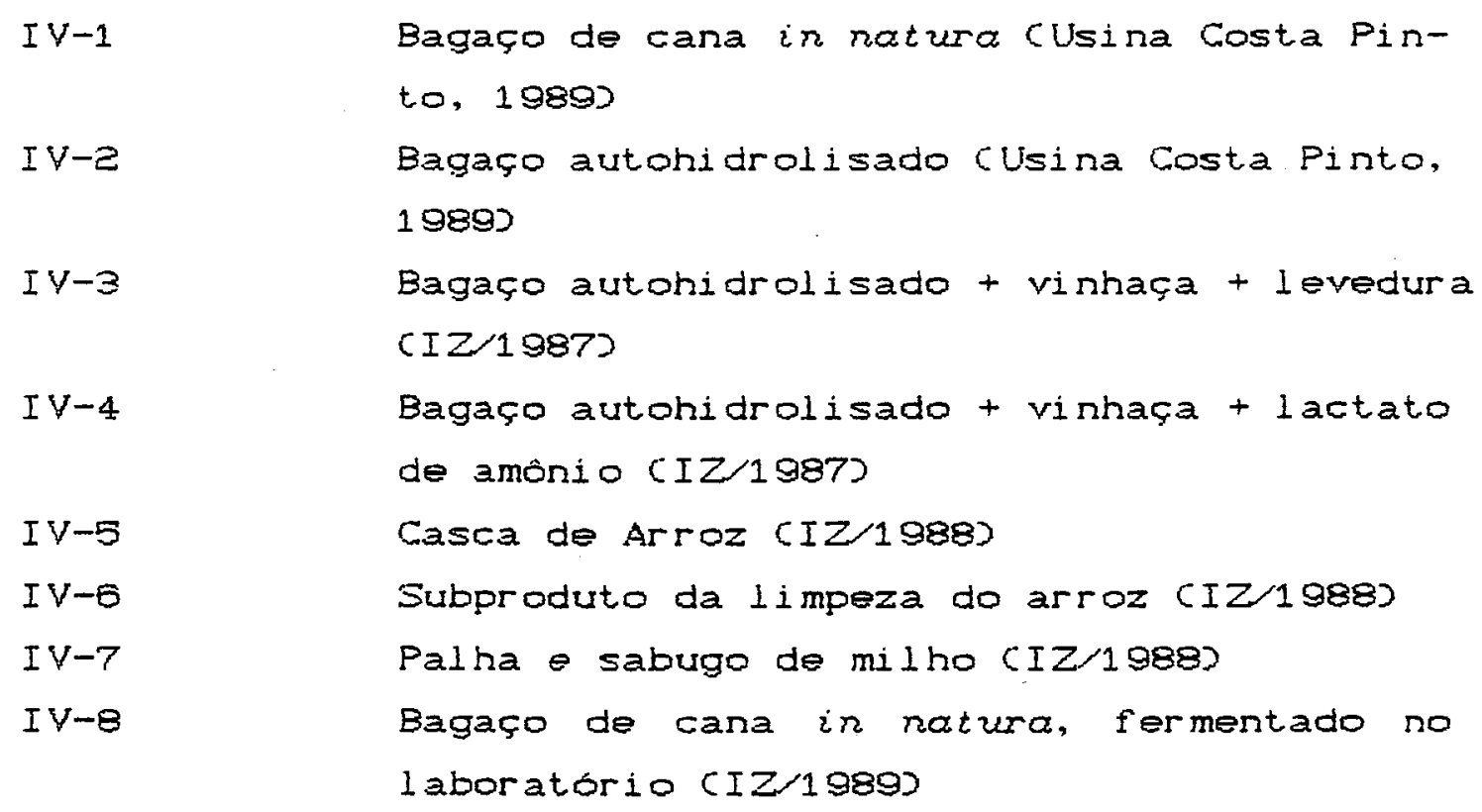

3.2.2. Reagentes e Soluções

a) Tampões

* Saliva Artificial de MCDOUGAL

g 1 CSol ução-tampão)

9,80 Bicarbonato acido de sodio

3,71 Fosfato dibasico de sódio

0.57 Cloreto de potássio

0,47 Cloreto de sódio

0,12 Sulfato de magnesio

40,00 (Solução de cloreto de calcio, $100 \mathrm{ml}$ ) 
58.

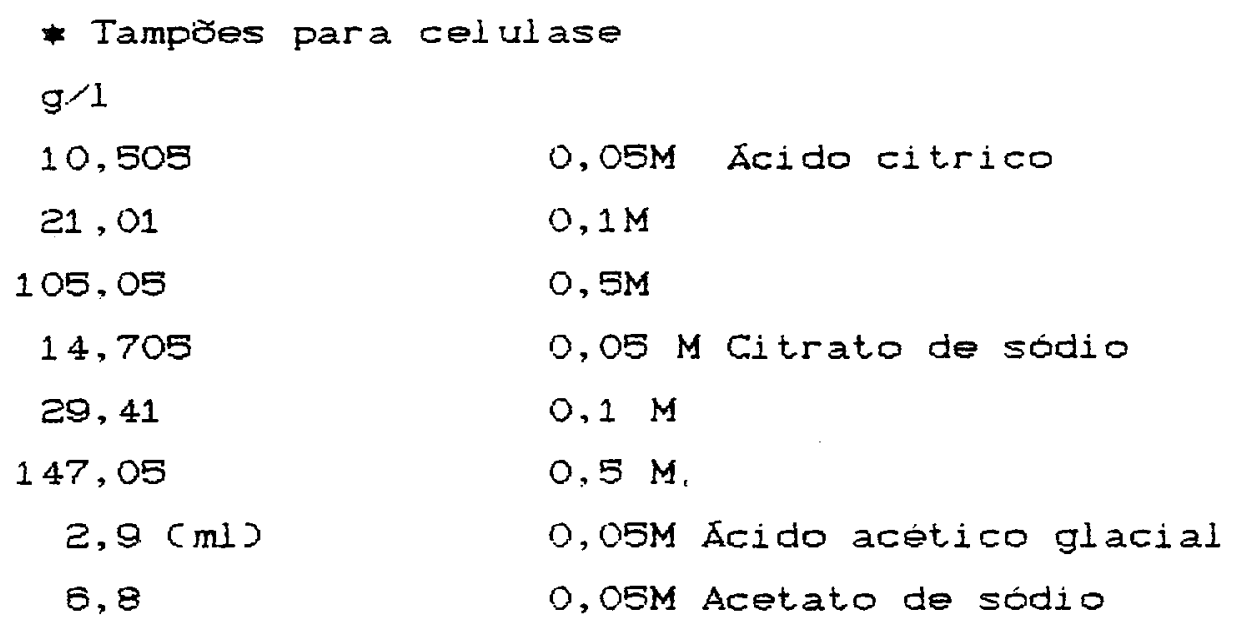

b) Solução Detergente Neutro (YAN SOEST \& ROBERTSON, 1980 )

$\begin{array}{ll}\text { qtde } / 1 & \\ 30.00 \mathrm{~g} & \text { Laurilsulfato de sodio } \\ 18,61 \mathrm{~g} & \text { Etilenodiaminotetraacetato } \\ & \text { dissodico } \\ 6,81 \mathrm{~g} & \text { Borato de sódio decahidratado } \\ 4.56 \mathrm{~g} & \text { Fosfatobisodicoanidro } \\ 10,0 \mathrm{ml} & \text { Etoxietanoletilenoglicol }\end{array}$

c) Sol ução HCl-Pepsina

gtde 1

$200,0 \mathrm{ml} \mathrm{HCl} \quad 20 \%$ peso/volume $(2,4 \mathrm{~N}$

$8,5 \mathrm{ml} \mathrm{HCl} \quad 0,85 \%$ peso $/ \mathrm{Volume} C 0,1 \mathrm{NJ}$

$50,0 \mathrm{~g} \quad$ Pepsina $1: 10000$, 5\% pesor

vol ume

$2,0 \mathrm{~g} \quad$ Pepsina 1:10000, 0,2\% pesor

vol ume

d) Enzi mas celuloliticas

Celulaşes de Trichoderma reesei, dos laboratoriOS, NOVO INDUSIRI DO BRASIL IND. E COM. LIDA (Enzima 1 ) BIOBRAS, BIOQUIMICA DO BRASIL S/A. CEnzima 2S. 
59.

Celulase de Aspergillus niger, da BIOCON DO BRASIL INDUSTRIAL LTDA. CEnzima 3 .

e) Soluçao de DNS (MILLER, 1959 )

$\begin{aligned} 19,8 \mathrm{~g} & \text { Hidroxido de Sodio } \\ 306,0 \mathrm{~g} & \text { Tartarato de sodio e potássio } \\ 8,3 \mathrm{~g} & \text { Metabissulfito de sodio } \\ 10,6 \mathrm{~g} & \text { Ácido } 3,5 \text { dinitrosalicilico } \\ 7,6 \mathrm{ml} & \text { Fenol Caquecido a } 50^{\circ} \mathrm{C} \\ 1416,0 \mathrm{ml} & \text { Agua destilada }\end{aligned}$

\section{i) Inóculo ruminal}

O inóculo foi obtido de um novilho mestiço, arraçoado sob nível de mantença, uma vez ao dia, basicamente com silagem de milho/1987. Mantido em baia individual e sob as condiç̧es normais para avaliaçăes in vitro pela ténica convencional (Tilley \& Terry), rotina do laboratirio da Seção de Avaliação de Forragens

\subsection{Métodos}

\section{3. 1 Coleta e preparo de forragens}

Foi jogado o quadrado para a amostragem do material forrageiro, obtido da planta inteira, com corte acima de $10 \mathrm{~cm}$ do chăo no caso de cespitosas, com algumas exceços para as de crescimentos diferentes e arbustos. Os cortes foram feitos em dias estiados, intercalados pör um dia chuvoso, no horário das 9:00̈ as 11:00 h. Após a pesagem, 
60.

- material foi picado e acondicionado em sacos plásticos identificados, e imediatamente levadas ao laboratorio para secagem en estufas a $50^{\circ} \mathrm{C}$ com ventilação forçada por pelo menos dois dias até a constancia de peso final. Em seguida, moídas em moinho-faca do tipo willey-mil l com peneira 1 , $0 \mathrm{~mm}$ (40 mesh) e estocadas em vidros apropriados. Os residuos agricolas e forragens conservadas foram submetidos a primeira secagem somente quando necessario Cumidade altas. Todos os alimentos foram submetidos a segunda secagem, em estufas a $105^{\circ} \mathrm{C}$, com ventilação forçada, por pelo menos $24 \mathrm{~h}$, para as devidas correçbes dos valores finais obtidos.

\section{3.2. Preparo de tampões e soluções}

os tampores para soluçס̄es enzimáticas foram preparados pelo menos na mesma semana de uso, tentando evitar contaminaçð̃es, e mantidos em geladeira co-4 ${ }^{\circ} \mathrm{C}$. Procedeu-se a uma titulaçăo com o acido na concentraçăo desejada $60,05 \mathrm{M} ; 0,1 \mathrm{M}$ e 0,5 $\mathrm{D}$ ate atingir o $\mathrm{pH}$ desejado 64,8$)$ na base. Para $500 \mathrm{ml}$ de base gastaram-se de $320-330 \mathrm{ml}$ de ácido. Os reagentes foram mantidos à temperatura ambiente antes do preparo. Executou-se tal procedimento com o auxilio de bureta graduada (50 $\mathrm{ml}$ ), agitador magnetico e potenciómetro aferido a $\mathrm{pH} 4,01$ e pH 7,01 com os respectivos padrbes.

A ordem de adição dos reagentes indi vi dualmente na solução de DNS segui u àquela indicada no item 3.2 .2 . (E), o que facilitou suas solubilizaçäes. As demais soluçăes nå apresentaram problemas com relação ao seu preparo. 


\section{3. 3. Determinações gravimétricas}

As amostras de celulose elou forragens pré-secas, apos pesagens em balanças analiticas foram submetidas as respectivas reaç⿸尸es com enzimas, com inóculo ruminal $\theta$ outros. Foram em seguida filtradas em cadinhos Cporosidade 1 e 2), previamente tarados, com o auxilio de bomba de vácuo. Em seguida, foram secas em estufas a $105^{\circ} \mathrm{C}$, com ventilaça forçada para forragens, por pelo menos 24 horas. As pesagens finais foram realizadas após a estabilizaço das amostras nos respectivos cadinhos, por pelo menos $1 \mathrm{~h}$ em dessecador com silica-gel, para equilibrio de temperatura.

\section{3.4. Determinações colorimétricas}

\section{a) Dosagens de açúcares redutores de acordo com o método proposto por MILLER, 1959.}

A partir de uma soluça-padrão de glucose $61 \mathrm{mg} / 1 \mathrm{ml}$ em tampão padronizado, prepararam-se aliquotas om duplicatas, fazendo variar de 0,0 a $1,0 \mathrm{mg}$ em 22 tubos 611 pontos. As amostras de hidrolisados com substratos puro, especificos e forragens, foram diluidas em $1 \mathrm{ml}$, de acordo com a expectativa de leitura. Antes de cada grupo de analises, procedeu-se a determinação de uma reta-padrão CFigura 7), inclusive com o objetivo de zerar o colorimetro com o branco (sol uçao tampão sem açúcares). 


\section{Procedimento:}

1. Foi retirada uma alíquota da amostra previamente resfriada e completou-se a $1 \mathrm{ml}$ com tampão.

2. Foram adicionados $3 \mathrm{ml}$ da soluçăo de DNS com dispensador automático.

3. Ferveu-se por $5 \mathrm{~min}$ em banho-maria.

4. Esfriou-se e adicionaram-se $15,5 \mathrm{ml}$ de água destilada com dispensador automático.

5. Homogeneizou-se por $15 \mathrm{~min}$ em agitador tipo BURREL, com aproxi madamente $240 \mathrm{rpm}$.

6. Leu-se em colorimetro BAUSCH \& LOMB, SPETRONIC 20, a $540 \mathrm{~nm}$, om $1 \mathrm{uz}$ visivel zerado continuamente com o branco da reta-padrão, dentro de 6 h após a etapa 3.

7. Aceitou-se toda diluiça em hidrolisados e brancos de tratamentos (tampão + enzima) que mostraram leitura em absorvância na faixa de 0,2 a $0,9 \mathrm{mg}$ glucoserm na reta padrăo.

8) Procedeu-se ao seguinte tratamento matematico dos dados:

$$
c(\mathrm{mg} / \mathrm{ml})=(1,0783+0,0402 \mathrm{~A}) \times \text { Dilui ̧̧̃ }
$$


63.

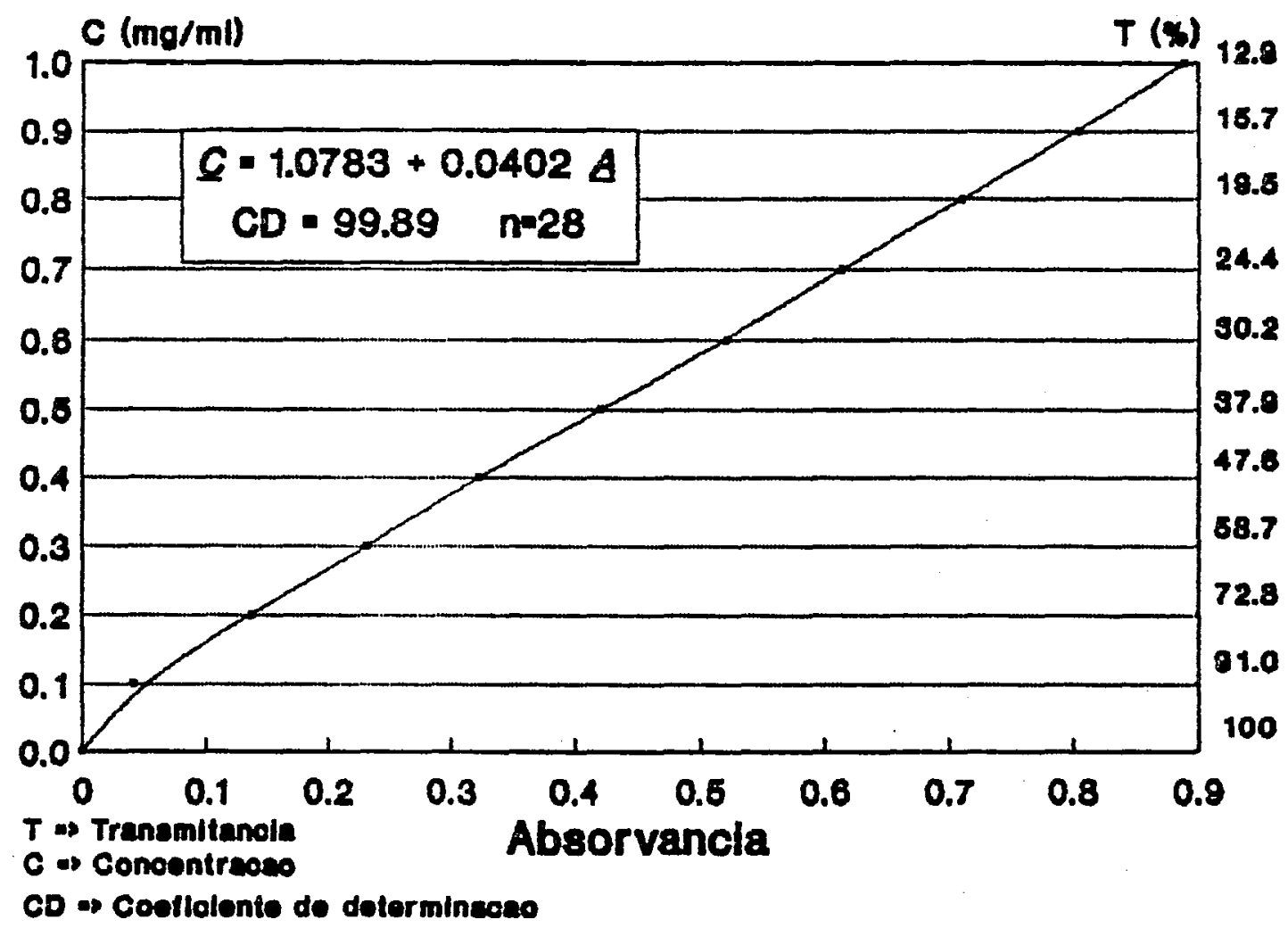

Figura 7 - Reta padrão de gl ucose para dosagem de açúcares redutores CDNS.

b) Dosagens de proteínas totais de acordo com o método proposto por LOWRY et alii, 1954.

Foram feitas pelo método do FOLIN-CIOCALTAU, que consiste na reaçåo do biureto com o fon $\mathrm{Cu}^{++}$em meio alcalino e reduça do reagente fosfomolibdico e fosfotungstenico pelo triptofano e tirosina.

3. 3.5. Determinações da parede celular

a) Pelo sistema detergente neutro CVAN SOEST \& ROBERTSON, $1980)$.

Colocaram-se amostras pre-secas de forragens (1,00 g) em tubos apropriados de um bloco digestor. Adicio- 
naram-se $100 \mathrm{ml}$ da solução detergente neutro e aqueceu-se ate fervura. Manteve-se por $50 \mathrm{~min}$ nessas condif̧̋es, com sistema de refluxo do vapor, em seguida, filtrou-se e lavou-se com água quente $(3 x)$ acetona $(2 x)$. Os cálculos foram tomadas por diferenças de pesagens em dupilicata para cada repetiçăo.

b) Pelo sistema enzinático

Colocaram-se amostras de forragens pre-secas co,s glem tubos de ensaios. Foram umedecidas com agua destilada a adicionaram-se $50 \mathrm{ml}$ de uma soluçăo de HCl $0,1 \mathrm{~N}$ com pepsina $0,2 \%$ peso/volume. Manteve-se em banho-maria, previamente aferido a $40^{\circ} \mathrm{C}$ por $24 \mathrm{~h}$. 0 residuo foi filtrado em cadinhos e lavado com água quente c2x. O procedimento de calculo de insolubilização foi o mesmo descrito no item a).

3.3.6. Determinações de digestibilidade pela técnica convencional (TILLEY \& TERRY, 1963$).$

As coletas de inoculo ruminal foram obtidas sempre a mesma hora nos respectivos ensaios (8:00 - 8:30 h), de um animal-doador em jejum de alimento (1己 h). As amostragens foram feitas em diferentes pontos do rúmen evitando-se tanto os locais mais profundos quanto os mais superficiais. O fluido ruminal foi coado en 4 camadas de gase e transportado até o laboratorio em garrafas termicas pre-aquecidas $\pm 40^{\circ} \mathrm{C}$. Imediatamente antes do uso, foi coado novamente em 4 
camadas de gase e adicionado ao tampăo Csaliva artificial de MCDOUGAL já aquecido e homogeneizado.

As amostras de forragens $60,5 \mathrm{gl}$ foram colocadas em tubos de digestão $( \pm 80 \mathrm{ml}$. O tampão foi aquecido antes do uso $\left(39^{\circ} \mathrm{C}\right)$, quando adicionou-se $1 \mathrm{ml}$ da solução de $\mathrm{CaCl}_{2}$ (4\% peso/volume) homogeneizado por $15 \mathrm{~min}$ com borbu1 hamento constante de $\mathrm{CO}_{2}$. En seguida, colocou-se o inóculo na proporção requerida e manteve-se o borbulhamento aqueeimento por $15 \mathrm{~min}$. A adiçăo de saliva artificial (40 ml) inoculo (10 $\mathrm{ml}$ foi precedida pelo umedecimento do material forrageiro com água destilada $(1-2 \mathrm{ml}$. Imediatamente após a adiço da saliva e inóculo, os tubos foram arrolhados e mantidos em banho-maria $\left(39^{\circ} \mathrm{C}\right)$ por $48 \mathrm{~h}$. Interrompeu-se a reaçăo adicionando-se aliquotas de $1 \mathrm{ml}$ de HCl a $20 \%$ C2.4 ND, agitando-se vagarosamente os tubos para evitar borbulhamento Crada tubo recebeu $6 \mathrm{ml}$ de HCll. Em seguida, adicionaram-se $2 \mathrm{ml}$ de uma solução de pepsina a 5\% peso/vo1 ume em $100 \mathrm{ml}$ de água destilada. Após $48 \mathrm{~h}$ de reação, a partir do horario do inicio da $1^{a}$ fase, o material foi retirado, filtrado e lavado com água quente. Parte dos tubos foi mantido em geladeira ate a filtragem. O residuo foi então seco em estuf́a a $105^{\circ} \mathrm{C}$ por $24 \mathrm{~h}$ com ventilação forçada - pesado apos a estabilizaça em dessecador $( \pm 1 \mathrm{~h}$. Os calculos foram obtidos por diferença de pesagens considerando inclusive os brancos $\left.{ }_{n}=4\right)$ por batch. As análises foram tomadas em duplicatas para cada repetiçăo. 
3.3.7. Determinações de digestibilidade pela técnica enzimática

As soluçőes enzimáticas foram preparadas imediatamente antes do seu uso, e a concentração expressa em relaçăo ao tampăo, por pesorvolume ou volume/volume quando se tratava de enzima em pó ou 1 lquida, respectivamente. Para a homogeneização no tampão, as soluçbes foram postas em agitaçå por $15 \mathrm{~min}$.

Os substratos puros (100 mg: $10 \mathrm{ml}$ sol ução) e forragens $(200 \mathrm{mg}: 20 \mathrm{ml}$ para analise foram colocados em tubos de ensaio $(50-80 \mathrm{ml}$ nas respectivas grades para a hidrolise. Um sistema batch foi usado, tomando-se amostras de hidrolisados nos respectivos tempos, de acordo com os tratamentos aplicados. Foram adicionadas 2 gotas de tolueno/tubo com substrato puro e 4-5 gotas/tubo com forragens. Os tubos em triplicatas para substratos puros o duplicatas para forragens foram casualizados aos tratamentos em cada repetição. Após a hidrolise, os tubos foram retirados do banho e resfriados rapidamente. Aguardou-se pelo menos 2 i para a centrifugaçăo a $3000 \mathrm{rpm}$ por $10 \mathrm{~min}$ para substrato puro e $15 \mathrm{~min}$ para forragens. Procedeu-se a amostragem do sobrenadante $(5-10 \mathrm{ml})$, que foi estocado em vidros identificados, com 1 -2 $\mathrm{ml}$ de tolueno. Mantidos em geladeira ate a Leitura colorimetrica, procedida dentro de 2 semanas, quando as amostras receberam mais tolueno e foram congeladas. 
67.

As forragens antes do tratamento com celulase foran submetidas a solubilizaçăo com pepsina, 0 , 2\% peso/volume, em HCl $0,1 \mathrm{~N}$, por 24 horas, a $40^{\circ} \mathrm{C}$. Após o ajuste do $\mathrm{pH}$ $(1,5--) 4,8)$ com $5 \mathrm{ml}$ de citrato de sódio $(0,5 \mathrm{M}$, as amostras foram centrifugadas, e com o auxilio de bomba de rácuo num sistema de valvulas em quitassato, retirou-se o sobrenadante.

o tratamento com celulase $61 \%$ pesorvolume, ?2 h) equiparou o procedimento enzimatico ao sistema convencional (microbiológico) na detecçăo de materia seca digestivel (96 h.). A quantidade da sol ução enzimática adicionada nesta fase foi determinada en relaçåo a quantidade de amostra pré-seca inicial. Apos a centrifugação e a amostragem (5-10 $\mathrm{ml})$, os residuos foram filtrados a lavados com agua quente. As determinaçöes foram tomadas por diferença considerando os brancos $G \Omega=2$ por batch para as avaliaçzes gravimétricas e colorimétricas.

\subsubsection{Procedimento estatistico}

Para o ensaio 1 foram feitas tentativas de ajustes por equaçöes linear e nåo-lineares para os dados. Os modelos não-lineares testados objetivaram detectar uma possivel regressão assintotica CSNEDECOR \& COCHRAN, 19723. Os modelos testados foram: 
68.
M1: LINEAR
$Y=A+B X$
ME: LOGARI TMI CO
$Y=A\left(B^{x}\right)$
M3: QUADRATIGO
$Y=A+B X+C X^{2}$
M4: GOMPERTZ
$\left.Y=\operatorname{EXP} C A+B \rho^{X}\right)$

Os ensaios preliminar, 2,3 e 4 foram discutidos com análise grafica. Para as análises de dados com forragens, nos ensaios 5 e 6 , respectivamente, aplicaram-se trés modelos de equaçbes $\mathrm{CM}_{1}, \mathrm{Mz}$, MaJ. Na avaliação do ensaio 9 procedeu-se a uma análise de covariancia para teores de parede celular pelos dois possiveis metodos cdetergente $x$ enzimáticos na tentativa de ajustar o modelo. As análises da(s) covariavel(is) foram avaliadas pelos seus valores e significancia do $F$. As equaçoes foram escolhidas a partir dos valores e significancias do $F$ para analises de regressão (M1, Mz, Ma). Os modelos de equaçbes foram definidos com base nos coeficientes de determinaçăo, assumindo-se no minimo diferenças na ordem de 4 unidades percentuais, para a discussão dos tratamentos. As analises foram executadas pelo S. A.S. CGeneral Linear Models. 
69.

\section{RESULTADOS E DISCUSSÃO}

\section{Ensaio 1}

A primeira fase do trabal ho teve como objetivo observar alguns fatores que interferem no comportamento cinetico das enzimas alostericas celuloliticas. Na fase pré-experimental, algumas condiçőes foram padronizadas, como por exemplo, concențraçăo minima e tempo máximo de reação. Outros fatores, como tamanho de particulas e indice de cristalinidade no substrato-teste săo conhecidos em relaçăo a alguns materiais disponi veis e constam na Tabela 5 cMaterial e Métodosj. Os resultados obtidos no ensaio auxiliar são mostrados na Figura 6 (Material e Métodos), a concentração enzimática foi manipulada na relação $1: 10 @ 1: 1$ do referido substrato com tempo fixo $672 \mathrm{~h}$ o os resultados demonstram que as enzimas 1 e de Trichoderma reesei são menos sensiveis ao referido tratamento en relação à de Aspergillus niger, enzima 3 . Os resultados da literatura sugerem grande interesse em aumentar a eficiencia hidrolitica nos substratos lignocelulósicos, por manipulaçóes na concentraçăo enzimatica cate $10 \%$ peso/volume, BUGGE, 1980 . Aparentemente, o potencial máximo hidrolitico difere nos distintos sistemas enzi máticos. 
o referido estudo foi executado em esquema fatorial, inteiramente casualizado, com 4 niveis de concentraGŏes $(C 1,1: 1 ; \mathrm{CZ}, 2: 1 ; \mathrm{C}, 4,4: 1 ; \mathrm{C} 4,8: 1)$ e 6 de tempos $(3$, 6. $12,24,48$ e $72 \mathrm{~h}$, com o intuito de se conhecer melhor as interaçbes dos fatores de estudo nos respectivos sistemas celuloliticos.

Os dados ajustados conforme modelos matematicos (descritos no item 3.3.8) tiveram o objetivo de distinguir melhor a possivel assintota descrita na Figura 8A, 8B, $8 C$ e $8 D$ para as respectivas variáveis. Observa-se atraves dos valores e significancia de $F$ e coeficientes de determinaçăo descritos na Tabela 1 CApendices, que esta assintota corresponde a um 1 imite potencial do substrato e dos sistemas celuloliticos, e ainda, o Me (logaritmicos descreve melhor os dados obtidos nas diferentes variáveis.

Com base nas Figuras 8A, 8B, 8C e 8D, observa-se que na concentraçao a $1 \%$ Crelaça $1: 1$ de enzima/substratos atingiu-se o referido 1 imite, descrevendo o mecanismo hidrolftico nas condiç̧es de estudo. E possivel que na faixa entre 1:10 1:1, atinja-se a concentraçăo-enzimática limite do ponto de saturaça dos sitios cataliticos e moduladores dos diferentes componentes bioquimicos. 


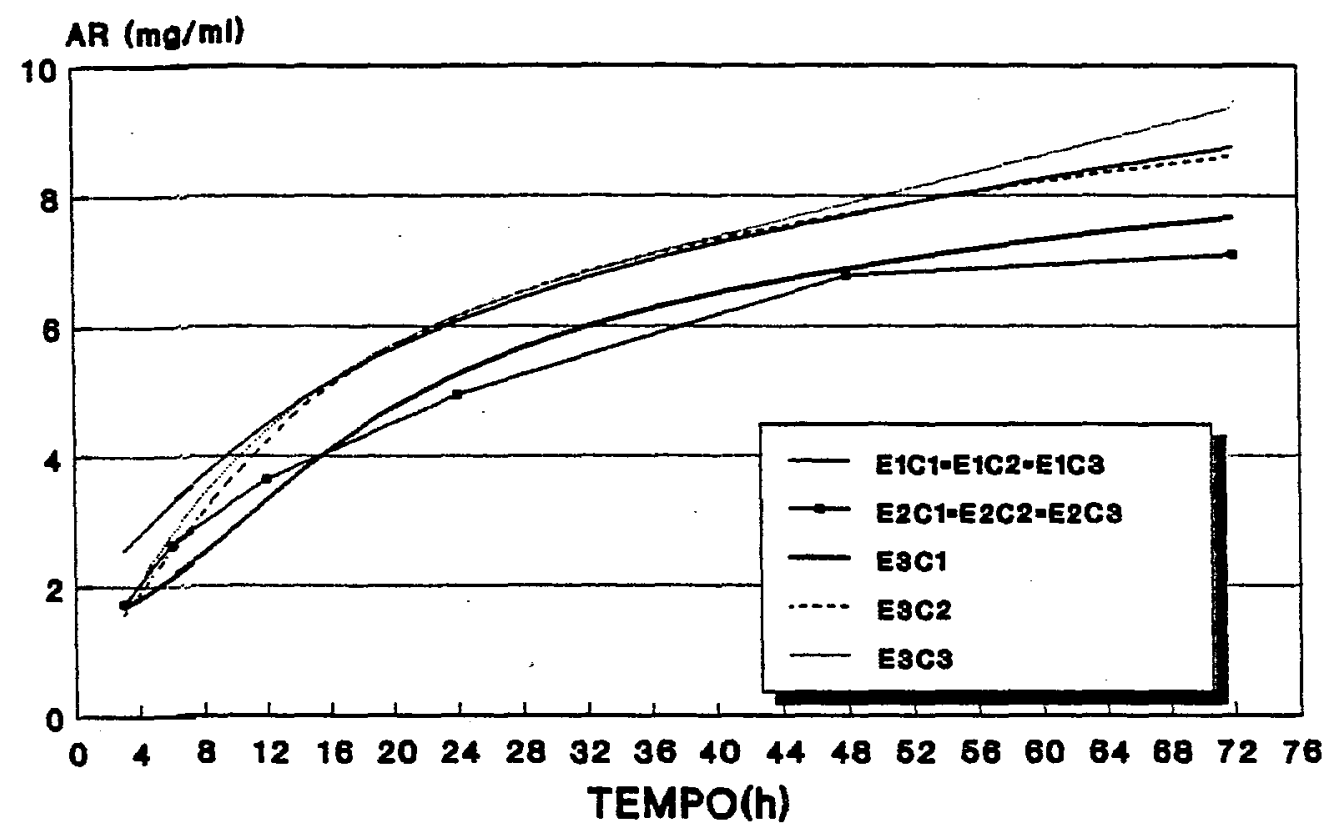

\begin{tabular}{|c|c|c|c|}
\hline TRAT & EQUACAO & Coef. Determ. & VOMR(8y.x) \\
\hline E1C1 & I(AR) $=0.6090+0.3994$ I (t) & 0.9823 & 0.06 \\
E2C1 & I(AR) $=0.1240+0.4606$ I (t) & 0.9669 & 0.09 \\
E3C1 & I(AR) $-0.1026+0.6243$ I (t) & 0.9376 & 0.16 \\
E3C2 & I(AR) $=-0.0631+0.6526$ I (t) & 0.8972 & 0.21 \\
E3C3 & I(AR) $=0.0268+0.6407$ I (t) & 0.8970 & 0.21 \\
\hline
\end{tabular}

Yariavel 1, Açúcar redutor (media de trés repetiçßes).

Figura 8A - Potencial hidrolitico em função de concentraçăo enzimatica e tempo de reaçăo, em três sistemas enzimaticos obtidos a partir de Trichoderma reesei (El e Ez) e de Aspergilius niger (Ea).

C1; C2; C3 $\Rightarrow 1 \% \mathrm{P} / \mathrm{V} ; 2 \% \mathrm{P} / \mathrm{V} ; 4 \% \mathrm{P} / \mathrm{V}$. 

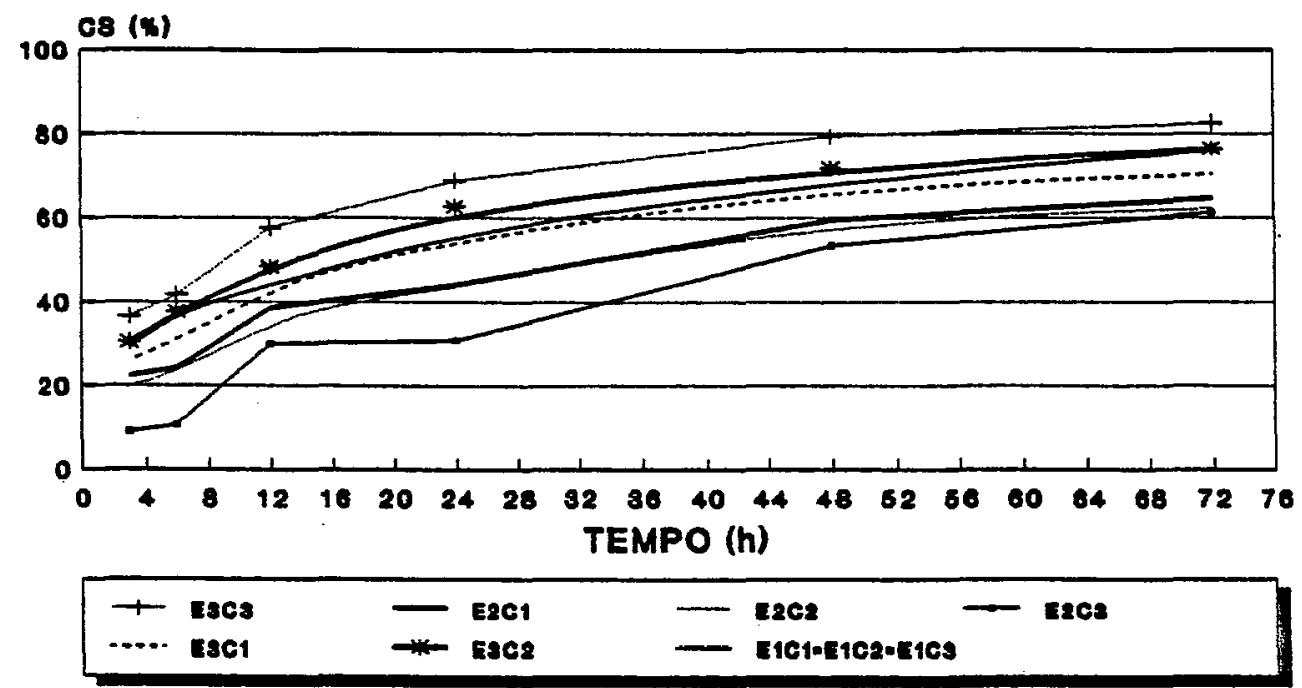

\begin{tabular}{|c|c|c|c|}
\hline TRAT & EQUACAO & Coef. Determ. & JQMA(8y.x) \\
\hline $\begin{array}{l}E 1 C 1 \\
E 2 C 1 \\
E 2 C 2 \\
E 2 C 3 \\
E 3 C 1 \\
E 3 C 2 \\
E 3 C 2\end{array}$ & $\begin{array}{l}I(C S)=3.0601+0.3013 I(t) \\
I(C S)=2.6637+0.3590 I(t) \\
I(C S)=2.5143+0.3944 I(t) \\
I(C S)=1.3678+0.6694 I(t) \\
I(C S)=2.8734+0.3392 I(t) \\
I(C S)=3.1078+0.3007 I(t) \\
I(C S)=3.3068+0.2730 I(t)\end{array}$ & $\begin{array}{l}0.9559 \\
0.9456 \\
0.8892 \\
0.8511 \\
0.8704 \\
0.9482 \\
0.9539\end{array}$ & $\begin{array}{l}0.07 \\
0.10 \\
0.16 \\
0.32 \\
0.15 \\
0.08 \\
0.07\end{array}$ \\
\hline
\end{tabular}

Variável 2 , Teor de solubilizaçăo (media de três repetiçoses.

Figura 8B - Potencial hidrolitico em função de concentração enzimática e tempo de reação, em trés sistemas enzimáticos obtidos a partir de Trichoderma reesei (E1 e Ez) e de Aspergillus niger (Ea). C.1; C.2; C.3 $\Rightarrow 1 \% \mathrm{P} / \mathrm{V} ; 2 \% \mathrm{P} / \mathrm{V} ; 4 \% \mathrm{P} / \mathrm{V}$. 


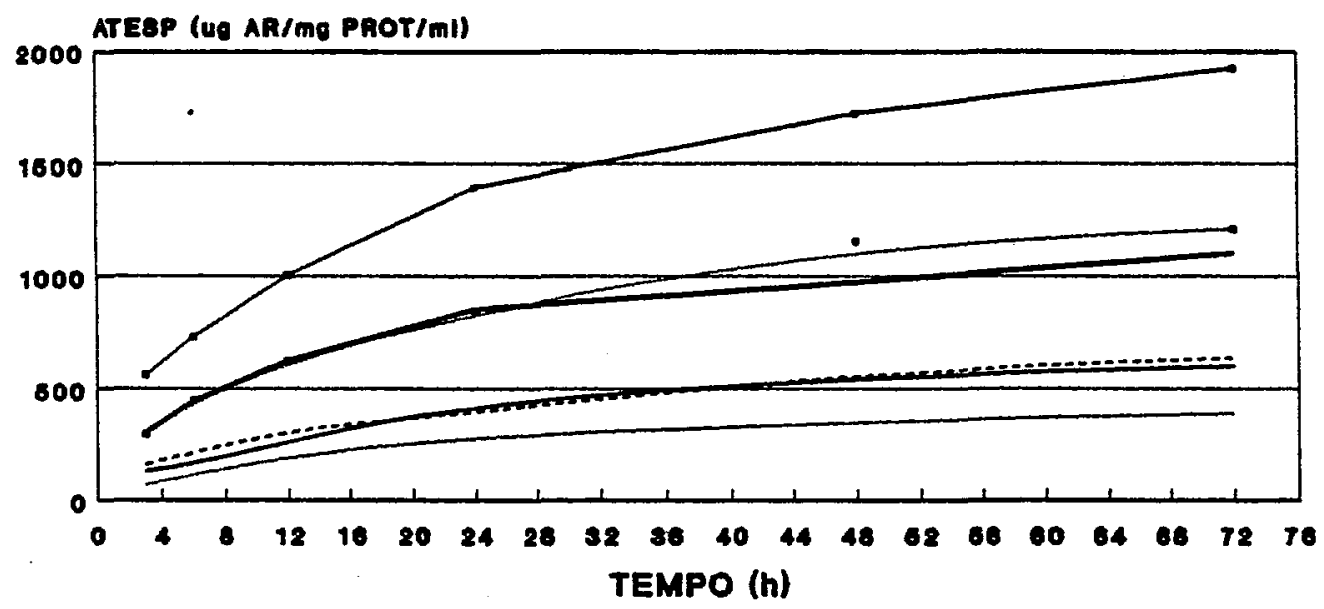

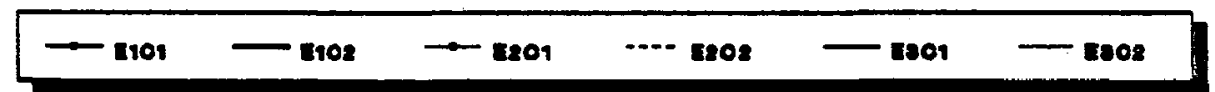

\begin{tabular}{|c|c|c|c|}
\hline TRAT & EQUACAO & Coef. Determ. & $\operatorname{VAMR}(8 y . x)$ \\
\hline $\begin{array}{l}\mathrm{E} 1 \mathrm{C1} \\
\mathrm{E} 1 \mathrm{C2} \\
\mathrm{E} \mathrm{C1} \\
\mathrm{E} \mathrm{C2} \\
\mathrm{ESC1} \\
\mathrm{E} 3 \mathrm{C2}\end{array}$ & 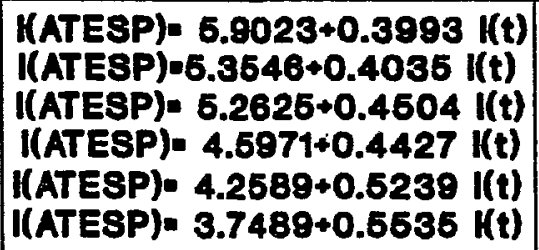 & $\begin{array}{l}0.9806 \\
0.9318 \\
0.9677 \\
0.9388 \\
0.9187 \\
0.8894\end{array}$ & $\begin{array}{l}0.06 \\
0.12 \\
0.11 \\
0.13 \\
0.17 \\
0.22\end{array}$ \\
\hline
\end{tabular}

Yariável 3, Atividade especifica (média de trés repetiçoes).

Figura 8C - Potencial hidrolitico em função de concentraçăo enzimática e tempo de reação, em tres sistemas enzimáticos obtidos a partir de Trichoderma reesei (E1 e E2) e de Aspergillus niger (Eз).

C.1; C. C F C.3 $\Rightarrow 1 \% \mathrm{P} / \mathrm{V} ; 2 \% \mathrm{P} / \mathrm{V} ; 4 \% \mathrm{P} / \mathrm{V}$. 

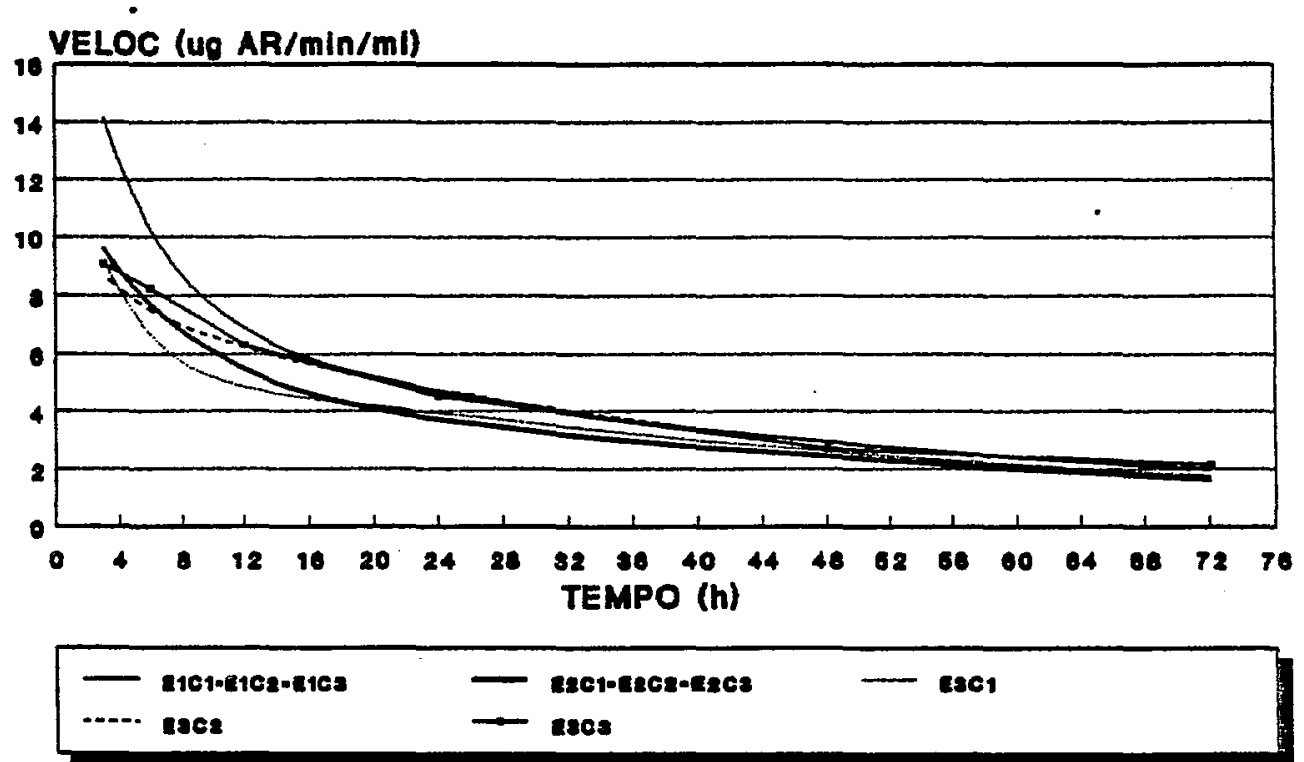

\begin{tabular}{|l|c|c|c|}
\hline TRAT & EQUACAO & Coef. Determ. & VamR(8y.x) \\
\hline E1C1 & I(VELOC)= 3.3233-0.6009 l(t) & 0.9920 & 0.06 \\
E2C1 & I(VELOC)= 2.9383-0.5486 I(t) & 0.9776 & 0.09 \\
E3C1 & IVELOC)= 2.7110-0.4756 I(t) & 0.9248 & 0.16 \\
E3C2 & IVELOC)= 2.7630-0.4482 I(t) & 0.8510 & 0.21 \\
E3C3 & I(VELOC)= 2.8392-0.4689 I(t) & 0.8619 & 0.21 \\
\hline
\end{tabular}

Variavel 4, Velocidade de reaçăo (média de tres repetif̧ós).

Figura 8D - Potencial hidrolitico em funçăo de concentração enzimática o tempo de reaçă em très sistemas enzimaticos obtidos a partir de Trichoderma reesei (E1 E El e de Aspergillus niget (E).

C1; CE; C3 $C 1 \% \mathrm{P} / \mathrm{V} ; 2 \% \mathrm{P} / \mathrm{Y} ; 4 \% \mathrm{P} / \mathrm{V}$. 
75.

Paralelamente, observou-se tambem que por aumento em concentraçăo ou na relaçăo enzima/substrato, não se detectou aumento em atividado celulolitica com exceçăo da enzima 3 Cde Aspergillus niger). Os dados indicam certa regularidade da atividade no tempo, nas diferentes concentraçäes de estudo, sugerindo que o fator tempo tem importância fundamental nos estudos de mecanismos hidroliticos. A resposta diferenciada na enzima 3 possivelmente está indicando alteraçbes na relaçăo entre os tamanhos medios de particulas da enzima e do substrato, o que altera a acessibilidade das refieridas enzimas aos respectivos substratos. GOEL \& RAMACHANDRAN (1983) descreveram que o tamanho ideal de particulas do substrato $e$ de $63 \mathrm{\mu m}$, indicando que a partir deste valor o tamanho de particulas do substrato pode interferir com o potencial hidrolitico dos sistemas celuloliticos, principalmente nos tempos iniciais em condiços variantes da saturação. Apesar das diferenças observadas quanto a concentraçåo enzimática, foram estabelecidas condiçâs comparativas $61 \%$ peso/volume) para os demais estudos nos trôs sistemas enzi máticos.

As tecnicas para determinaçăo de area acessivel e tamanho de particulas em substratos não săo tão simples. De ordem prática, a questão pode ficar mais dificil, principalmente, porque os tratamentos e formas naturais dos substratos lignocelulosicos diferem enormemente em acessibilidade, inclusive promovendo alteraç̧es significativas em formas tridimensionais da parede celular CGOEL \& RAMACHAN- 
DRAN, 1983; WEIMER \& WESTON, 1985; ROLZ et ai $i$, 1986). Ate $10 \%$ de lignina no substrato teste o efeito sobre a acessibilidade e minimo, conforme demonstraram GOEL \& RAMACHANDRAN (1983).

A concentração enzimática máxima de $8 \%$ foi desprezada das análises estatisticas em virtude dos resultados obtidos em celulose solubilizada. Em funç̃o principalmente do aumento em concentração enzimática houve um decréscimo significante da celulose solubilizada (Figura 8BD. Comparando-se as tres enzimas do referido estudo, pode-se supor que a enzima 2 apresenta menor grau de pureza, contaminantes que interferem nos resultados, principalmente, nos tempos iniciais de estudo.

Na variável açúcar redutor (Figura 8 A n nas enzimas 1 1 , não se detectou tal efeito, sugerindo a confiabilidade do DNS nos estudos relativos a concentração tempo. Alguns estudos preliminares foram desenvol vidos para reconhecer a necessidade de brancos (tampăo + enzima) por tratamentos. Devido ao grande número de tratamentos, decidiu-se optar pelo uso de brancos nas diferentes concentraGöes, com tempo fixo (72 hl, apesar de se reconhecer a necessidadede de seu uso em cada tempo, principalmente, para corrigir os dados da variável 2 , solubilização (Figura 8B).

Observou-se ainda que a variável atividade especifica (Figura BC. decresceu acentuadamente em função de concentração enzimática nos diferentes sistemas enzimáticos. A enzima 3 apresentou elevadas concentraçäes de proteinas 
totais, quando comparada com as enzimas 1 e 2 , entretan- to a atividade celulolftica mostrou-se semelhante para tais comparaçóes. O sistema hemicelulolitico da enzima 3 pode estar afietando de alguma forma as interpretaçôs dos estudos com os sistemas celuloliticos.

A variável velocidade de reação CFigura 8D sugeriu que o acumulo do produto final interferiu na atividade dos sistemas enzimáticos em condiçbes batch. A velocidade decresceu ate o limite potencial do sistema celulolitico no referido substrato, conforme descreve a Figura 8D, atingindo o máximo de inibição a 72 h. A relaçăo interdependente dos componentes individuais sera melhor descrita no ensaio 4. Conforme descreveu IAKAGI (1984), a remogăo do produto final por algum procesșo biotecnologico resulta em aumento da eficiencia do processo hidrolitico. Outra forma de aumentar a eficiencia do processo é a adiça de soluçbes enzimáticas ricas em beta-glucosidase; entretanto, algumas analises laboratoriais confirmaram aumento em aproximadamente $10 \%$ nas solubilizaçöes, sem observaças correspondentes em açúcares redutores. Ao se transporem as referidas informaços para os substratos naturais cforragenss, frequentemente a eficiencia é reduzida, conforme demonstraram (ROUGHAN \& HOLLAND, 1977), principalmente devido ao efeito associado da lignificação e da cristalinidade.

A Iignina e o caráter cristalino dos diferentes materiais 1 ignocelulosicos provavel mente atuam inativando os sitios cataliticos e moduladores de forma reversivel 
erou irreversivelmente, das respectivas enzimas do estudo. Ao serem removidas ou modificadas tais estruturas, os efeitos podem ser minimizados. Alterando-se a acessibilidade dos substratos às respectivas enzimas, promovem-se modificaçôs de especificidade elou alteraçoes no processo hidrolitico, sem se conhecer efetivamente as caracteristicas fisico-quimicas dos substratos envolvidos CGOEL \& RAMACHANDRAN, 1983; DAVID et alii, 1986 .

Em sintese, a lignina atua como barreira fisica ao processo hidrolitico e o mecanismo de inibição, apesar de bastante estudado, é pouco conhecido por não se dispor de metodologias apropriadas para sua caracterização CBARTON, 1988; REEVES, 19883. A 1 ignina ainda pode atuar diferentemente nos distintos componentes bioquimicos dos sistemas enzimaticos. Por outro lado, a cristalinidade confere variaçôs em grau de polimerização atuando como modificadores de especificidade, Iimitando a reaçăo nos substratos em questăo (WEIMER \& WESTON, 1985; ROLZ et ai ii, 1986).

A inibição por produtos intermediários dos diferentes componentes bioquímicos não apresenta uma forma usual de inibiçăo. Assim não se pode descrever o mecanismo pelas formas gráficas convencionais competitiva e não competitiva) de estudo (LEHNINGER, 1988 ) devido principalmente 3 especificidade e potencia enzimatica e diferentes niveis de inibiçăo. A lignina e o carater cristalino dos materiais Iignocelulósicos conferem o heterotropismo, configurado para as referidas enzimas alostericas. 


\section{Ensaio 2}

Após fixar o limite potencial ou a assintota como a extensão máxima de solubilização, a $72 \mathrm{~h}$, for am planejados alguns tratamentos visando observar efeitos de outros fatores determinantes da atividade celulolitica. E ainda, o comportamento cinetico em $\mathrm{pH}$ semelhante ao do $r$ úmen.

Neste segundo ensaio, for am estudados os seguintes fatores: temperatura $640^{\circ} \mathrm{C}=50^{\circ} \mathrm{CO}$, tampaes Ccitrato acetato de sodios e pH $(4,8$ e 6,5$)$, tomando-se como referencia o potencial de solubilizaçăo máxima. atingido no ensaio 1. As variaveis 3 e 4 não foram avaliadas neste ensaio, por serem mais importantes em estudos com concentraça e tempo, e tambem por serem medidas compostas a partir da variável 1 .

Os efeitos dos tampres citrato e acetato de sódio $0,05 \mathrm{M}$ não diferiram entre si nas variáveis 1 e 2 (Figuras 9A 9 AB). Nä houve diferenças significativas entre as temperaturas avaliadas para os diferentes sistemas celuloliticos. Em pH 6,5 observou-se uma redução de aproximadamente metade do potencial hidrolitico em relação ao $\mathrm{pH}$ otimo no tampão citrato. As respostas foram semelhantes para os sistemas de Trichoderma reesei, enquanto que no de Aspergillus niger, em pH 6,5 , a reduçăo foi mais marcante a $50^{\circ} \mathrm{C}$. Ao contrário, a $40^{\circ} \mathrm{C}$ e $\mathrm{pH}$ 6,5, o sistema celulolitico de Aspergilius niger mostrou alguma atividade, indicando possivelmente condiçbes para expressão de atividade hemicelulolitica, certamente em condiç̧̄es de subavaliaçăo por problemas 
metodologicos csubstratos inadequados e dosagens de açúares redutores pelo DNSS. De acordo com as informaçớs obtidas junto as fontes de substratos e sistemas enzimaticos, o de Aspergilius niger usado no referido estudo contém hemicelulase e o substrato-teste não e puro.

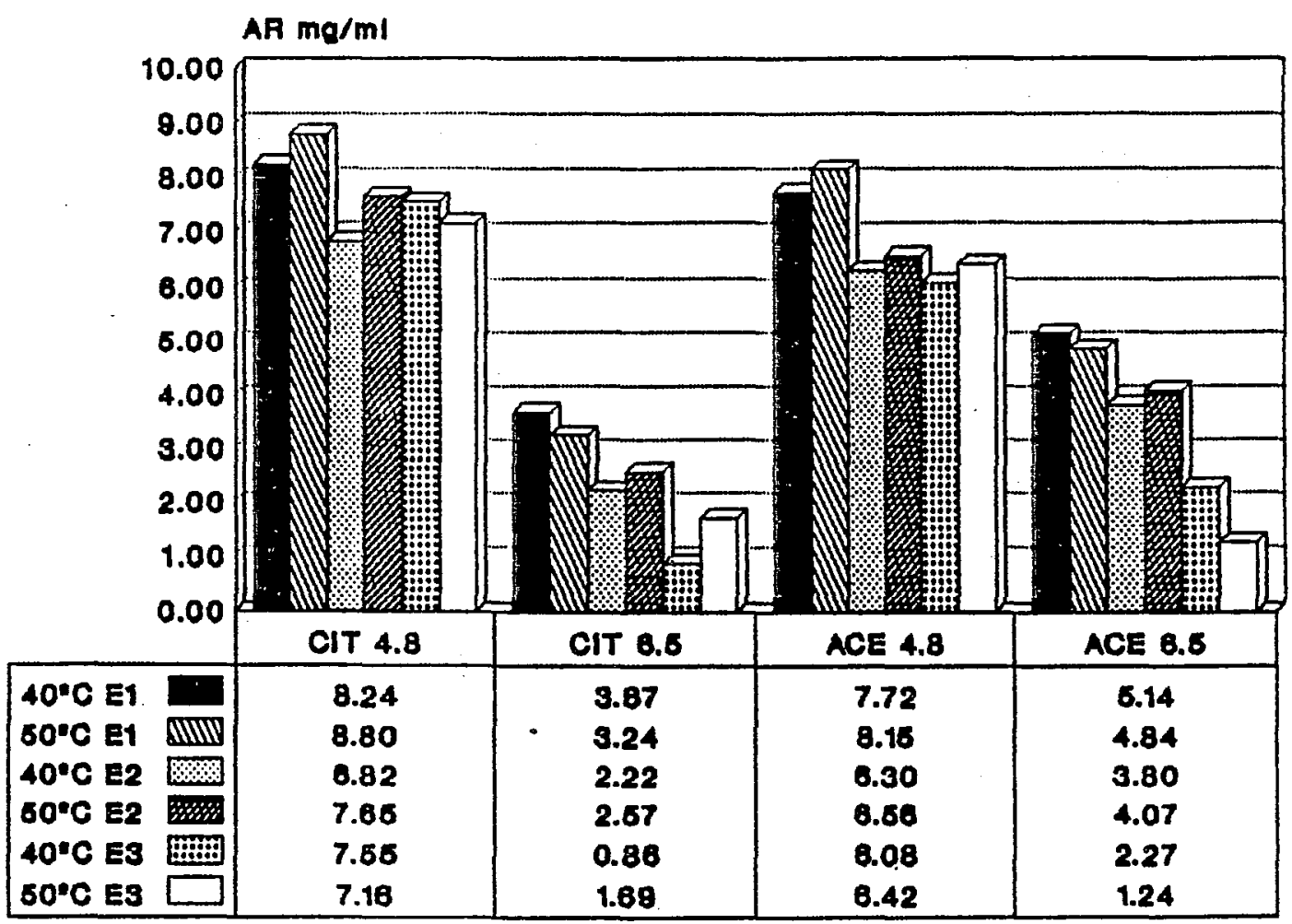

An - Agnon muston

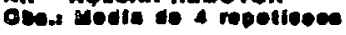

Variável 1, Açúcar redutor.

Figura $9 A$ - Efeito da temperatura, tampão e pH sobre o potencial hidrolitico, em tres sistemas enzimáticos obtidos a partir de Trichoderma reesei CE1, E2) e de Aspergillús niger (E3). 


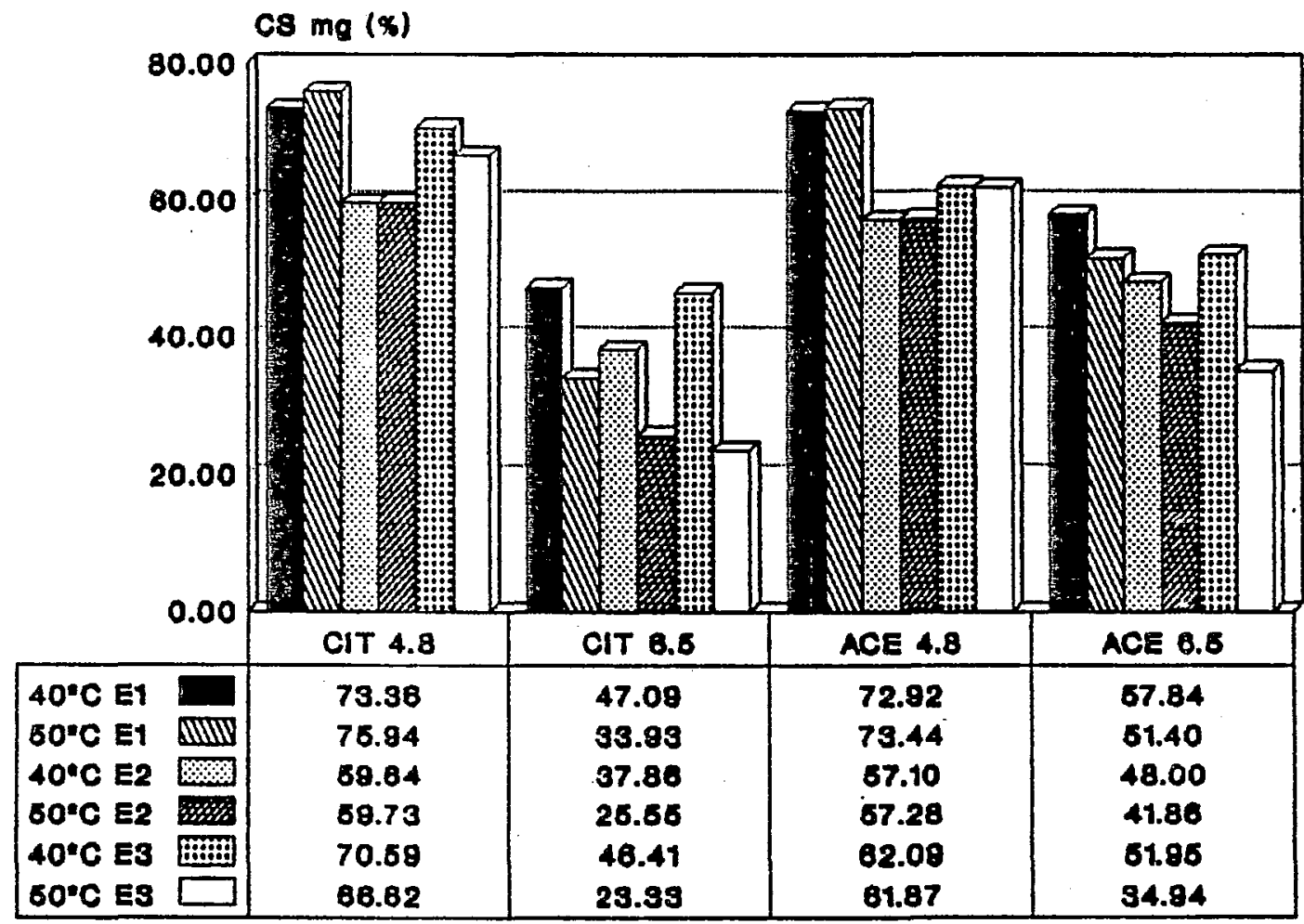

OS - OELULOSE SOLUEILIzAOA

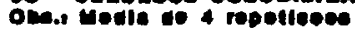

Yariável e, Teor de solubilizaçăo.

Figura $9 \mathrm{~B}$ - Efeito da temperatura, tampao pH sobre o potencial hidrolitico, em tres sistemas enzimáticos obtidos a partir de Trichoderna reesei CE1, Ez) e de Aspergilius riger (Ea).

Os referidos fatores podem interferir sobre a atividade celulolitica, entretanto, o mecanismo mais provavel seria por desnaturaçă, como no caso do pH (pI). A temperatura pode dar confundimento no efeito pelos componentes 
bioquimicos do sistema celulolitico e hemicelulolitico diferirem quanto a temperatura otima, principalmente. em funço dos microrganismos que os produzem CDURAND et alii, 1984; DEKKER, 1985 .

Para observaçōes do efeito destas enzimas sobre o metabolismo ruminal CDANIELS \& HASHIM, 1977; ROLZ et alii, 1986), sugere-se melhores estudos, en condiças mais apropriadas, pois o pH 6,5 não desnaturou completamente os sistemas celuloliticos. Outros fatores podem interferir, observando os resultados com tampão acetato, o efeito do pH foi minimizado em relação ao tampão citrato, a 40 e $50^{\circ} \mathrm{C}$. conforme descrito anteriormente. Possivelmente, as condiçöes ruminais podem apresentar interaçöes bioquimicas com os sistemas enzimáticos do referido estudo.

\section{Ensaio 3}

O ensaio 3 visow obter o efeito da concentraఢão molar de sódio nas condiç̋es definidas nos estudos anteriores em trés niveis CM1, 0,05 M; Me, 0,1 M e MB, 0.5 M para os três sistemas celuloliticos. Nao foram detectadas diferenças entre $M 1$ e Me, entretanto o efeito foi notorio em M3. Os dados sugerem que possivelmente o fon $\mathrm{Na}^{++}$interferiu sobre o potencial hidrolitico dos sistemas celuloliticos em estudo CFigura 102, corroborando com as observaç̃̃es de GROUS et alii (1985); MANONMANI \& SREEKANTIAH (1987) em substratos puros e naturais. 


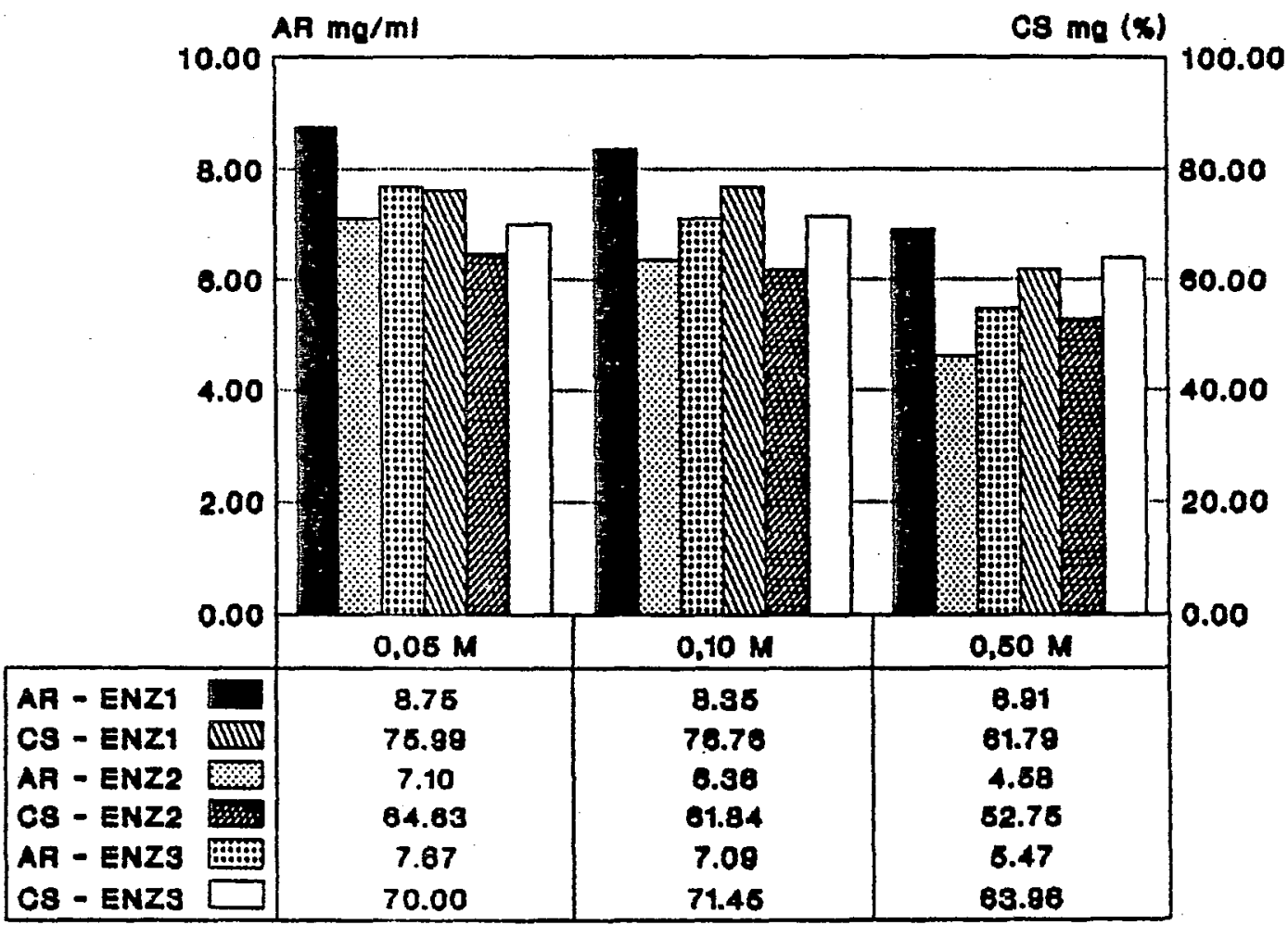

An - apaona maputon

os - orluloun soluBllizaD

Desal Modile do a repotiboes

Figura 10 - Elelto da concentracăo moiar de sodio sooro o potencial hidrolitico, em três sistemas enzimaticos obtidos a partir de Trichoderma reesei (E1, Ez) o de Aspergillus niger (Eз).

O interesse pratico nesse estudo foi de verificar a possibilidade de se preparar as soluçöes enzimaticas diretamente, com o acerto de $\mathrm{pH}(1,5 \rightarrow 4,8)$ para a fase 2 Colulasej jà adicionar uma base com concentraça necessaria para atingir o pH ideal $(4,8)$. Os resultados năo mostraram-se f’avoraveis a tal possibilidade, assim deve-se levar em 
consideraça que o pH intertere na estabilidade das enzimas. a dados sugeriram então que o acerto de pH pode ser feito com citrato de sodio $0,5 M(5 \mathrm{ml})$, e apos a centrifugação $\theta$ remoçăo do sobrenadante, adicionaram-se as soluçŏes enzimaticas num tampăo citrato 0, osm com pH $(4,8)$.

\section{Ensaio 4}

A modificaço proposta na metodologia para as dosagens de acucares redutores em soluçbes enzimáticas com substratos especificos visou obter o comportamento cinetico de dois oomponentes bioquimicos nos sistemas celuloliticos Cbeta-endogl ucanase e beta-glucosidase). Os dados apresentados referem-se a atividade molecular (açúcar redutor ug/ml) - velocidade de reaçăo (ug $A R / m i n / m L$ em função de 4 tempos (1h, $12 \mathrm{~h}, 24 \mathrm{~h}, 72 \mathrm{~h})$, considerando tempo como fator determinante da atividade celulolitica, nas condiços préfixadas de estudo.

As propostas referentes a tempo de reaçăo mostram ser adequadas para as referidas enzimas; no caso de beta-glucosidase, a atividade a 1 h mostrou seu potencial maximo, entretanto, por ser o componente mais fortemente inibido pelo produto final, apareceu o referido efeito no sistema batch CFiguras 11A; $11 \mathrm{~B}$ e $11 \mathrm{C}$. No caso de identificaçăo por unidades internacionais (UI), deve-se tomar cuidado nas interpretaçőes mais práticas. 
ug AR/mi

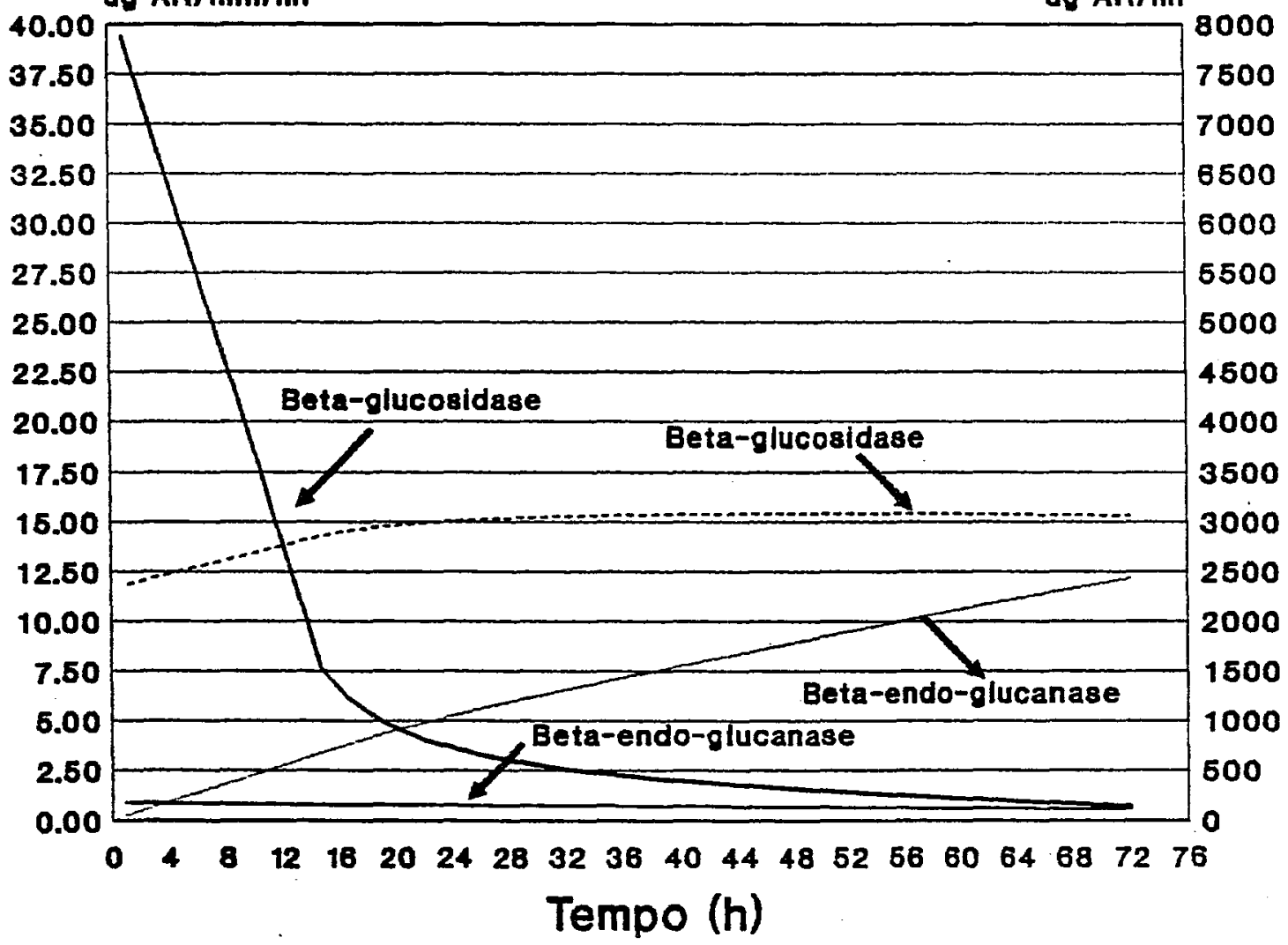

Enzima 1, E1 Cmédia de tres repetiçZes).

Figura $11 \mathrm{~A}$ - Identificaçăo bioquímica de beta-endoglucanase e beta-gl ucosidase, em tros sistemas enzimáticos obtidos a partir de Trichoderma reesei CE1, Ez) e de Aspergillus niger (Ea). 
86.

ug AR/min/ml

ug AR/mI

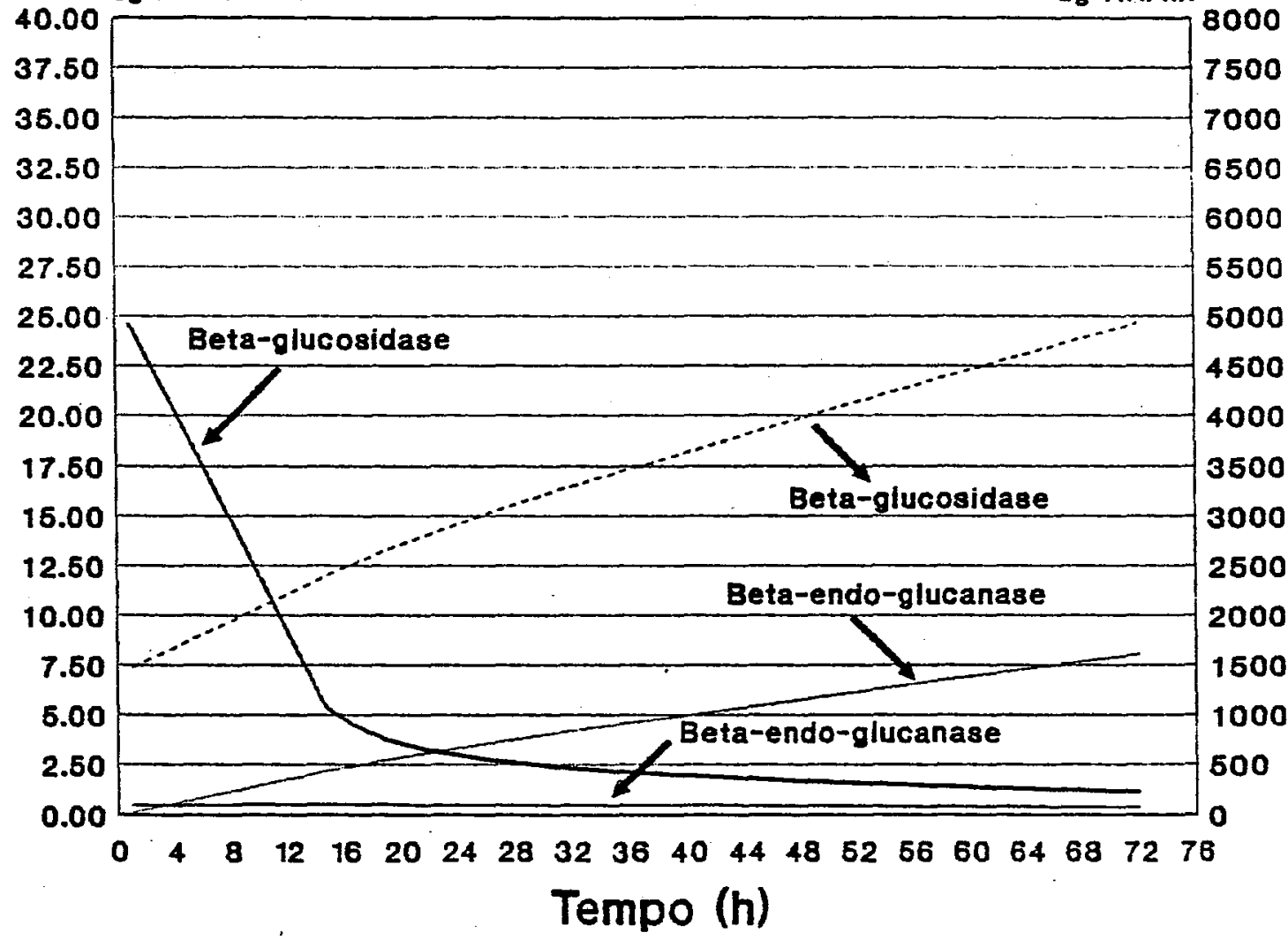

Enzima 2, EZ Cmedia de três repetiç̋es).

Figura 11B - Identificação bioquímica de beta-endoglucanase - beta-glucosidase, em trés sistemas enzimáticos obtidos a partir de Trichoderma reesei CE1, $\left.E_{2}\right)$ de Aspergillus niger (Eз). 
o potencial de beta-endoglucanase nos dois sistemas celuloliticos de Trichoderma reesei E1 e Ez CFiguras $11 \mathrm{~A}$ e 11B demonstrou comportamento semelhante. Entretanto, o de Aspergillus niger, Ea (Figura 11 C mostrou-se diferenciado a $1 \mathrm{~h}$, evidenciando inibicăo pelo produto final nos tempos subsequentes.

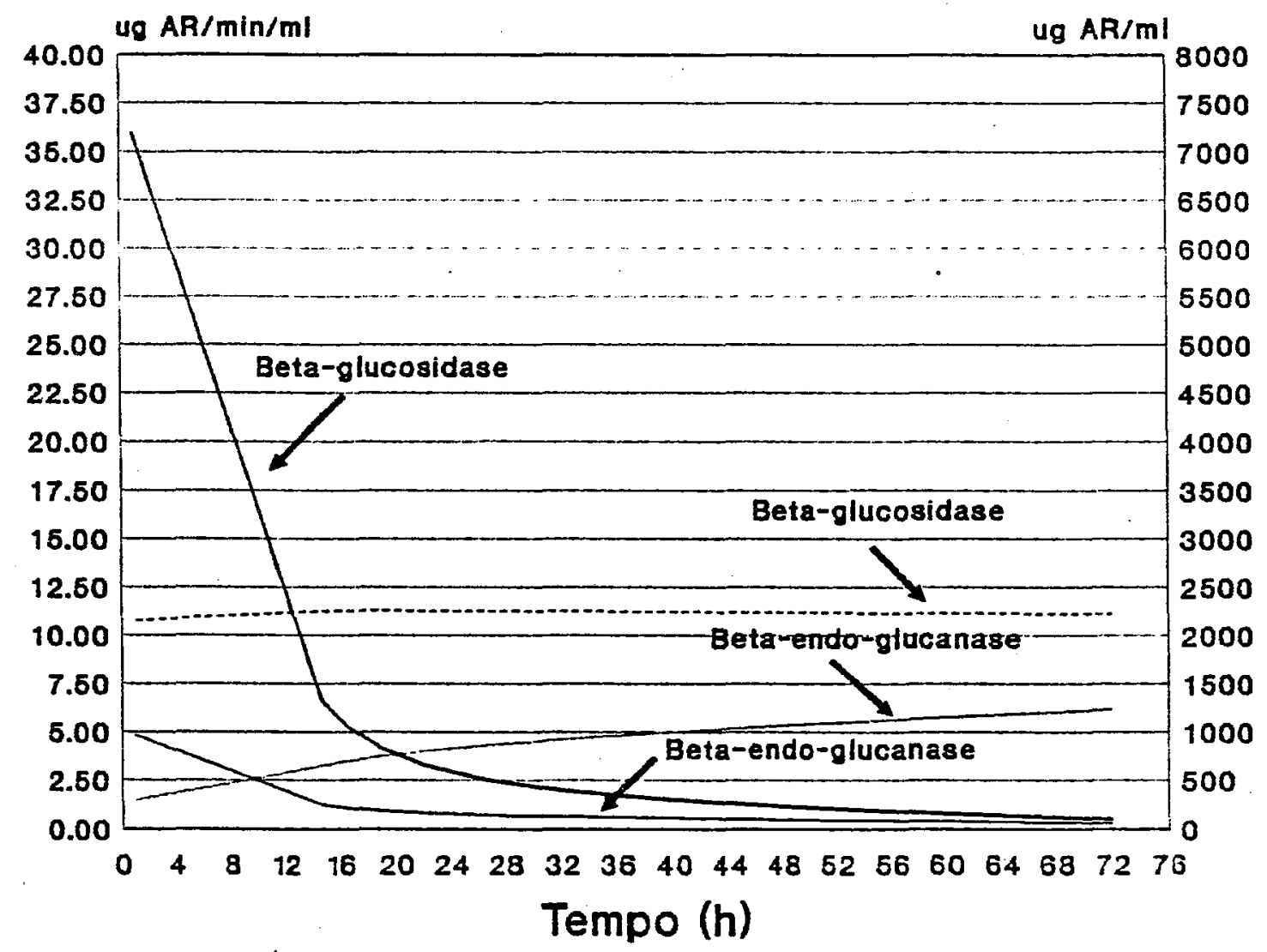

Enzima 3, E3 Cmédia de trés repetiçơses.

Figura $11 \mathrm{C}$ - Identificação bioquímica de beta-endogl ucanase e beta-glucosidase, em tras sistemas enzimáticos obtidos a partir de Trichoderma reesei CE1, Ez) de Aspergillus niger (Ea). 
88.

Ds sistemas diferiram quanto ao potencial de beta-glucosidase: a enzima 1 apresentou potencial de ativi-. dade mais elevado que a enzima 2 , entretanto a 1 a 3 nåo pareceram diferir com relaçăo a esta caracteristica. A beta-glucosidase de Aspergillus riger parece ter comportamento semelhante a de Trichoderma reesei, no que se refere ao mecanismo de inibiçăo por produto final, ao serem avaliados conjuntamente, potenciais máximos e velocidade de reação.

A exemplo dos estudos de mecanismos hidroliticos com enzimas purificadas ou. não CDURAND et alii, 1984; DEKKER, 19863, os problemas inerentes às enzimas alostericas devem ser considerados, inclusive tomando-se o fator tempo como determinante da atividade.

Outros experimentos sugeriram que a inibiça clássica por glucose em beta-glucosidase de Aspergillus niger e Trichoderma reesei (ENARI, 1983; DEKKER, 1986) diferente, conforme mostram os resultados da Tabela 6 . O referido componente é bastante susceptivel à modificaçőes geneticas, o que parece estar envol vido nos resultados das enzimas em estudo. Sugere-se então que essas enzimas sejam melhor caracterizadas, inclusive com maior controle nas fontes Gmicrorganismos, laboratorios e procedimento de obtenção). 
Tabela 6 - Constante de Michaellis-Menten $\mathrm{KM}$ e Constante de Inibiçăo $\mathrm{CKi}$ j para beta-gl ucosidase de Trichoderma reesei o de Aspergillus niger.

\begin{tabular}{lccc}
\hline $\begin{array}{c}\text { Fonte } \\
\text { ENzIMATICA }\end{array}$ & $\begin{array}{c}\text { Km } \\
(\mathrm{mM})\end{array}$ & $\begin{array}{c}\text { GLUCOse } \\
\text { (mM) }\end{array}$ & $\begin{array}{c}\text { GLuconolactona } \\
\text { (mM) }\end{array}$ \\
\hline Aspergillus niger & 0,8 & 2,1 & 0,04 \\
Irichoderma reesei & 0,2 & 0,7 & 0,04 \\
\hline
\end{tabular}

Fonte: ENARI, 1903.

Ao se avaliar a importancia relativa dos componentes bioquimicos (Tabela 7 , a contribuiçăo de beta-endogl ucanase é mínima em relação à celobiohidrolase, confirmando a participaçăo do úl timo componente na atividade celuLolitica dos sistemas de Trichoderma reesei. Por outro lado, as enzimas de Aspergilius niger contem pouca beta-endoglucarase e suficiente beta-glucosidase (ENARI, 19833 e não apresentam celobiohidrolase, indicando a procedencia da discussão nos ensaios 1 e 2 , sugerindo-se a participação de componentes hemiceluloliticos e alteraçzes em acessibilidade das enzimas aos referidos substratos.

Tabela 7 - Enzimas celuloliticas produzidas por Trichoderma reesei e. Aspergilius riger.

COMPONENTES B IOQUIMICOS
QUANTIDADE RELATIVA

(S PROTEINAS TOTAIS EXTRAGELULARES)
T. reese $i$.
A. niger

Celobiohidrolase Endoglueanase

Beta-glucosidase

$\begin{aligned} 50 & -80 \\ 8 & -12 \\ 0,2 & -1,0\end{aligned}$

0

$2-3$

$2-3$ 
90.

\section{Ensaio 5}

Centralizou-se o objetivo do presente estudo em correlacionar dois metodos para extraçå de conteúdo celular: fibra em detergente neutro e insolubilizaçăo em HCl-pepsina. Conforme descritos na maioria das determinaçßes de materia seca digestivel pelo metodo enzimático, os referidos tratamentos podem mostrar resultados significativos em diferenciar estruturas indisponfveis, ao se somar o efeito dos sistemas enzimaticos $624 \mathrm{~h}, 48 \mathrm{~h}, 72 \mathrm{~h}$, nos estudos de extensão de solubilizaça.

Ds grupos de forragens e alimentos que foram usados nesta fase estão descritos no ftem 3.2.1 (B). As análises do referido estudo seguiram o descrito no item 3.3.8, com o objetivo de adequar os dados a um modelo de equaçbes para correlacionar os metodos propostos. Os resultados estå melhor detalhados na Tabela 2 (Apendice).

As equaç⿸尸es selecionadas para os referidos grupos de alimentos CTabela 8 s sugerem que o procedimento analitico alternativo (insolubilizaçăo em HCl-pepsina) pode substituir o sistema convencional cdetergente neutros para os alimentos volumosos, com a maxima resposta no grupo de residuos agricolas, tratados ou não. A variação observada em coeficientes de determinação pode ser explicada pela heterogeneidade do material, e ainda os referidos coeficientes podem ser corrigidos ao se avaliar os materiais em diferentes fases de crescimento e com diferentes potenciais de digestibilidade. Pode-se corrigir as referidas 
equaçbes, basicamente ao se amostrar maior número possivel de formas de parede celular.

Tabela 8 - Modelos e equaç̋es definidas para estimativa de parede celular $6 \%$ pelos sistemas analiticos, detergente e enzimático.

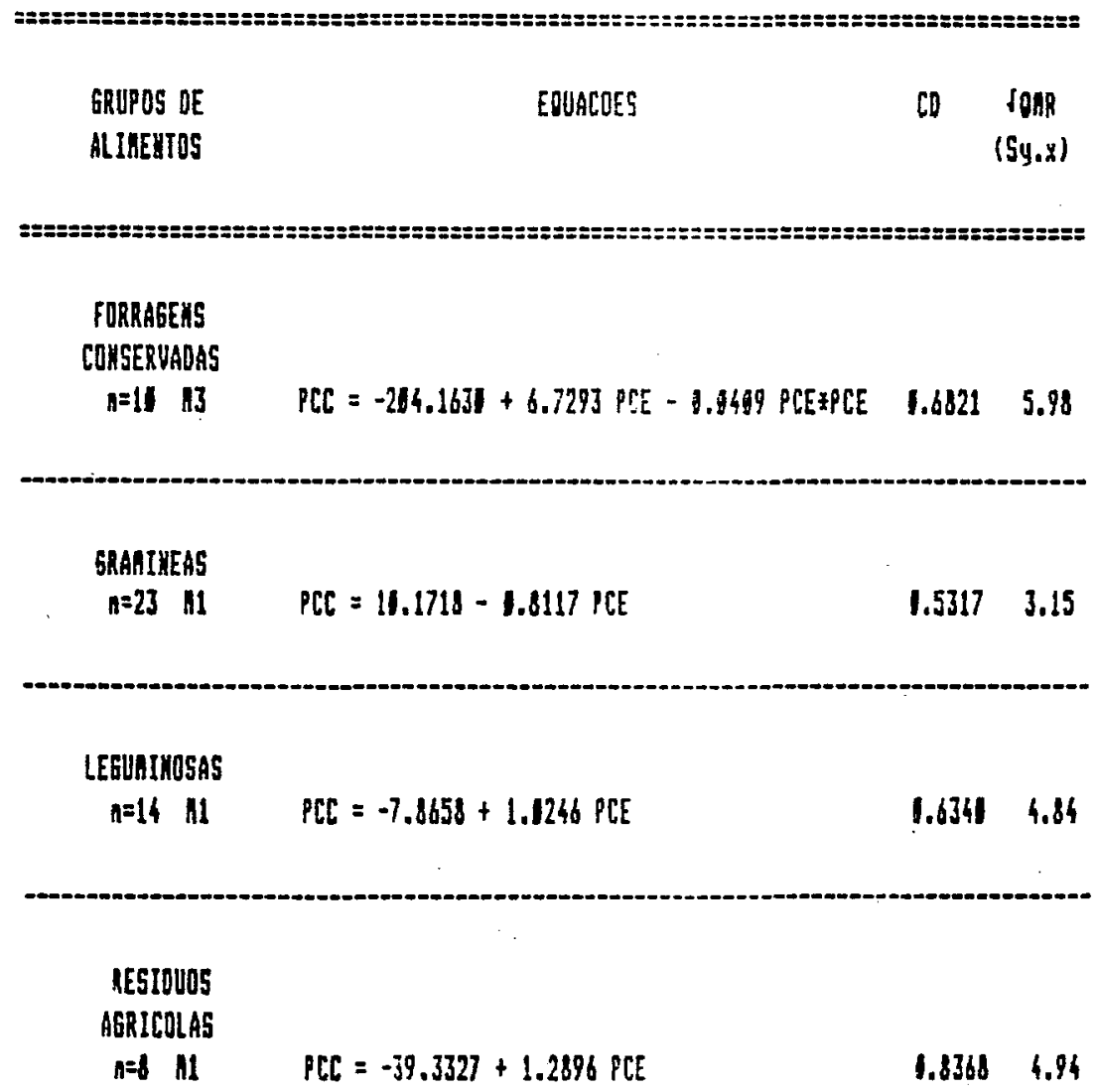

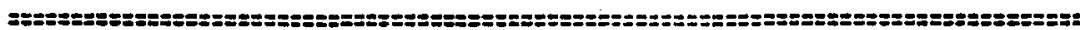

SERAL

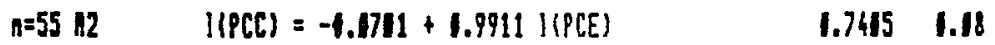

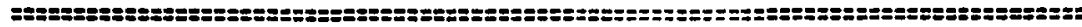

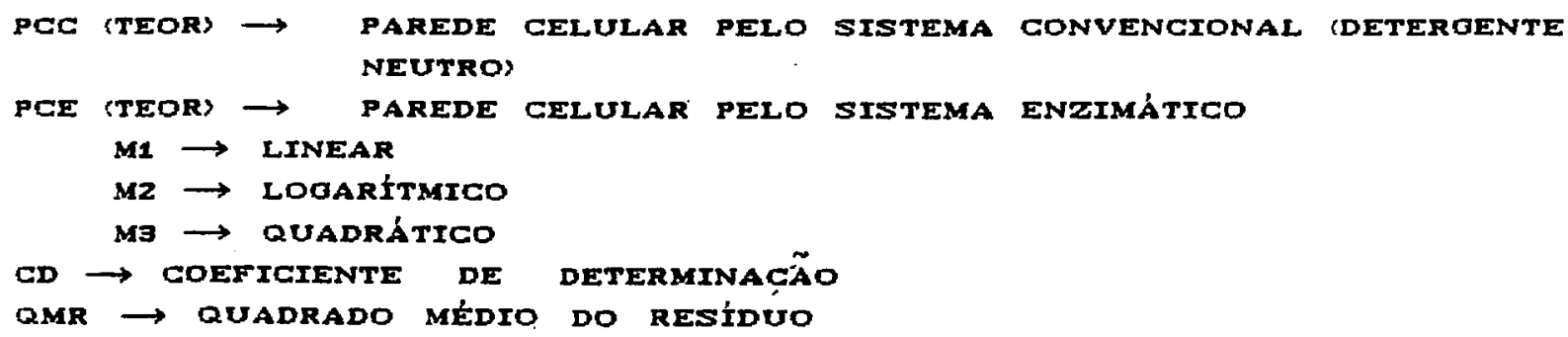


92.

Por outro 1 ado, como sugerem alguns autores, em estudos do potencial digestivel, a avaliaço pode ser obtida por especies forrageiras semelhantes ou por agrupamento definido do alimento em questão CMCLEOD \& MINSON, 1978; MASAOKA \& TARUMOTO, 1979; MCLEOD \& MINSON, 19823 O que aparentemente tem dado resultado.

Os resultados deste estudo sugerem que ambos os metodos são apropriados para remover o conteúdo celular Camido, proteinas e lipideoss en grande número de alimentos, comprovando as sugesties de JONES \& HAYWARD (1975) 8 HOLLAND (1977). A solubilização em HCl-0,1N, pepsina $0,2 \%$ peso/volume por $24 \mathrm{~h} / 40^{\circ} \mathrm{C}$ pode ser insuficiente para remover conteúdo celular de concentrados energéticos. DOWMAN \& COLLINS, (1982); DEBOEVER (1986) sugeriram a adiç̃o de amiloglucosidase CAGIDEXJ e tratamento termico $80^{\circ} \mathrm{Co} 45 \mathrm{~min} \mathrm{com}$ efeitos complementares aos tratamentos do estudo. Os dados sugerem uma melhor avaliação dessa metodologia para grupos de alimentos como concentrados proteicos $\theta$ energeticos $\theta$ mistura de alimentos.

\section{Ensaio 6}

O referido estudo teve como objetivo avaliar atraves de medidas gravimetricas e colorimetricas, o efeito de fontes enzimáticas, visando substituir o metodo microbiologico convencional (IILLEY \& TERRY, 1963 ) nos distintos grupos de forragens. Assim, tentou-se compatibilizar fonte enzimatica e substratos forrägeiros. Para os referidos 
93.

objetivos toram escolnidas as enzimas 1 cde Trichoderma reeseil e a 3 (de Aspergillus niger) por constituirem sistemas enzimaticos distintos, nas condiçöes avaliadas nos estudos anteriores. As mesmas passam a ser referidas aqui por enzimas 1 e respectivamente.

Observou-se que a heterogeneidade de parede celular, e por conseguinte dos substratos em questăo, interferem marcadamente nas avaliaçöes gravimetricas e colorimétricas. REEVES (1988) descreveu que os componentes individuais quimicos da Iignina não fornecem correlaç̋es com parede celular e parede celular digestivel CVAN SOEST et alii, 1966 se avaliados sem o ajuste com o próprio alimento como covariável. No caso foi tentado un ajuste para parede celular pelos metodos propostos no ensaio 5 . As resultados constam na Tabela 3 (Apendice) e indicam a procedencia do ajuste, principalmente nas medidas colorimetricas para os sistemas enzimáticos 1 e 2 .

A procedencia do ajuste está associada aos grupos de forragens conservadas e gramineas, onde apareceram os mais baixos coeficientes de determinação nos respectivos procedimentos gravimetrico e colorimetrico, que constam da Tabela 4 (Apendice). Observa-se de forma clara que no grupo de leguminosas, com altos coeficientes de determinação, a covariável foi ineficaz para ambas as avaliaç̋es Cgravimétricas e colorimetricas?.

Por năo haver diferenças significativas entre os dois metodos propostos para isolar parede celular, a 
94.

procedencia do ajuste pode ser interpretada por ambos os procedimentos. Nos casos especificos de inadequaça do procedimento, a dúvida pode refletir a ineficiencia dos sistemas analiticos envolvidos cideterminaçós de parede celular, materia seca digestivel e carboidratos estruturais disponiveis nos diferentes alimentos?.

Com relação ao teste de modelo de equaçós mostrado na Tabela 4 (Apendices para materia seca digestivel e carboidratos estruturais disponiveis nos diferentes grupos, os dados estão ligeiramente de acordo com o observado no ensaio 5. O Ma Guadraticos ajustou-se melhor para as forragens conservadas. No caso de gramineas, o Ma sugeriu melhores ajustes sem modificar o resultado com relação ao objetivo do trabalho. Com leguminosas, o Me (linear) mostrou-se eficaz para as medidas gravimetricas, enquanto o Ma mostrou-se eficaz em explicar as avaliaçôs colorimetricas. Para os residuos, talvez pelo pequeno número de amostras, a definiç̃o do modelo não ficou muito clara. Aparentemente, o M2 (logaritmico) explicou melhor os dados observados, entretanto, os modelos năo interferiram nos resultados finais com relação aos objetivos do trabalho. Numa análise conjunta, o Mz conferiu melhores ajustes, inclusive concordando com os resultados do ensaio 5, apesar dos modelos $(\mathrm{M} 1=\mathrm{M}=\mathrm{M}=$ não diferirem muito. Esses resultados sugerem importantes diferenças no carater das medidas avaliadas prineipalmente, om relação aos carboidratos estruturais disponiveis, cujas diferenças são maiores, ao "se aplicar os testes de 
covariància e modelos de equaçöes Cresumo dos dados constam na Tabela 9 .

Tabela 9 - Modelos e equaçbes definidas para estimativas de matéria seca digestivel entre os sistema microbiológico e enzimático.

\begin{tabular}{|c|c|c|c|}
\hline 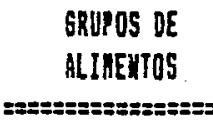 & 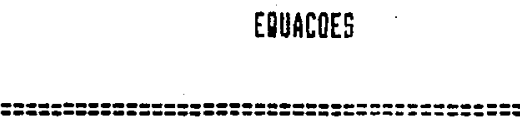 & 60 & 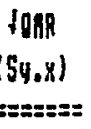 \\
\hline $\begin{array}{l}\text { FORRAGENS } \\
\text { COHSERUADAS }\end{array}$ & $\begin{array}{l}11=158.3437-5.3182 x+1.8574 x=x \\
12=119.1238-3.1378 x+8.8354 x=x\end{array}$ & $\begin{array}{l}0.7414 \\
1.6874\end{array}$ & $\begin{array}{l}7.43 \\
6.64\end{array}$ \\
\hline$n=11 \quad 13$ & $\begin{array}{l}Y C 1=15.3711-1.3651 X+1.805 ! X x \\
Y C 2=-77.4761+3.1812 x-1.8271 X \times X\end{array}$ & $\begin{array}{l}1.4899 \\
1.3951\end{array}$ & $\begin{array}{l}2.19 \\
3.69\end{array}$ \\
\hline GRAAIMEAS & $\begin{array}{l}11=86.7738-1.9151 x+8.1229 x x x \\
Y 2=62.6214-1.3585 x+8.0195 x=x\end{array}$ & $\begin{array}{l}0.4736 \\
1.6212\end{array}$ & $\begin{array}{l}4.69 \\
4.41\end{array}$ \\
\hline$n=23 \quad$ A3 & 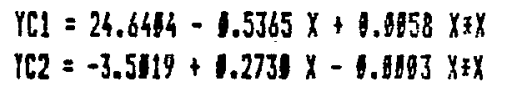 & $\begin{array}{l}1.1359 \\
1.1111\end{array}$ & $\begin{array}{l}2.17 \\
4.83\end{array}$ \\
\hline LEGUHINOSAS & $\begin{array}{l}Y 1=2.3614+1.1186 x \\
Y 2=3.6515+1.1218 x\end{array}$ & $\begin{array}{l}1.8934 \\
0.8286\end{array}$ & $\begin{array}{l}3.33 \\
4.39\end{array}$ \\
\hline$n=14 \quad n 1$ & $\begin{array}{l}Y C 1=1.9381+1.1772 x \\
Y C 2=-11.8644+5.3674 x\end{array}$ & $\begin{array}{l}1.2708 \\
1.5375\end{array}$ & $\begin{array}{l}2.75 \\
3.22\end{array}$ \\
\hline $\begin{array}{l}\text { RESIOUDS } \\
\text { AGRICOLAS }\end{array}$ & 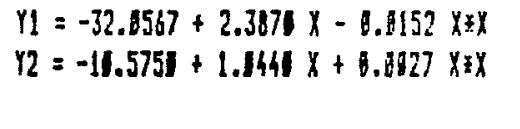 & $\begin{array}{l}1.5793 \\
1.7714\end{array}$ & $\begin{array}{l}17.25 \\
11.58\end{array}$ \\
\hline$n=8 \mathrm{MB}$ & 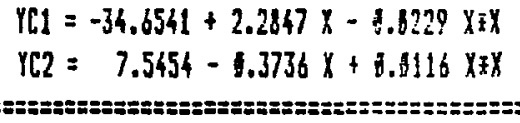 & 1.3351 & $\begin{array}{r}11.48 \\
8.82 \\
=:=-==\end{array}$ \\
\hline GERAL & $\begin{array}{l}l(Y)=-1.8995+1.1954 l(x) \\
1(Y 2)=-1.1191+1.2376)(x)\end{array}$ & $\begin{array}{l}1.6392 \\
8.7196\end{array}$ & $\begin{array}{l}1.19 \\
1.16\end{array}$ \\
\hline$n=55 \quad$ H2 & $\begin{array}{l}\| Y C 1)=1.1186+1.62851(X) \\
I(Y C 2)=-2.3641+1.179 ! I(X)\end{array}$ & $\begin{array}{l}0.1512 \\
1.2464\end{array}$ & $\begin{array}{l}1.32 \\
1.44\end{array}$ \\
\hline
\end{tabular}

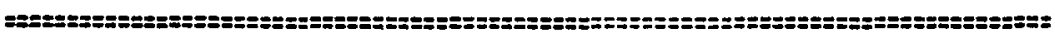

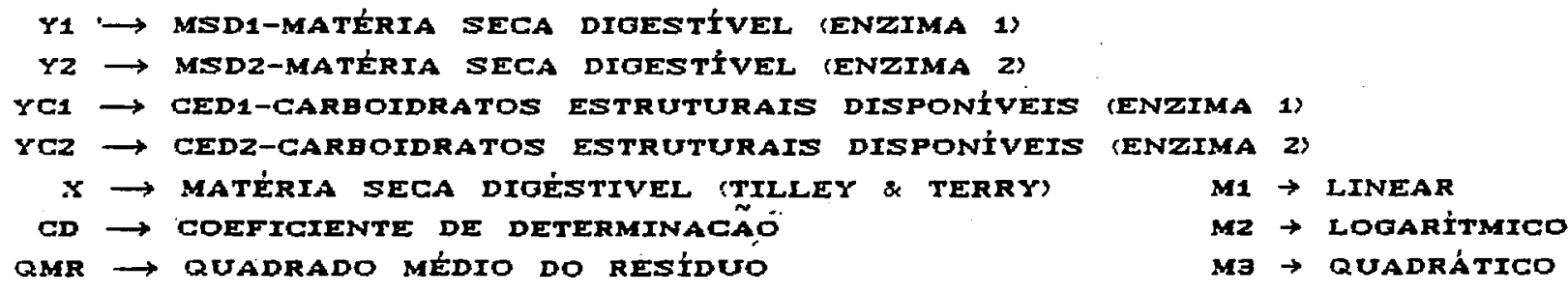


As avaliaçóes indicam que pelo pequeno número de amostras e heterogeneidade dos materiais estudados Cparede celular e sistemas celuloliticosl, as tentativas por modelo de equaçóes e covariáncia podem fornecer dados interessantes, comparando-se os referidos testes com maior variaçăo de resultados. Por outro lado, a dificuldade em avaliar a heterogeneidade dos materiais lignocelulosicos de obter amostras com diferentes faixas de disponibilidade têm impossibilitado reunir as condiços ideais para estudos de regressăo. Alguns trabal hos sugeriram tentati vas de equaços por especie forrageira ou tipo de alimento CALISSON \& BORZUGKI, 1978; MASAOKA \& TARUMOTO, 19792. E ainda, as interaçठes possiveis destas enzimas sobre o modelo de digestão podem dar resultados de dificil interpretaço, principalmente por alterar a disponibilidade biológica dos substratos em questao (DANIELS \& HASHIM, 1977; ROLZ et alii, 1986 ).

As diferencas estruturais dos substratos lignocelulósicos podem ser comprometidas pelo estado de oxidaçăo da Iignina (HARTlEY et alii, 1974; REEVES, 1988). As tecnicas convencionais de hidrolise e uso de marcadores isotopicos ou não conferem modificaçŏes na estrutura química dos carboidratos estruturais, por submeterem paralelamente a Iignina a um estado de oxidação CBARION, 1988; REEVES, 19883, podendo gerar dúvidas nas interpretaçöes dos dados. As referidas enzimas constituem um meio biológico de comparar os mecanismos de hidrolise envolvidos, bem como, de testar a eficiencia comparativa dö processo nos dois sistemas, 
microbiológico e enzimático.

Observando a questão de especificidade enzima-substrato, aparentemente a enzima 1 (Trichoderma reesei) mostrou-se melhor para forragens conservadas e leguminosas, - que e tambem corroborado pelos ajustes de equaçás. Entretanto, para gramineas e residuos agricolas, a enzima 2 CAspergilius niger) proporcionou melhores resultados. Numa avaliaça geral, a enzima 2 parece ser mais indicada para os substratos estudados. A metodologia deveria contemplar alimentos concentrados e ainda controlar melhor fonte enzimatica (indicaçós de laboratorios na Tabela 4), como sugeriram GLARK \& BEARD (1977); COTIYN et ali $(1984)$.

o procedimento gravimetrico cmateria seca digestivell parece ser mais indicado que o colorimetrico para se avaliar os resultados com as enzimas envolvidas no estudo. A especificidade indicada na literatura, entre os sistemas celuloliticos de Trichoderma reesei e Aspergilius niger para os substratos lignocelulósicos deve ser melhor estudada, seguindo os criterios adotados neste estudo Cprocedimento gravimetrico $x$ colorimetricol.

Ao se avaliar os carboidratos estruturais disponiveis, deve-se considerar que a eficiencia dos sistemas enzimaticos no tempo pode ser maior em 'relação a dos microrganismos ruminais, conseguindo-se assim, extrair açucares en quantidade maior e bastante variável pelas diferentes fontes enzimáticas. o potencial hidrolitico dos sistemas enzimáticos e as conformaçōes tridimensionais da 
98.

parede celular influenciaram o resultado final. A disponibilidade de parede celular é extremamente variável, principalmente, por variaçües em composiçăo e disposiçăo tridimensional. Medidas comparativas para melhor detectar tais efeitos podem ser a tecnica de fracionamento diferencial nas determinaçöes de parede celular e lignina, isotópica exou marcadores de fase sólida.

Recentemente, o infravermelho tem mostrado correlaços interessantes com os procedimentos in vitro, microbiologico e enzimatico CCOELHO et alii, 1988; GABRIELSEN et alii, 1988 ) métodos quimicos (REEVES, 1988; BARTON, 1988). A equação obtida por HARTLEY et alii (1974) reflete a eficiencia do metodo enzimático, principalmente por avaliar uma caracteristica importante no mecanismo de digestăo, as ligaçöes esteres dos compostos fenolicos com os carboidratos estruturais. O mesmo trabalho ainda mostra diferenças entre as forragens quanto aos piques de absorfăo no ultravioleta $C \lambda=324 \mathrm{~nm}$. A identificaçăo de ligaç̧es especificas $C \mathrm{C}-\mathrm{H}$, O-H, N-H em extensão e disposiço possiveis no infravermel ho - ancilises conformacionais por ressonáncia magnética sugerem melhores condiçaes comparativas, com o procedimento colorimetrico, pela ténica enzimatica (REEVES, 1988; BARTON, 1988 ).

A fonte de inoculo pode ser outro fator a ser considerado no presente estudo. CLARY et alii (1988) propuseram que pode ocorrer uma grande variação nos dados em înfăo do animal doador, quando os alimentos apresentam valores 
99.

de 40-70\% de materia seca digestivel. os mesmos autores sugeriram que subamostragens reduzem pouco a variabilidade observada, enquanto o número de animais-doadores (2-3) controla com maior eficiencia a variabilidade das referidas amostras.

Com relação ao método microbiológico, sugerem-se algumas modificaçbes. A concentraçăo ácida na $2^{\text {a }}$ fase de digestão, certamente dara resultados mais proximos ao tipo de avaliação proposta, uma vez que HCl O,1N deve afetar menos a celulose e hemicelulose, avaliando-se de forma mais decisiva o potencial dos microrganismos ruminais. Por outro lado, a digestibilidade verdadeira da parede celular CVAN SOESI et ai i 1966 deve tambem fornecer dados mais próximos. Entretanto, os dados de literatura.sugerem a metodologia convencional. (TILLEY \& TERRY, 1963 ) para as comparaç̧es com o enzimático.

Outro problema das medidas avaliadas certamente está relacionado com a heterogeneidade dos sistemas celuloliticos, de diferentes laboratorios, como está indicado na Tabela 4 CRecentes propostas da metodologia enzimática para estudos da f̀ração potencialmente digestívels.

Com os baixos coeficientes de determinação c< 0,60$)$ obtidos no ensaio 6 coolorimetrico, enzima 1 e $x$ microbiologicol ficou a dúvida guanto as estruturas reconhecidas pelos respectivos sistemas enzimáticos. Assim, sugere-se que pelo menos entre o gravimetrico e colorimetrico, em cada sistema enzimático ocorra alguma correlaçăo. A Tabela 5 
100.

CApendices mostra os ralores e significancia de $F$ e coeficientes de determinaçăo obtidos nos diferentes grupos de alimentos, inclusive, testando os modelos de equaçăes.

Os resultados do referido teste com a enzima $a$ mostraram altas correlaços entre materia seca digestivel e carboidratos estruturais disponiveis, confirmando certa especificidade com os substratos em questão. Ao contrário, os resultados fom a enzima 1 mostraram correlaç̋̈es mais baixas en todos os grupos de forragens, inclusive nas forragens conservadas, o coeficiente de determinaçăo aproxi mou-se de zero nos tres modelos de equaçbes, sugerindo baixa especificidade erou necessidade de modificaçós analiticas para - referido grupo. Por outro lado, a avaliaçăo dos modelos sugere que o M3 e mais indicado para as medidas de carboidratos estruturais disponíveis, o que já havia sido sugerido para alguns grupos de forragens em analises anteriores.

\section{SUGESTÕES E APLICAÇÕES PRÁTICAS}

1) Os resultados apresentados na Tabela 9 , com relação ao grupo de leguminosas, com coeficiente de determinaçăo $\simeq 0,90$, indicam que a metodologia e funcional e sugerem-se melhores estudos com objetivos mais definidos, em outros grupos de alimentos.

2) A questão da especificidade necessita ser testada com um controle maior de fonte enzimática e variaçăo natu- 
ral possivel de substratos lignocelulósicos e respecti vas disponibilidades.

3) A avaliação de carboidratos estruturais disponiveis exige um tratamento mais apurado no que diz respeito às equaçß̋es estimativas. As observaçäes laboratoriais demonstram ser esta medida interessante para o acompanhamento de reduçăo de disponibilidade de parede celular pelos efeitos naturais de lignificaçăo e cristalinidade.

4) A metodologia deve ser ampliada a outros grupos de alimentos, como concentrados energeticos e protéicos, e conferir possiveis modificaçaes visando seu aperfeiçomento.

5) As diferenças estruturais mais significativas podem ser obtidas ate $24 \mathrm{~h}$ de reaçăo, com substratos purificados e naturais nos distintos sistemas celuloliticos, inclusive com menores interferencias dos inibidores intermediários e finais. Assim permite sugerir a possibilidade de se detectar materia seca digestivel em $48 \mathrm{~h}$ de análises laboratoriais, combinando com a fase em HCl-pepsina (24 h).

6) Ha evidencias tambem de que a dosagem de CED Ccarboidratos estruturais disponiveisl pode expressar resultados de tratamentos especificos sobre os residuos agricolas. 


\section{CONCLUSÕES}

Os resultados experimentais permitem concluir

que:

1. No presente estudo, observa-se que a condiço de saturạ̧ăo, para os sistemas celuloliticos, foi estabelecida com a concentração minima (1\% peso/volume) e tempo maxi mo de reação (72 hl, condiçöes nas quais os efeitos inibitorios de produtos finais e intermediarios foram maximizados, como moduladores negativos nos distintos componentes enzimáticos individuais.

2. As enzimas alostericas heterotropicas Ccelulases de Trichodema reesei e Aspergillus nigerl são afetadas por diferentes graus de lignificaçăo e cristalinidade dos distintos materiais utilizados no ensaio com substratos naturais (forragens?.

3. Os referidos sistemas de Trichoderma reesei e Aspergillus niger apresentam as diforenças básicas quanto aos componentes beta-endo-gl ucanase o beta-gl ucosidase, diferindo em potenciais maximos e mecanismo de inibiçăo por produto final. 
4. A metodologia alternativa de análise de parede cel ular mostra-se efetiva em remover conteúdo celular de forragens conservadas, gramineas, leguminosas e residuos agricolas, podendo ser extendida a outros grupos de al imentos.

5. A covariavel avaliada (parede celular) e procedente, principalmente para corrigir as correlaçóes nas avaliaçBes de carboidratos estruturais disponiveis, refletindo a heterogeneidade e especificidade dos materiais em estudo.

6. A materia seca digestível pode ser obtida por meio enzimático comparável ao método microbiológico, e portanto, as condiçbes in vivo com oficioncia que varia de 0,60 a 0,90 de coeficientes de determinação, para os distintos grupos de forragens, considerando os testes de covariancia e modelos de equaçós.

7. A enzima 1, de Trichoderma reesei mostra-se mais especifica para forragens conservadas e leguminosas, enquanto a enzima 2 , de Aspergillus niger mostra-se mais indicada para gramineas e residuos agricolas. 


\section{REFERENNCIAS BIBLIOGRÁFICAS}

AGARWAL, P.K.. Heterogeneus denaturation of enzymes: a distributed activation energy model with nonuniform activities. Biotechnology and Bioengineering, New York, 27: $1554-63,1985$.

ALBERTS, B.; BRAY, D. ; LEWIS, J. ; RAFF, M. ; ROBERTS, K. HATSON, J.D. Molecular biology of the cell. New York, Garland Publishing, 1983. 1146 p.

ALLISON. M. \& BORZUCKI, R. Cellulase methods for efficient digestion of grasses and brassicas. Journal of Science Food and Agriculture, London, 29: 293-7. 1978.

ALURRALDE, I. L. \& ELLENRIEDER, $G$. Ef fect of at tached carbohydrates on the activity of Ifichoderma viride cellulase. Enzyme and Microbial Techonology, Stoneham, 6: 467-70, 1984.

AUFRERE, I. \& MI GHALET-DOREAU, B. Comparison of methods for predicting digestibility of feeds. Animal Feed Science and Technology, Amsterdan, 20: 203-18, 1988.

BAILEY, R. H. \& IONES, D.I.H. Pasture quality and.ruminant nutrition III. Hydrolysis of ryegrass structural carbohydrates with carbohydrases in relation to rumen digestion. New Zealand Journal of Agricultural Research, Wellington, 14: $847-57,1971$. 
105.

BARTON, F.E. Chemistry of lignocellulose; methods of analysis and consequences of structure. Animal Feed Science and Technology, Amsterdam, 21: 279-86, 1988.

BORGMEYER, J.R. \& CRAWFORD, D.L. Production and characterization of polymeric lignin degradation intermediates from two different Streptomyces spp. Applied and Environmental Microbiology, Washington, 49(2): 273-8, 1985.

BREUIL, G. S SADDLER, J.N. Comparison of the 3.5 dinitrosalicylic acid and Nelson-Somogyi methods of assaying for reducing sugars and determining cellulase activity. Enzymes and Microbial Technology, Stoneham, 7: 327-32, $1985 a$.

BREUIL, C. \& SADDLER, J.N. Limitations of using the D-glucose-oxidase peroxidase method for measuring glucose derived from lignocellulosic substrates. Biotechnology Letters, Kew, $7(3): 191-6,1985 \mathrm{~b}$.

BUGGE, G. A simplified cellulase digestion technique for predicting dry matter digestibility of grasses. Journal of Agronomy and Crop Science, Berlin, 149: 206-12, 1980.

CHIRICO, W.J. \& BROWN JR., R.D. Separation of cellooligosaccharides by thin-layer chromatography assay for cellulolytic enzymes. Analytical Biochemistry, San Diego, 150: $254-72,1985$.

CLARK, J. \& BEARD, J. Prediction of the digestibility of ruminants feeds from their solubility in enzyme solutions. Animal Feed Science and Technology, Amsterdam, 2: $153-9,1977$.

CLARY, W.P.; WELGH, B.L.; BOOTH, G.D. In vitro digestion experiments: importance of variation between inocula do- 
nors. Journal of Mildlite Management, Bethesda, 52(2): $358-61,1988$.

GLESGERI, L.S. ; SINITSYN, A.P. ; SAUNDERS, A. M. ; BUNGAY, H.R. Recycle of the cellulase-enzyme complex after hydrolysis of steam-exploded wood. Applied Biochemistry and Biotechnology, Gifton, 1166): 433-44, 1985.

COELHO, M. : HEMBRY, F.G.; BARTON, F.E.; SAXTON, A.M. A cOmparison of microbial, enzymatic, chemical and near-infrared reflectance spectroscopy methods in forage evaluation. Animal Feed Science and Technology, Amsterdam, zo: $219-31,1988$.

COLBERG, P.J. \& YOUNG, L.Y. Anaerobio degradation of soluble fractions of $[14 \mathrm{C}-1$ ignin] lignocellulose. Applied and Environmental Microbiology, Washington, 49(2): $345-9$, 1985 .

COTTYN, B.G.; AERTS, J.V.; VANACKER, J.M.; MOERMANS, R. J.; BUYSSE, F.X. The prediction of the net energy value of compound feedstuffs for dairy cattle. Animal Feed Science and Technology, Amsterdam, 11: 137-47, 1984.

COUGHLAN, M.P. The properties of fungal and bacterial cellulases with comment on their production and application. Biotechnology and Genetic Engineering, Reviews, Ponte1 and, 3: $39-109,1985$.

CRAWFORD, R.L. \& CRAWFORD, D.L. Recent advances in studies of the mechanisms of microbial degradation of lignins. Enzyme and Microbial Technology, Stoneham, 6: 434-42, 1984.

CUTIER, E.G. Plant anatomy: part 1; cells and tissues. 2 . ed. London, Edward Arnold, 1979. 315p. 
GZERKAHSKI,.J.W. An introduction to rumen studies. Oxford, Pergamon Press, 1986 . 236p.

DANIELS, L.B. \& HASHIM, R.B. Evaluation of fungal cellulases in rice hull base diets for ruminants. Journal of Dairy Science, Champaign, 60: 1563-7, 1977.

DAVID, C. ; FORNASIER, R. ; THIRY, P.H. Utilization of waste collulose VI. Pretreatment of lignocellulosic materials with sodium hypochlorite and enzymatic hydrolysis by Trichoderma viride. Applied Biochemistry and Biotechnology, Gifton, 11: $351-65,1985$.

DEBOER, G.; MURPHY, J.J. ; KENNELLY, J.J. A modified method for determination of in situ rumen degradation of feedstuff's. Canadian Journal of Animal Science, Ottawa, 67: $93-1$ OZ, 1987 .

DEBOEVER, J.L.; GOTTYN, B.G.; ANDRIES, J.I.; BUYSSE,.F.X.; YANACKER, J.M. The use of a cellulase technique to predict digestibility, metabolizable and net energy of forages. Animal Feed Science and Technology, Amsterdam, 19: $247-60,1988$.

DEBOEVER, J.L.; COTTYN, B.G.; BUYSSE, F.X.; WAINMAN, F. W. ; VANAGKER, J. M. The use of an enzymatic technique to predict digestibility, metabolizable and net energy of compound feedstutifs for ruminants. Animal Feed Science and Technology, Amsterdan, 14: 203-14, 1986.

DEKKER, R.F.H. Bioconversion of hemicellulose: aspects of hemicellulase production by Trichoderma reesi OM 9414 and enzymic saccharification of hemicellulose. Biotechnology and Bioengineering, New York, 25: 1127-46, 1985. 
DEKKER, R.F.H. Kinetic, inhibition and stability properties of a commercial $\beta$-D-glucosidase (celobiase) preparations from Aspergillus niger and its suitability in the hydrolysis of lignocellulose. Biotechnology and Bioengineering, New York, 28: 1438-42, 1986.

DESHPANDE, M. V. \& ERIKSSON, K.E.R. Reutilization of enzymes for saccharification of lignocellulosic materials. Enzyme and Microbial Technology, Stoneham, 6: 338-40, 1984.

DONEFER, E.; NIEMANM, P.J.; GRAMPTON, E. H. LLOYD, L. E. DrY matter dissapearance by enzyme and aqueous solutions to predict the nutritive value of forage. Journal of Dairy Science, Champaign, 46: 965-70, 1963.

DOWMAN, N.G. S. COLLINS, F.C. The use of enzymes to predict the digestibility of silages using cellulase. Journal of the Science of Food and Agriculture, London, 28: 1071-4, 1977 .

DOWMAN, N.G. B COLLINS, F.C. The use of enzymes to predict the digestibility of animal feeds. Journal of the science of Food and Agriculture, London, 33: 689-96, 1982.

DURAND, H. ; SOUCAILLE, P.; TIRABY, G. Comparative study of cellulase and hemicellulase firom four fungi: mesophiles Irichoderma reesei and Pennicillium sp. and thermophiles Thielavia terrestris and sporotrichum ceiluphilum. Enzyme and Microbial Technology, Stonehan, 6: 175-80, 1984.

ENARI, T. Microbial cellulases. In: FOGARTY, W.M., ed. Microbial enzymes and biotechnology. London, Applied Science Publishers, 1983 . cap. 4, p. 183-223.

ESAL, K. Anatomy of seed plants. $2^{2}$ ed. New York, John WiLey \& Sons, 1977 . S50p. 
109.

FAISON, B.D. \& KIRK, T.K. Factors involved in the regulation of a ligninase activity in Phanerochaete chrysosporium. Applied and Environmental Microbiology, Washington, 49(2): $299-304,1985$.

FOX, D.J.; GRAY, P.G.; DUNN, N.W.; MARSDEN, W.L. An explanation of the discrepancy between the results of h.l.p.c. and DNS assays in the analysis of lignocellulosic hydrolysates. Journal of Chemical Technology and Biotechnology., Osney Mead, 34B: 171-5, 1984.

FUJJI, M. Se KAWAMURA, Y. Synergistic action of a-amylase and glucoamylase on hydrolysis of starch. Biotechnology and Bioengineering, New York, 27: 260-5, 1985.

FUJII, M. \& SHIMIZU, M. Synergism of endoenzyme and exoenzyme on hydrolysis of soluble cellulose derivatives. Biotechnology and Bioengineering, New York, 28: 878-82, 1986 .

FUJII, M.; MURAKAMI, S.; YAMADA, Y; ONA, T.; NAKAMURA, T. A kinetic equation for hydrolysis of polysaccharides by mixed exo and endoenzyme systems. Biotechnology and Bioengineering, New York, 23: 1393-8, 1981 .

GABRIELSEN, B. C.; VOGEL, K.P.; KNUDSEN, D. Comparison of in vitro dry matter digestibility and cellulase digestion for derivind near infrared reflectance spectroscopy calibration equation using cool-season grasses. Crop Science, Madison, 28: 44-7, 1988.

COEL, S. \& RAMACHANDRAN, K. B. Comparison of the rates of enzymatio hydrolysis of pre-treated rice-straw and bagasse with cellulases. Enzyme and Microbial Technology, Stoneham, 5: $281-4,1983$. 
6OTO, I. 8 MINSON, D.J. Prediction of the dry matter digestibility of tropical grasses using a pepsina-cellulase assay: Animal Feed Science and Technology, Amsterdam, 2: $247-53,1977$.

GRETHLEIN, H.E. Pretreatment for enhanced hydrolysis of cellulosic byomassa. Biotechnology Advances, Elmsford, 2: 43-62, 1984.

GRIFFIN, H.; DINTZIS, F.R.; KRULL, L.; BAKER, F.L. A microfibril generating factor from the enzyme complex of Trichoderma reesei. Biotechnology and Bioengineering, New York, 26: $296-300,1984$.

GROUS, W.; CONYERSE, A. ; GRETHLEIN, H.; LYND, L. Kinetics of cellobiose hydrolysis using cellobiase composites from Trichoderma reesei and Aspergillus riger. Biotechnology and Bioengineering, New York, 27:463-70, 1985.

GUSAKOV, A. V.; SINITSYN, A. P. ; KLYOSOV, A. A. Kinetics of the enzymatic hydrolysis of cellulose: 2 . A mathematical model for the process in a plug-flow column reactor. Enzyme and Microbial Technology, Stoneham, 7: 383-8, 1985.

GUSAKOY, A.V.; SINITSYN, A.P.; KLYOSOV, A.A. A theoretical comparison of the reactors for the enzymatic hydrolysis of cellulose. Biotechnology and Bioengineering, New York, 29: 898-900, 1987 .

HADIIPANAYIOTOU, M. ; HADJIDEMETRION, D.; HADIILOUCA, $T$. Determination of roughage digestibility in vivo, in vitro and with an enzimatic method. Nutrition Reports International, Stoneham, 3565): 957-61, 1987. 
HALLIWELL, G. \& GRIFFIN, M. The nature and mode of action of the cellulolytic component Cl of Trichoderma koningii on native cellulose. Biochemical. Journal, Colchester, 135: $587-94,1973$.

HAPTLEY, R.D.; JONES, E.G.; FENLON, J.S. Prediction of digestibility of forages by treatment of their cell walls with cellulolytic enzymes. Journal of Science and Food and Agriculture, London, 25: 947-54, 1974 .

HOMMA, H. Cellulase activities of bacteria in liquid and solid phases of the rumen digesta of buffaloes and cattle. Japanese Journal of Zootechnical Science, Tokyo, $57(4): 336-41,1986$.

HOPSON, I.D.; JOHNSON, R.R.; DEHORITY, B. A. Evaluation of the dacron bag technique as a method for measuring cellulose digestibility and rate of forage digestion. Journal of Animal Science, Albany, 22: 448-53, 1963.

ISRAELSEN, M. ; REXEN, B.; THOMSEN, V. Cellulase insoluble fibre as a measure of inavailable organic matter in cattle compounds containing alkali-treated straw. Animal Feed Science and Technology, Amsterdam, 3: 227-34, 1978.

JACOB, F. \& MONOD, J. Genetic regulatory mechanisms in the synthesis of proteins. Journal of Molecular Biology, London, 3: $318-56,1961$.

IARRIGE, R. B THIVEND, P. Action d'une cellulase fongique sur les membranes et son interet pour prevoir la digestibilite des plantes fourrageres. Annales de Biologie Animale Biochimie Biophysique, Montrouge, $9625: 171-90,1969$.

JARRI GE, R. ; THIVEND, P. ; DEMARQUILLY, C. Development of a cellulolytic enzyme digestion for predicting the nutriti- 
ve value of forages. In: INTERNATIONAL GRASSLAND CONGRESS, 11, Queensland, 1970. Proceedings, p.762-6.

IONES, D.I.H. \& HAYWARD, M.V. A cellulase digestion technique for predicting the dry matter digestibility of grasses. Journal of the Science of Food and Agriculture, London, 24: 1419-26, 1973.

JONES, D.I.H. \& HAYWARD, M.V. The effect of pepsina pretreatment of herbage on the prediction of dry matter digestibility from solubility in fungal cellulase solutions. Journal of the Science of Food and Agriculture, London, 26: $711-8,1975$.

KAHAMORI, M.; MORIKAWA, Y.; SHINSHA, Y.; TAKAYAMA, K.; TAKASAWA, S. Preparation of mutants resistant to catobolite repression of Trichoderma reesei. Agricultural and Biological Chemistry, Tokyo, 49(10): 2875-9, 1985.

KELLEY, R.L. 8. REDDY, A.G. Purification and characterization of glucose-oxidase from lignolytic cultures of Phanerochaece chrysosporium. Journal of Bacteriology, Washington, $166(1): 269-74,1986$.

KELLNER, R.J. \& KIRCHGESSNER, M. Estimation of forage digestibility by a cellulase method. Zeitschrift fuer Tierphysiologie, Tierernaehrung und Futtermittelkunde, Hamburg, 39: $9-16,1977$.

KIRCHGESSNER, M. \& KELLNER, R.J. Estimation of digestibility, metabolizable energy and net energy of forage by a cellulase method. Livestock Production Science, Amsterdam, s: $373-7,1978$.

LEHNINGER, A.L. Principios de bioquimica. Sao Paulo, Sarvier, 1988. 725p. 
LIN, K.W.; PAITERSON, J.A. ; LADISCH, M. R. . Anaerobic fermentation: microbes from ruminants. Enzyme and Microbial Technology, Stoneham, 7: 98-107, 1985.

LOBARZEWSKI, J. \& PASZCZYŃSKI, A. Lignocellulose biotransformation with immobilized cellulase, $\dot{D}$-glucose oxidase and fungal peroxidases. Enzyme and Microbial Technology, Stoneham, 7: 564-8, 1985.

LOHRY, O.H.; ROSEBROUGH, N.; FARR, A.L.; RANDALL, R. J. Protein measurement with the folin phenol reagent. Journal of Biological Chemistry, Bethesda, $193: 265-75,1954$.

MCCLUSKEY, J.G.; ALLISON, M. J. ; DUNCAN, H.J. ; JARYIS, M. C. Isolation of anatomically defined cell walls from fodder kale, and their contributions to determining the in vitro cellulase digestibility of the whole plant. Journal of Agricultural Science, Cambridge, 103: 347-52, 1984.

MCLEOD, M.N. \& MINSON, D.J. The accuracy of the pepsina-ollulase technique for estimating the dry-matter digestibility in vivo of grasses and legumes. Animal Feed Science and Technology, Amsterdam, 3: 277-87, 1978.

MCLEOD, M.N. \& MINSON, D.J. Accuracy of predicting digestibility by the cellulase technique: the effect of pretreatment of forage samples with neutral dettergent or acid-pepsin. Animal Feed Science and Technology, Amsterdam, 7: 83-92, 1982 .

MCLEOD, M.N. \& MINSON, D.J. A note on Onozuka $3 S$ cellulase as replacement for Onozuka SS CP150OS celiulase when estimating forage digestibility in vitro. Animal Feed Science and Technology, Amsterdam, 5: 347-50, 1980. 
MCLEOD, M.N. \& MINSON, D.J. Sources of variation in the in vitro digestibility of tropical grasses. Journal of British Grasslasnd Society, Oxford, 24: 244-9, 1969.

MCQUEEN, R. \& VAN SOEST, P.J. Fungal cellulase and hemicellulase prediction of forage digestibility, Journal of Dairy Science, Champaign, 58: 1482-91, 1975.

MALOSSINI, F.; PACE, V.; SETIINERI, D. Valutazione della digeribilita dei foraggi medianti enzimi. Zootecnica e Nutrizione Animale, Bologna, 8: 107-13, 1982.

MANDELS, M. ; ANDREOTII, R.; ROCHE, C. Measurement of saccharifying celiulase. In: GARDEN JUNIOR, E.L.; MANDELS, M.H. ; REESE, E. T.; SPANO, L. A., ed. Enzymatic conversion of cellulosic materials: technology and applications. New York, John Wiley, 1976. p. 21-33 CBiotechnology and bioengineering symposium, 6 .

MANONMANI, H. K. \& SREEKANTIAH, K. R. Saccharification of sugar-cane bagasse with enzymes from Aspergillus ustus and Trichoderma viride. Enzyme and Microbial Technology, Stoneham, 9: 484-8, 1987 .

MARSDEN, W.L.; GRAY, P.P.; DUNN, N.W. Alternative pathawy for glucose production from using Trichoderma reesei M9414 celiulase. Biotechnology Letters, Kew, 4(9): $589-94,1982 a$.

MARSDEN, W.L.; GRAY, P.P.; NIPPARD, G.J.; QUINLAN, M.R. Evaluation of the DNS method for analysing lignocellulosic hydrolysates. Journal of Chemical Technology and Biotechnology, Osney Mead, 32: 1016-22, $1982 b$.

MARTEN, G.C. Chemical, in vitro and nylon bag procedure for evaluating forage in the U.S.A. In: HHEELER, J.L. \& 
115.

MOCHRIE, R.D. ed. Forage evaluation: concepts and techniques. Lexington, American Forages and Grassland Council; Melbourne, CSIRO, 1981 . p. 39-56.

MASAOKA, Y. \& TARUMOTO, I. Influence of cellulase concentrations and incubation period on in vitro digestibility of fresh sorghum leaf by simple cellulase digestion method. Journal of the Japanese Society of Grassland Science, Tokyo, 24: $337-44,1979$.

MERTENS, D.R. \& ELY, L.O. A dynamic model of fiber digestion and passage in the ruminant for evaluating forage quality. Journal of Animal Science, Albany, 49C45: $1085-95,1979$.

MILLER, G.L. Use of dinitrosalicylic acid reagent for determination of reducing sugar. Analytical Chemistry, Mashington, $31(3): 426-8,1959$.

MINSON, D.J. An Australian view of laboratory techniques for forage evaluation. In: WHEELER, J.L. \& MOCHRIE, R.D. ed. Forage evaluation: concepts and techniques. Lexington, American Forages and Grassland Council; Melbourne, CSIRO, 1981 . p. 57-74.

MINSON, D.J. Effect of chemical composition on feed digestibility and metabolizable energy. Nutrition Abstracts and Reyiews, Series B, Wallingford, 52(10): 591-615, 1982.

MINSON, D.J. S HAYDOKK, K.P. The val ue of pepsin dry matter solubility for estimating the voluntary intake and digestibility of six Panicum varieties. Australian Journal of Experimental Agriculture and Animal Husbandry, Melbourne, 11: $181-5,1971$. 
MULLINGS, R. \& PARISH, J.H. New reducing sugar assay for the study of cellulases. Enzyme and Microbial Technology, Stoneham, 6: $491-6,1984$.

MURPHY, M.R.; BALDHIN, R.L.; ULYATT, M.J. An update of a dynamic model of ruminant digestion. Journal of Animal Science, Albany, 62: $1412-22,1986$.

MURRAY, W.D. Effects of cellobiose and glucose on cellulose hydrolysis by both growing and resting cells of Bacteroides cellulosolvens. Biotechnology and Bioengineering, New York, 29: $1151-4,1987$.

NARASIMHALU, P. A comparison of laboratory method involving single or two-stage cellulase and two-stage rumem-inoculum with pepsin treatment for prediction digestibility and intake of hays in sheeps. Animal Feed Science and Technology, Amsterdam, 12: 101-7, 1984.

OSBOURN, D.F. Principles governing the use of chemical methods for assessing the nutritive value of forages: a review. Animal Feed Science and Technology, Amsterdam, 3: $265-75,1978$.

PACE, Y.; BARGE, M.T.; SEITINERI, D. ; MALOSSINI, F. COMParison of forage digestibility in vitro with enzymic solubility. Animal Feed Science and Technology, Amsterdam, 11: $125-36,1984$.

PEIJI, G.H. A simple method for estimating cellobiase activity by determination of reducing sugar. Biotechnology and Bioengi neering, New York, 29: 903-5, 1987.

POULSEN, O.M. \& PEIERSEN, L. W. A standard formula for the determination of the initial rate of hydrolysis of carboxymethilcellulose. Biotechnology and Bioengineering, New York, 27: 409-14, 1985 . 
REES, M. C. \& MINSON, D.J. The ralidity of in vitro techniques using rumen fluid or cellulase for predicting changes in the dry matter digestibility of grasses caused by fertilizer calcium, sulphur, phosphorus and nitrogen. Grass and Forage Science, oxford, 34: 19-25, 1979.

REESE, E.T.; SIU, R.G.H.; LEVINSON, H.S. The biological degradation of soluble cellulose derivatives and its relationship to the mechanism of cellulose hydrolysis. Journal of Bacteriology, Washington, 59: 485-97, 1950.

REEVES, J. B. Chemical assays for fiber, lignin and lignin components: interrelationships and near infrared reflectance spectroscopic analysis results. Journal of Dairy Science, Champaign, 71(11): 2976-85, 1988.

REXEN, B. Enzyme solubility - a method for evaluation the digestibility of alcali-treated straw. Animal Feed Science and Technology, Amsterdam, 2: 205-18, 1977.

REXEN, B. Use of enzymes for improvement of feed. Animal Feed Science and Technology, Amsterdam, 6: 105-14, 1981 .

ROUGHAN, P.G. \& HOLLAND, R. Predicting in vivo digestibilities of herbages by exhaustive enzymic hydrolisis of celis walls. Journal of the Science of Food and Agriculture, London, 28: 1057-64, 1977.

ROLZ, C.; CABRERA, S. de; VALDEZ, M.J.; ARRIOLA, M.C. de; VALLADARES, J. Biodegradation of pretreated ex-fermented sugar cane chips by fungal enzymes and mixtures of anaerobic bacteria. Biotechnology Progress, New York, $2(3): 120-30,1986$.

RYU, D.D.Y. \& MANDELS, M. Cellulases:" biosynthesis and applications. Enzyme and Microbial Technology, Stoneham, 2: $91-102,1980$. 
SNEDECOR, G.W. \& COCHRAN, W.G. Statistical methods. $6 \mathfrak{a}$ ed. Ames, The Iowa State University Press, $1972.593 p$.

STEWART, C.M. \& FOSTER, R.C. X-ray diffraction studies related to forest products research. Appita, Victoria, $29(6): 440-8,1976$.

STONE, J.E.; SCALLAN, A.M. ; DONEFER, E. ; AHLGREN, E. Digestibility as a simple function of a molecule of similar size to a cellulase enzyme. In: HAJNY, G.J. \& REESE, E.T., ed. Cellulase and their applications. Washington, American Chemical Society, 1965. p. 219. CAdvances in chemistry series, 95 .

TAKAGI, M. Inhibition of cellulase by fermentation products. Biotechnology and Bioengineering, New York, 26: $1500-7,1984$.

TAKAGI, M. Pretreatment of lignocellulosic materials with hydrogen peroxide in presence of manganese compounds. Biotechnology and Bioengineering, New York, 29: 165-70, 1987 .

TERRY, R. A.; MUNDELL, D.C.; OSBOURN, D.F. Comparison of the two in vitro procedures using rumen liquor-pepsin or pepsin-cellulase for predicting of forage digestibility. Journal of the British Grassland Society, Oxford, 33: $13-18,1978$.

TIEN, M. \& KIRK, I.K. Lignin-degrading enzyme from the hymenomycete Phanerochaete chrysosporium, Burds. Science, Washington, $12(6)$ : 61-2, 1983.

TILLEY, M. A. \& TERRY, R. A. A two-stage technique for the in vitro digestion of forage crops. Journal of British Grassland Society, Oxford, 18: 104-11, 1963. 
TJERNELD, F.; PERSSON, I.; ALBERTSSON, P.; HAHN-HAGERDAL, B. Enzymatic hydrolysis of cellulose in aqueous two-phase systems. I. Partition of cellulases from Trichoderma ressi. Biotechnology and Bioengineering, New York, 27 : $1036-43,19853$.

TJERNELD, F.; PERSSON, I. ; ALBERTSSON, P. ; HAHN-HAGERDAL, B. Enzymatic hydrolysis of cellulose in aqueous two-phase systems. II. Semicontinuous conversion of a modei substrate, Solka Floc BW 200. Biotechnology and Bioengineering, New York, 27: 1044-50, $1985 \mathrm{~b}$.

UDEN, P.; PARA, R.; YAN SOEST, P.J. Factors influencing reliability of the nylon bag technique. Journal of Dairy Science, Champaign, 57(1): 6ee, 1974.

ULYAIT, M.J. The feeding value of herbage. In: BUTLER, G. W. \& BAILEY, R. W. Chemistry and biochemistry of herbage, London, Academic Pross, 1973, p. $131-78$.

VALDES, E. Y. \& JONES, E.G. A comparison of in vitro and in rivo dry matter digestibility techniques for the evaluation of forage quality. Canadian Journal of Animal Science, Ottawa, 67: 573-6, 1987.

VANDERHAEGHE, S. \& BISTON, R. Estimation in vitro de 1 a digestibilite des herbages. Adaptation de 1 a méthode pepsine-cellulase au systeme Fibertec Enzymatique. Bulletin des Recherches Agronomiques de Gembloux, Gembloux, $22(3): 209-19,1987$.

YAM SOEST, P.J. Limiting factors in plant residues of low biodegradability. Agriculture, Ecosystems and Environment, Amsterdam, 6: 135-43, 1981 .

VAN SOEST, P.J. Nutritional ecology of the ruminant. Oregon, O8B Books, 1982, 374p. 
120.

YAN SOEST, P.I. The uniformity and nutritive availability of cellulose. Federation Proceedings, Bethesda, 32(7): $1804-8,1973$.

VAN SOEST, P. \& ROBERTSON, J.B. Systems of analysis for evaluation fibrous feeds. In: PIGDEN, W. J.; BALCH, C. C. ; GRAHAM, $M$. ed. Standardization of analytical methodology for feeds. Ottawa, IDRC, 1980 . p. 49-60.

YAN SOESI, P.J.; WINE, R.H.; MOORE, L. A. Estimation of the true digestibility of forages by the in vitro digestion of cell walls. In: INTERNATI ONAL GRASSLAND CONGRESS, 10. , Helsinki, 1966. Proceedings, p. 438-41.

VAN IILBEURGH, H.; PETIERSSON, G.; BHIKABHAI, R.; DE BOECK, H. ; CLAEYSSENS, M. Studies of the cellulolytic system of Trichoderma reesei QM9414. European Journal of Biochemistry, Berlin, 148: 329-34, 1985.

VARGA, S.A. \& HOOVER, W.H. Rate and extent of neutral detergent fiber degradation of feedstuffs in situ. Journal of Dairy Science, Champaign, 66: 2109-15, 1983.

WALDO, D.R. Model of cellulose disappearance from the rumen. Journal of Dairy Science, Champaign, 55(1): 125-9, 1972.

WALKER, H.G.; MACKAY, B.E. ; MONTAGUE JR, W.C. Composition and enzymatic digestibility of oregon grass-straw. Animal Feed Science and Technology, Amsterdam, 9: 283-90, 1983.

WEIMER, P.J. \& WESTON, W.M. Relationship between the fine structure of native cellulose and cellulose degradability by the cellulase complexes of Irichoderma reesi and Clostridium thermocellum. Biotechnology and Bioengineering, New York, 27: $1540-7,1985$. 
121.

$A P \hat{E} N D I C E$ 
Tabela 1 - Valores e significancia do F, coeficientes de determinaça e erro padrão da estimativa (roMR) para o estudo do potencial hidrolitico em funça de tempo de reação concentraçăo enzimatica, nos tres sistemas celuloliticos.

1.A: Variável 1 cobs.: médias de três repetiçoses
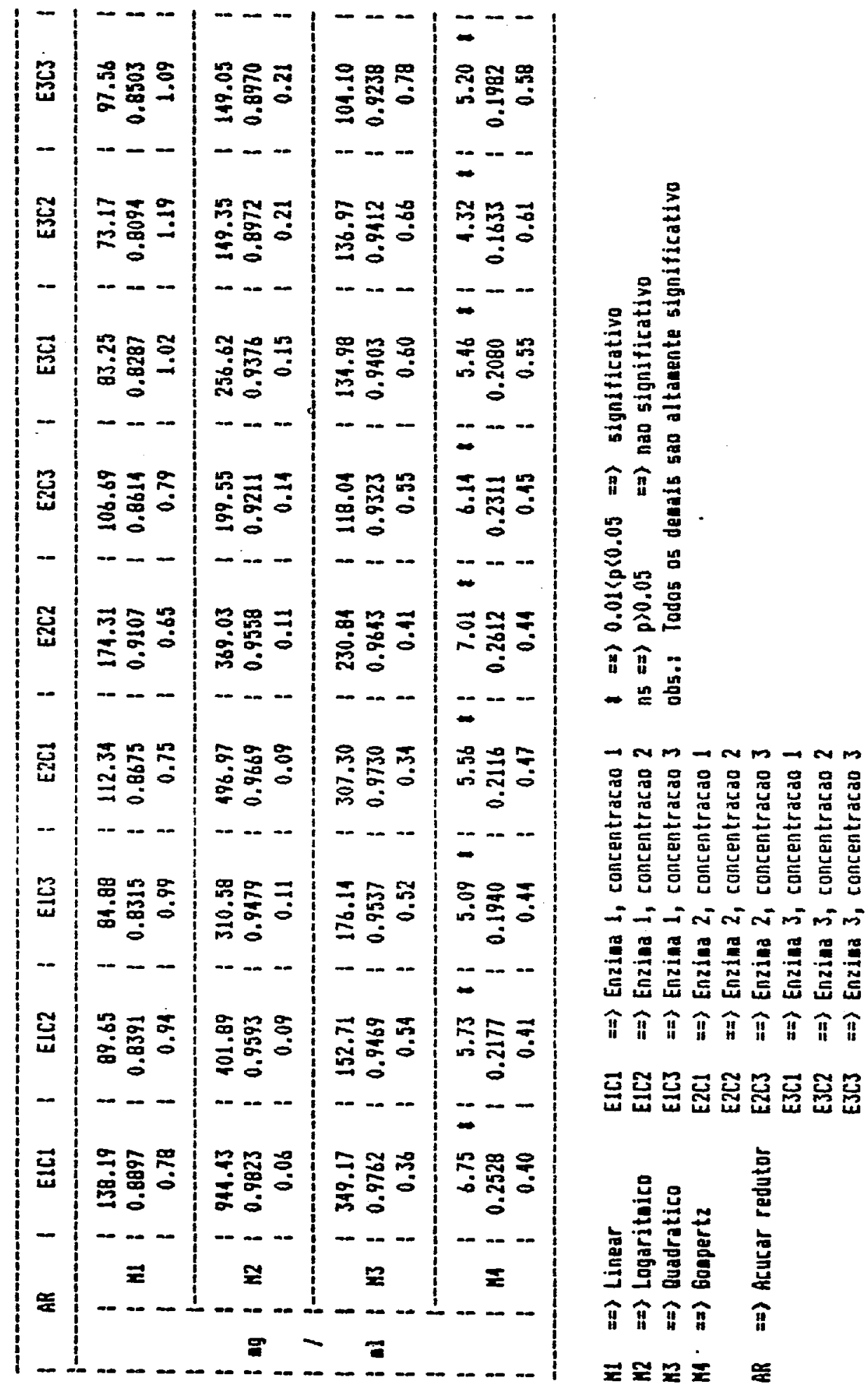
1R: Variável a cobs.: medias de tres repetif̧oses

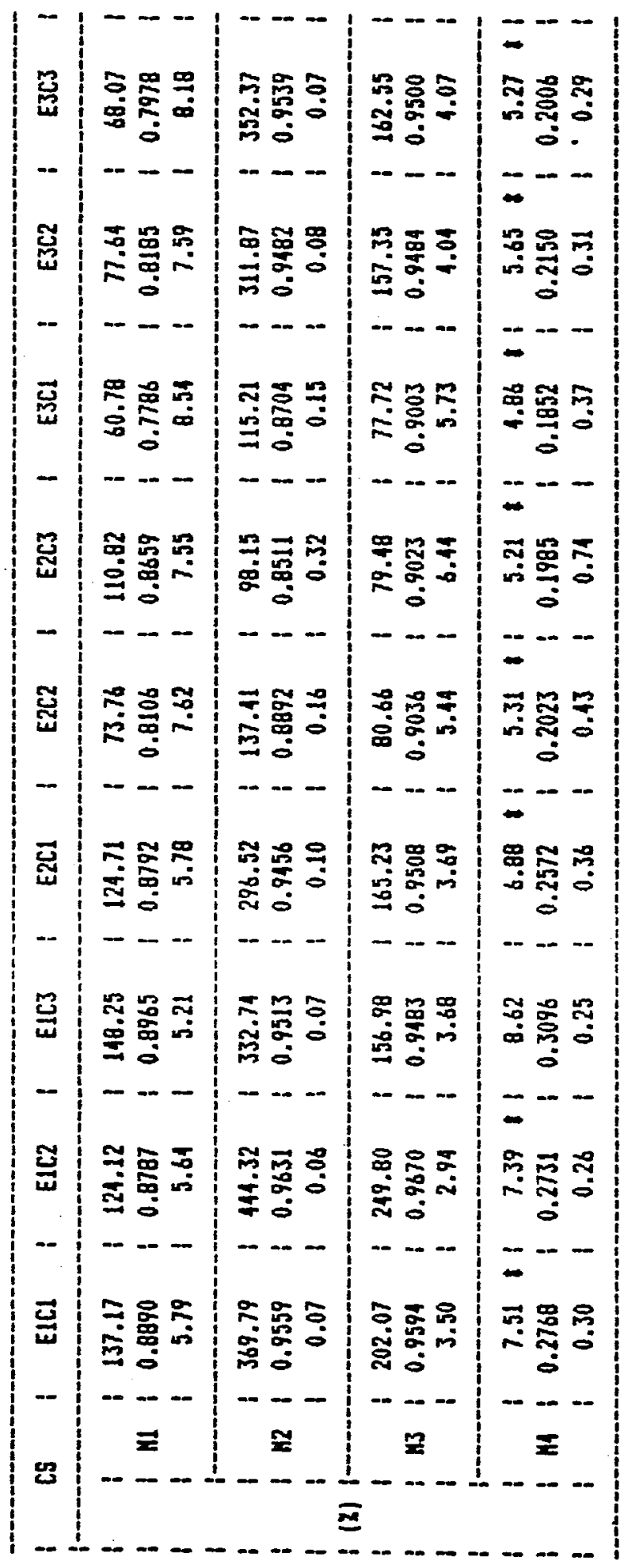

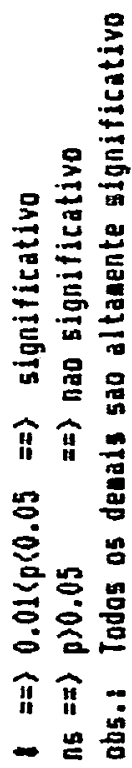

AMーNMーNm

号品品品品品品

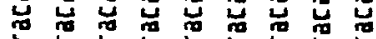

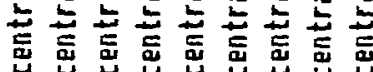

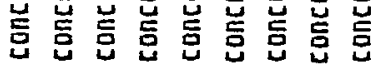

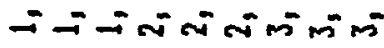

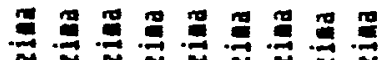

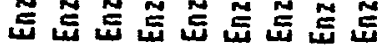

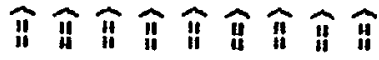

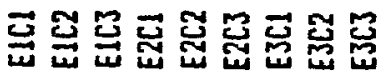

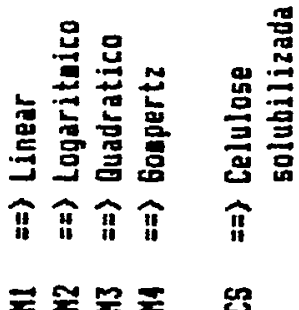


1C: Yariavel 3 Cobs.: medias de tres repetiçöes

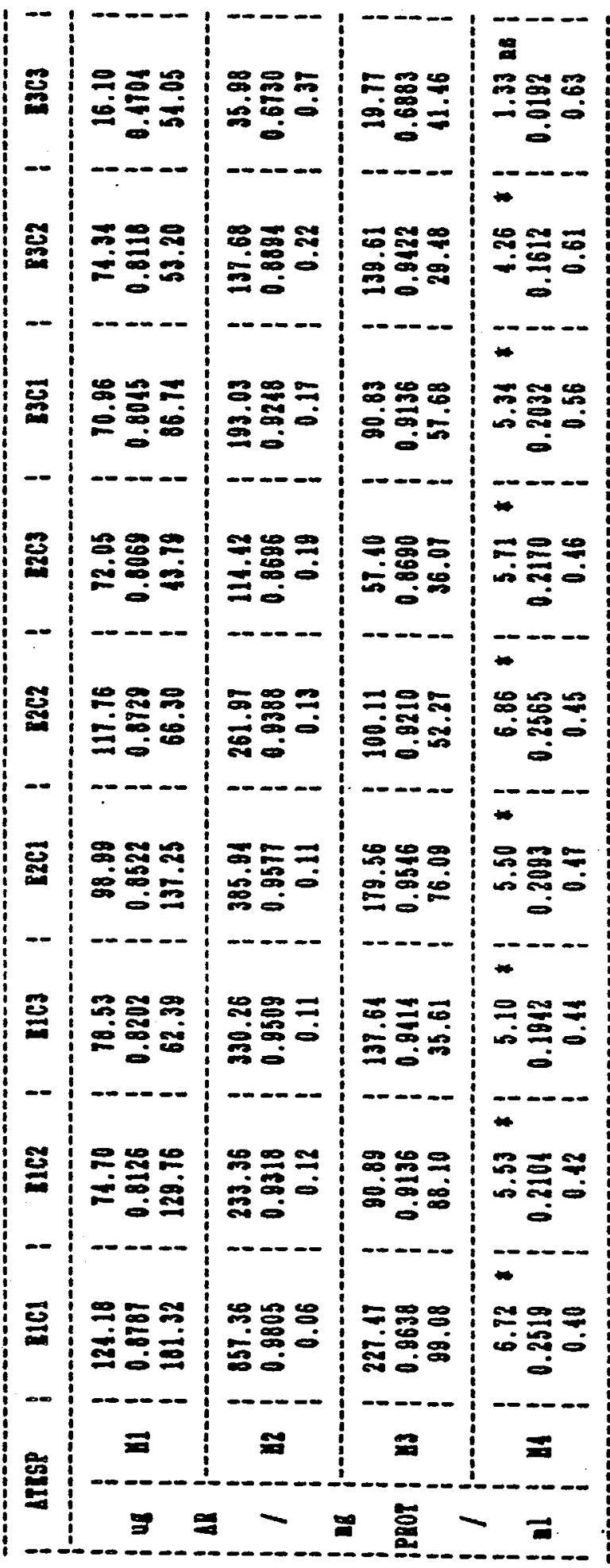

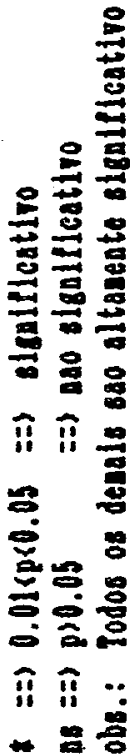

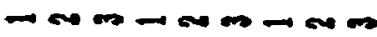

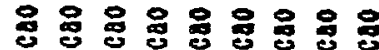

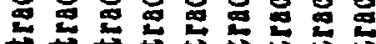

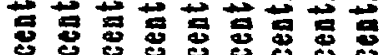

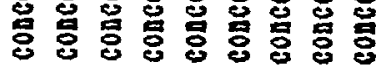

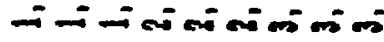

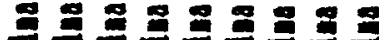

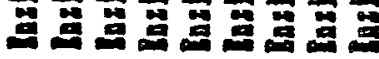

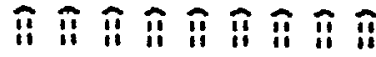

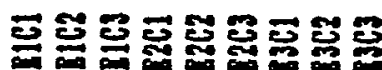

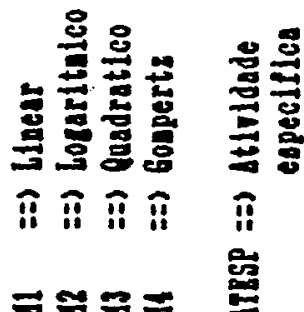


1D: Variável 4 Cobs.: medias de três repetiçöes

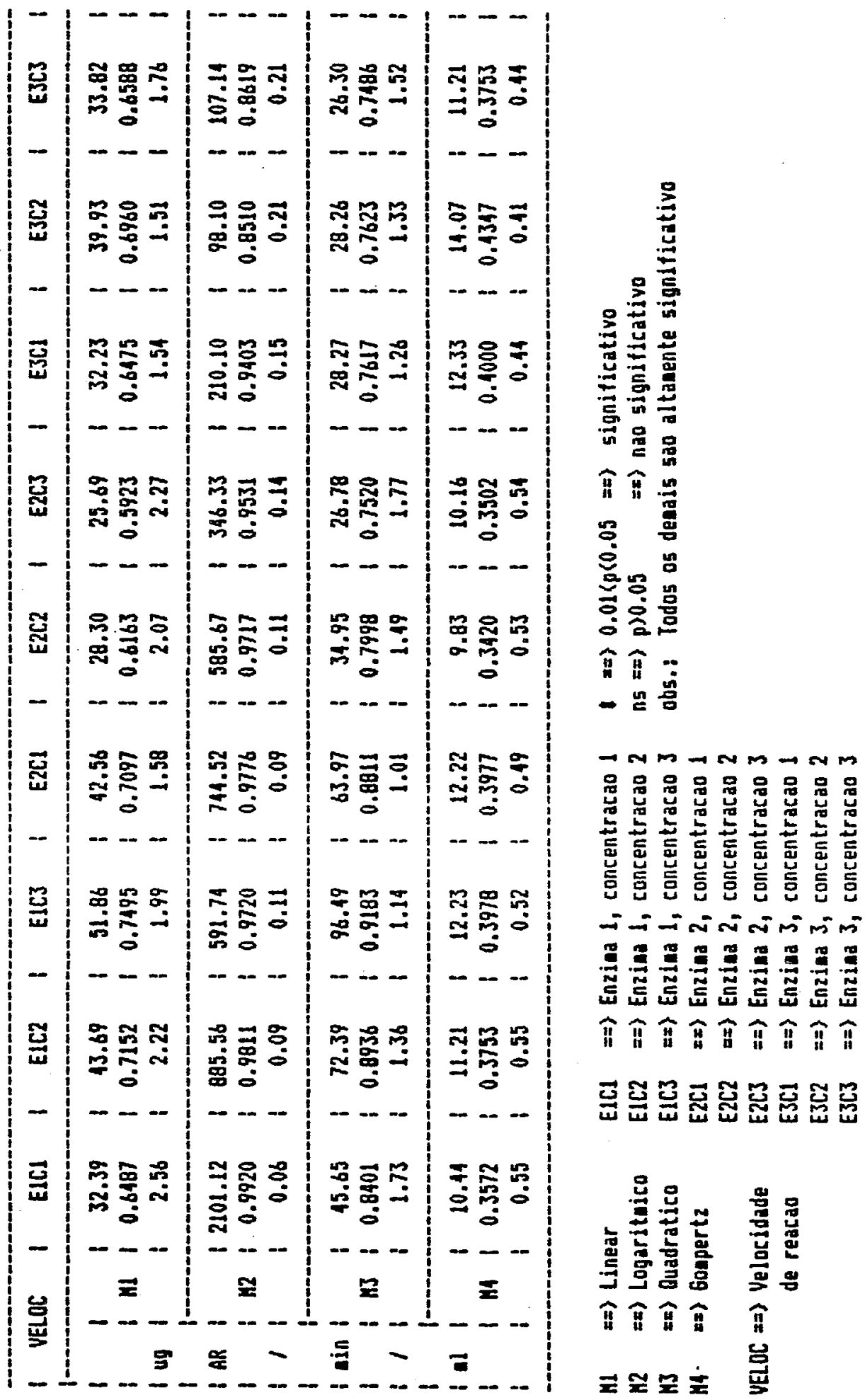


126.

Tabela 2 - Valores o significancia de F, coeficientes de determinaçăo e erro padrăo da estimativa ( $\sqrt{\mathrm{QMR}})$ para o estudo de correlaçðes entre os métodos analiticos de parede celular CPCC « PCES.

\begin{tabular}{|c|c|c|c|c|c|c|c|}
\hline & & & & & & & \\
\hline & & & ; & $F$ & CD & JEMR & : \\
\hline $\begin{array}{l}\text { FORRAGENS } \\
\text { I CONSERVADAS }\end{array}$ & $i$ & $\begin{array}{l}M 1 \\
M 2\end{array}$ & i & $\begin{array}{l}32.13 \\
47.15\end{array}$ & $\begin{array}{l}0.5344 \\
0.6274\end{array}$ & $\begin{array}{l}7.11 \\
0.09\end{array}$ & 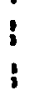 \\
\hline$n=10$ & : & $M 3$ & $:$ & 28.96 & 0.6821 & 5.98 & i \\
\hline ; GRAMINEAS & i & M1 & ; & 76.06 & 0.5317 & 3.15 & ; \\
\hline ; $\quad n=23$ & i & $M 2$ & : & 79.10 & 0.5414 & 0.04 & 1 \\
\hline i & i & $\mathrm{M3}$ & ; & 37.47 & 0.5317 & 3.17 & i \\
\hline ILEGUMINDSAS & i & M1 & i & 69.29 & 0.6340 & 4.84 & ; \\
\hline$n \quad n=14$ & : & $M 2$ & ; & 70.99 & 0.6396 & 0.08 & : \\
\hline ; & i & $\mathrm{M3}$ & ; & 33.95 & 0.6352 & 4.90 & ; \\
\hline RES1DUOS & : & $M 1$ & ; & 112.81 & 0.8368 & 4.94 & ; \\
\hline : AGR1CDLAS & : & $M 2$ & ; & 111.86 & 0.8357 & 0.07 & ; \\
\hline in $\quad n=8$ & i & $M 3$ & ; & 57.50 & 0.8456 & 4.91 & ; \\
\hline TOTAL & i & $M 1$ & i & 410.25 & 0.7157 & 5.83 & i \\
\hline$n=55$ & : & $\mathrm{mz}$ & ; & 465.19 & 0.7405 & 0.08 & ; \\
\hline 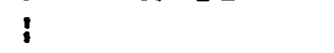 & i & $M 3$ & i & 209.66 & 0.7213 & 5.79 & . \\
\hline
\end{tabular}

$M 1 \rightarrow 1$ inear

$M 2 \rightarrow 1$ logaritmico

$M 3 \rightarrow$ quadratico

PCC $\rightarrow$ Parede celular pelo sistema convencional (detergente neutro) PCE - Parede celular pelo sistema enzimatico

$C D \rightarrow$ Coeficiente de determinaçåo

QMR - Quadrado medio do resi duo

Obs.: Todos os valores de F são altamente significativos (p<0.01) 
Tabela 3 - Valores e significancia do F para ajustes de modelo, tomando PCC, PCE e PCC $x$ PCE como covariareis para as avaliaçóes nos distintos grupos de forragens.

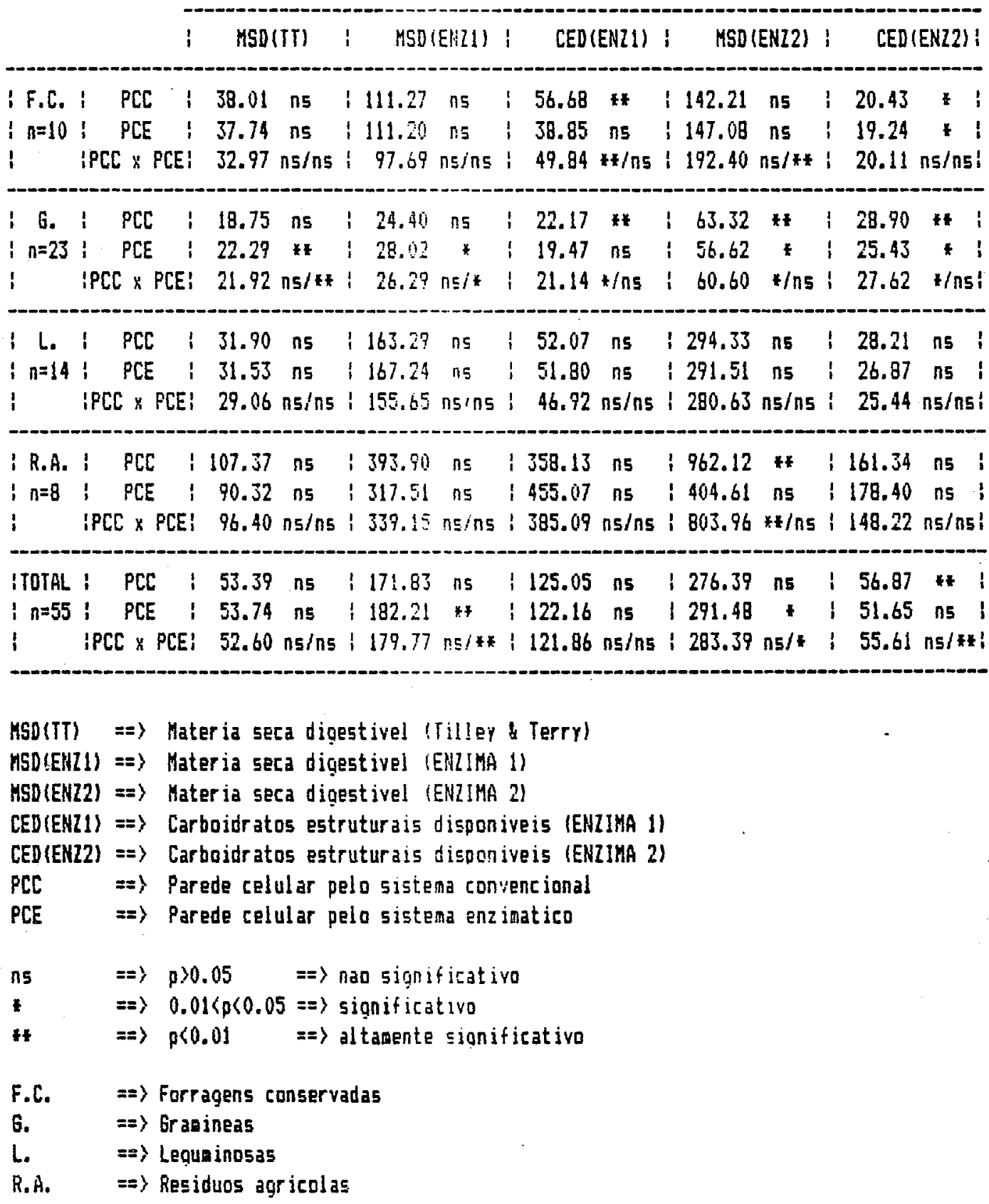


Tabela 4 - Valores e signiticancia do F, coeficientes de determinaçăo para estudos do potencial digestivel, por sistemas in vitro cmicrobiologico e enzimaticol.

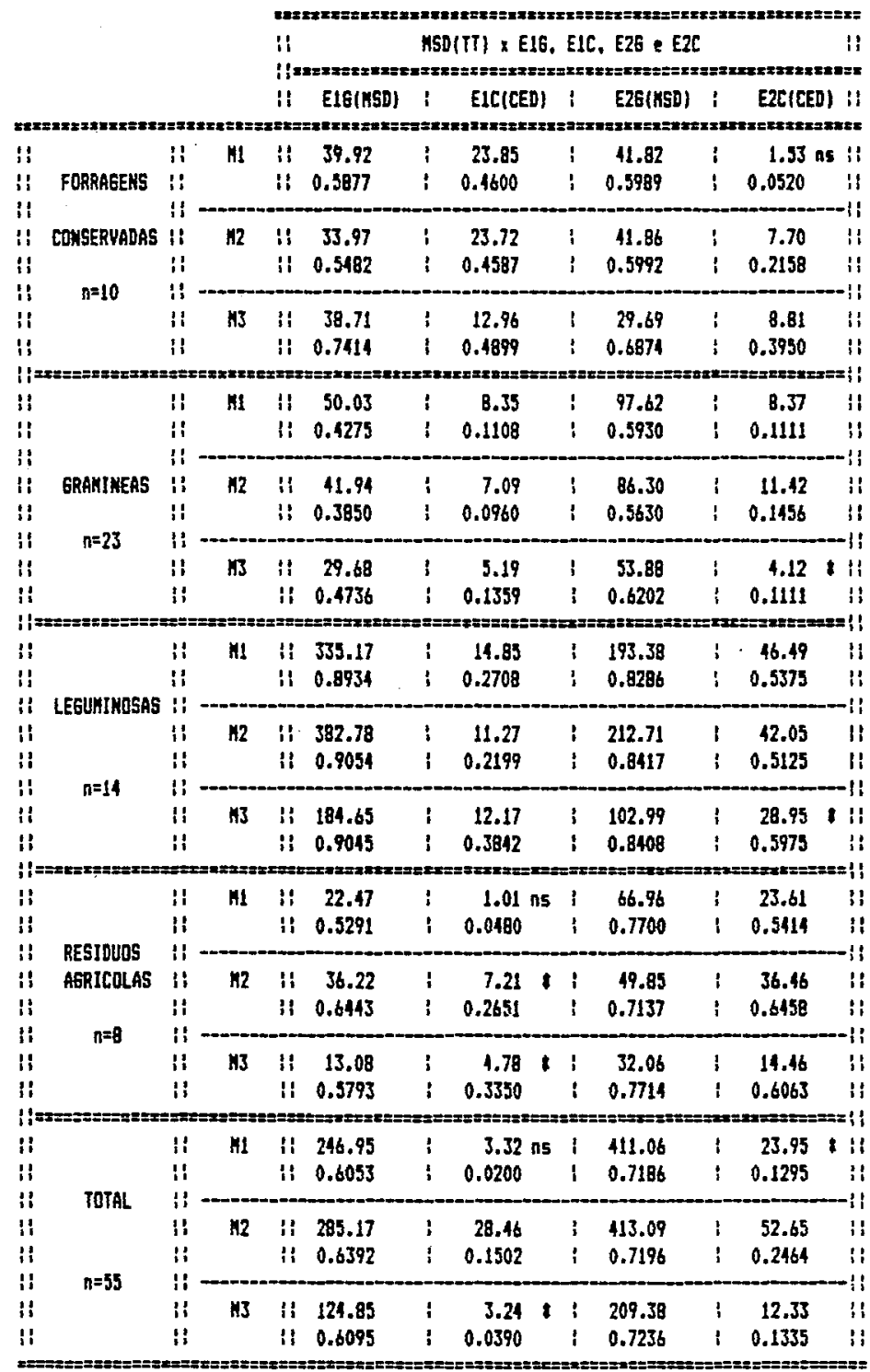

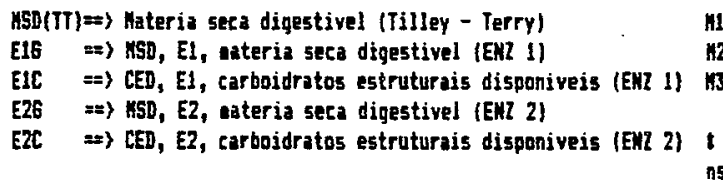

HI $\Rightarrow$ linear

$12 \quad \Rightarrow$ logariteico

$\Rightarrow$ quadratico

$\Rightarrow$ KSD, E2, ateria seca dinestivel (EMZ 2)

n5 $\Rightarrow p>0.05 \Rightarrow$ nao significativo

ob5.: $z=3$ Todos os detuis 530 altanente signifientivo 
129.

Tabela 5 - Yalores esignificancia de F, coeficientes de determinaçăo para estimativas de materia seca digestivel pelo metodo colorimetrico atraves dos sistemas enzimáticos. (in vitros.

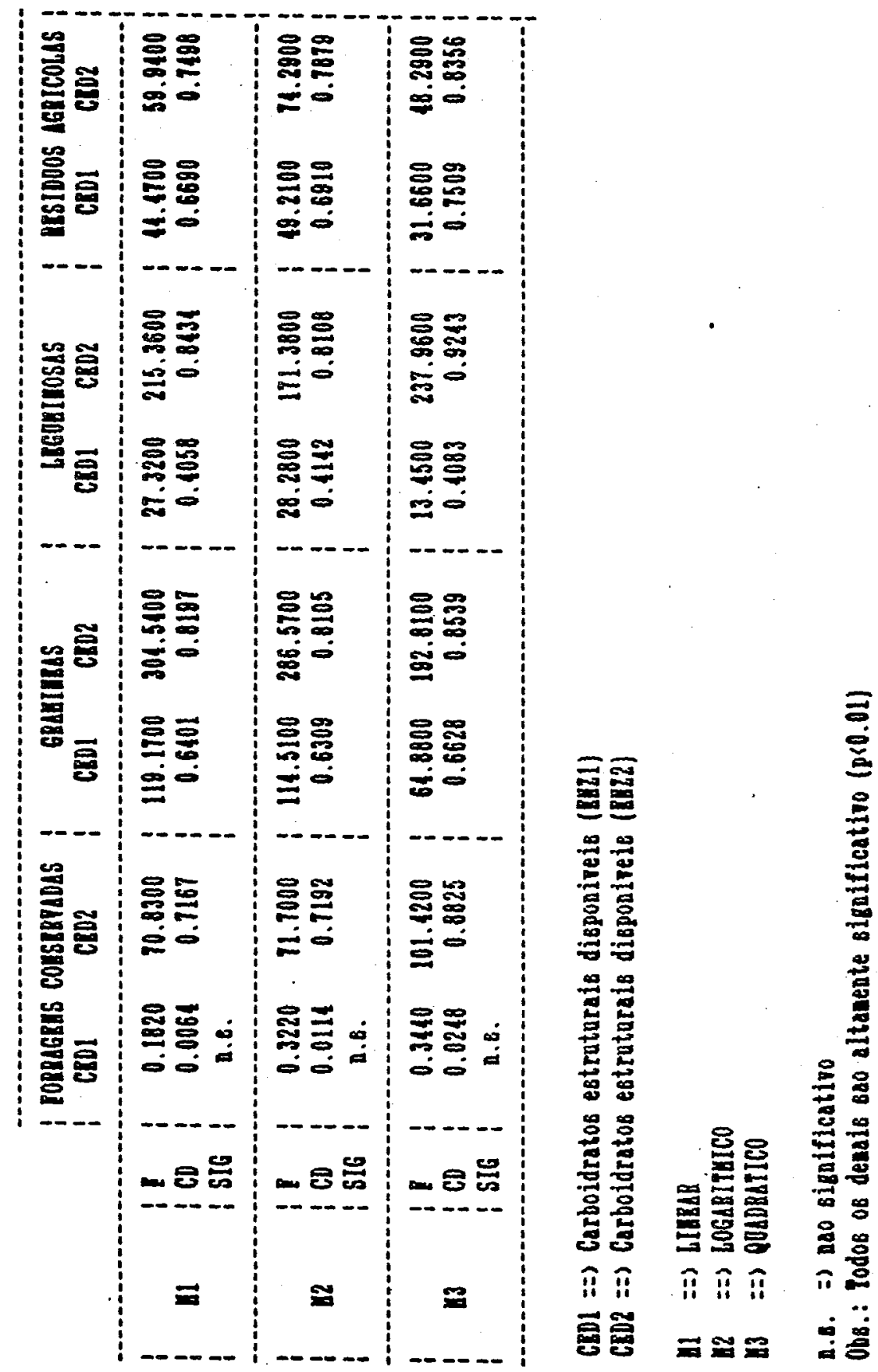

